\title{
Mars Orbiter Laser Altimeter: Experiment summary after the first year of global mapping of Mars
}

\author{
David E. Smith, ${ }^{1}$ Maria T. Zuber, ${ }^{2,1}$ Herbert V. Frey, ${ }^{1}$ James B. Garvin, ${ }^{1,3}$ James W. \\ Head, ${ }^{4}$ Duane O. Muhleman, ${ }^{5}$ Gordon H. Pettengill, ${ }^{2,6}$ Roger J. Phillips, ${ }^{7}$ Sean C. \\ Solomon, ${ }^{8}$ H. Jay Zwally, ${ }^{9}$ W. Bruce Banerdt, ${ }^{10}$ Thomas C. Duxbury, ${ }^{10}$ Matthew P. \\ Golombek, ${ }^{10}$ Frank G. Lemoine, ${ }^{1}$ Gregory A. Neumann, ${ }^{2,1}$ David D. Rowlands, ${ }^{1}$ \\ Oded Aharonson, ${ }^{2}$ Peter G. Ford, ${ }^{6}$ Anton B. Ivanov, ${ }^{5,10}$ Catherine L. Johnson, ${ }^{8}$ \\ Patrick J. McGovern, ${ }^{8,11}$ James B. Abshire, ${ }^{1}$ Robert S. Afzal, ${ }^{1}$ and Xiaoli Sun ${ }^{1}$
}

\begin{abstract}
The Mars Orbiter Laser Altimeter (MOLA), an instrument on the Mars Global Surveyor spacecraft, has measured the topography, surface roughness, and $1.064-\mu \mathrm{m}$ reflectivity of Mars and the heights of volatile and dust clouds. This paper discusses the function of the MOLA instrument and the acquisition, processing, and correction of observations to produce global data sets. The altimeter measurements have been converted to both gridded and spherical harmonic models for the topography and shape of Mars that have vertical and radial accuracies of $\sim 1 \mathrm{~m}$ with respect to the planet's center of mass. The current global topographic grid has a resolution of $1 / 64^{\circ}$ in latitude $\times 1 / 32^{\circ}$ in longitude $\left(1 \times 2 \mathrm{~km}^{2}\right.$ at the equator). Reconstruction of the locations of incident laser pulses on the Martian surface appears to be at the 100-m spatial accuracy level and results in 2 orders of magnitude improvement in the global geodetic grid of Mars. Global maps of optical pulse width indicative of $100-\mathrm{m}$-scale surface roughness and $1.064-\mu \mathrm{m}$ reflectivity with an accuracy of $5 \%$ have also been obtained.
\end{abstract}

\section{Introduction and Investigation Objectives}

The Mars Global Surveyor (MGS) spacecraft, launched November 7, 1996, by the National Aeronautics and Space Administration (NASA) and the Jet Propulsion Laboratory (JPL) of the California Institute of Technology, includes in

\footnotetext{
${ }^{1}$ Laboratory for Terrestrial Physics, NASA Goddard Space Flight Center, Greenbelt, Maryland.

${ }^{2}$ Department of Earth, Atmospheric and Planetary Sciences, Massachusetts Institute of Technology, Cambridge, Massachusetts.

${ }^{3}$ Now at Office of Space Sciences, NASA Headquarters, Washington, D.C.

${ }^{4}$ Department of Geological Sciences, Brown University, Providence, Rhode Island.

${ }^{5}$ Division of Geological and Planetary Sciences, California Institute of Technology, Pasadena, California.

${ }^{6}$ Center for Space Research, Massachusetts Institute of Technology, Cambridge, Massachusetts.

${ }^{7}$ Department of Earth and Planetary Sciences, Washington University, St. Louis, Missouri.

${ }^{8}$ Department of Terrestrial Magnetism, Carnegie Institution of Washington, Washington, D.C.

${ }^{9}$ Laboratory for Hydrospheric Processes, NASA Goddard Space Flight Center, Greenbelt, Maryland.

${ }^{10}$ Jet Propulsion Laboratory, Pasadena, California.

${ }^{11}$ Now at Lunar and Planetary Institute, Houston, Texas.
}

Copyright 2001 by the American Geophysical Union.

Paper number 2000JE001364.

0148-0227/01/2000JE001364\$09.00 its payload an optical remote sensing instrument, the Mars Orbiter Laser Altimeter (MOLA 2) [Zuber et al., 1992]. The primary objectives of the MOLA investigation are to map globally the topography of Mars at a level suitable for geophysical, geological, and atmospheric circulation studies of Mars. Secondary objectives are to measure the heights of atmospheric reflections to better understand the threedimensional structure of the Martian atmosphere; to measure 100-m-scale surface roughness of Mars to contribute to geological characterization of the surface and to assist in assessment of future potential landing sites; to measure the 1.064$\mu \mathrm{m}$ surface reflectivity of Mars to contribute to knowledge of surface composition and seasonal changes; and to attempt to measure the time-varying topography of the Martian polar caps to contribute to understanding seasonal cycles.

With data collected in the capture orbit, aerobraking hiatus, science phasing, and the first 15 months of mapping orbits of the Mars Global Surveyor mission [Albee et al., this issue], all MOLA objectives, with the exception of those relating to temporal changes, have been fully met, while those relating to temporal changes are currently being pursued. This report describes the function of the MOLA instrument, the measurement types, and the corrections and processing approach employed to produce the data products. In addition, the status and major accomplishments of the MOLA investigation are reviewed as of June 1,2000 , at which time the instrument was turned off for a 2-month period surrounding solar conjunction. 


\section{Pre-MGS Observations}

\subsection{Martian Topography}

Knowledge of the topography of Mars prior to Mars Global Surveyor was based on measurements obtained by the early Mariner and Viking spacecraft and on Earth-based radar measurements. These models and their errors are discussed in previous work [Davies et al., 1992b; Esposito et al., 1992; Zuber et al., 1992; Smith and Zuber, 1996]. The most widely used global topographic field prior to MGS was a digital elevation model (DEM) produced by the U.S. Geological Survey $[W u, 1991]$ that was based upon Earth-based radar [e.g., Pettengill et al., 1971; Roth et al., 1980; Downs et al., 1982], Mariner 9 and Viking 1 and 2 radio occultations [e.g., Kliore et al., 1965, 1972; Lindal et al., 1979], stereo and photoclinometric observations from Mariner 9 and Viking imagery [Soderblom and Wenner, 1978; Wu and Peltier, 1984], and the Mariner 9 ultraviolet and infrared spectrometers [ e.g., Hord, 1972; Conrath et al., 1973]. The USGS DEM was referenced to an areoid derived from fitting atmospheric pressures obtained from Mariner 9 occultations [e.g., Kliore et al., 1972, 1973] to a degree 4 gravity model [Lorell et al., 1973]. The DEM has a spatial resolution of $1 / 64^{\circ} \times 1 / 64^{\circ}$ and is typically characterized by randomly distributed vertical errors of $\sim 1 \mathrm{~km}$, though in some places deviations of over $5 \mathrm{~km}$ are observed [Smith and $\mathrm{Zu}$ ber, 1998; Zuber et al., 1998b; Smith et al., 1999b].

As discussed later, the USGS DEM did poorly in matching the relative elevations of the Viking lander sites determined from atmospheric pressure measurements. Consequently, many pre-MGS Mars atmospheric studies, particularly dynamical analyses that used general circulation models with topography as a lower boundary condition [ e.g., Pollack et al., 1990], instead utilized the Mars Consortium topographic model [Kieffer et al., 1981], which was based on orbital spectral data [e.g., Hord, 1972; Conrath et al., 1973]. The Consortium data set was more successful in matching the lander elevations but suffered from a global-scale systematic error. In the Consortium Model the north pole is $\sim 1$ $\mathrm{km}$ higher than the south pole with respect to the gravitational equipotential, whereas MOLA data have now shown that the south pole is $6 \mathrm{~km}$ higher than the north pole (see later discussion). This bias, along with other errors at shorter wavelengths, affected some past dynamical simulations of the circulation of the Martian atmosphere.

Smith and Zuber [1996] reanalyzed Viking and Mariner 9 occultation measurements to develop a topographic model of Mars that had poorer spatial resolution $(\sim 1300 \mathrm{~km})$ but significantly improved vertical accuracy $(\sim 500 \mathrm{~m})$ than the USGS DEM and in addition lacked the systematic errors of the Consortium Model. The uncertainty of the occultation measurements of Smith and Zuber [1996] was due to combined uncertainties in orbital reconstruction $(\sim 400 \mathrm{~m})$, atmospheric refraction ( $\sim 300 \mathrm{~m})$, timing errors in occultation measurements, and planetary ephemeris.

Earth-based radar range data have yielded regional measurements of elevation with a spatial resolution of $\sim 8 \times 80$ $\mathrm{km}^{2}$ in the approximate latitude range $\pm 25^{\circ}$ during Mars opposition periods [Pettengill et al., 1969, 1971, 1973; Goldstein et al., 1970; Rogers et al., 1970; Downs et al., 1975, 1978; Roth et al., 1980; Downs et al., 1971, 1982; Harmon et al., 1982; Harmon and Ostro, 1985; Esposito et al., 1992]. Radar ranges are subject to ephemeris errors as well as errors due to solar plasma effects, for a total uncertainty of $\sim 300 \mathrm{~m}$ in recent epochs. Selected radar observations in the vicinity of the Pathfinder landing site yielded an uncertainty of 100-200 m [Golombek et al., 1997a]. Comparison of radii from occultations, which tend to measure topographic highs, and radar returns, which preferentially reflect from valley floors, yields a systematic difference of $\sim 730 \mathrm{~m}$ [Smith and Zuber, 1996].

\subsection{Geodetic Grid}

Prior to Mars Global Surveyor, knowledge of locations on Mars on a planet-wide scale was based on spatial [Davies et al., 1978; Davies and Katayama, 1983] and vertical [Wu and Schaefer, 1984] control networks derived from a variety of Mariner 9 and Viking Orbiter observations. While spatial errors were estimated to be $<3 \mathrm{~km}$ [Davies et al., 1992b], actual errors in excess of $15 \mathrm{~km}$ were commonly observed [Smith et al., 1999b; Duxbury, 2000]. Vertical errors were at a level comparable to the USGS DEM [Wu, 1991] (see above).

The best known positions on Mars are the Viking and Pathfinder landing sites, because radio tracking has resulted in precise absolute positioning with respect to Mars' center of mass. While the position of Pathfinder based on radio tracking is known to a few tens of meters [Folkner et al., 1997], reconstructed positions of the landing site with respect to images differ by $5 \mathrm{~km}$ [Duxbury, 1995; Zeitler and Oberst, 1999].

\subsection{Macroscale Surface Roughness}

Previous measurements of surface roughness of Mars are limited to Earth-based delay Doppler data at a spatial scale of several tens of kilometers [Rogers et al., 1970; Pettengill et al., 1973; Downs et al., 1975, 1978; Harmon et al., 1982; Harmon and Ostro, 1985; Simpson et al., 1992]. There were no measurements of surface roughness at 100 -m spatial scales prior to MGS.

\subsection{Near-IR Reflectivity}

Before Mars Global Surveyor, knowledge of the absolute reflectivity of the Martian surface in the $1-\mu \mathrm{m}$ part of the spectrum was poorly known [Soderblom, 1992], with spacebased observations limited to Phobos 2 ISM data for equatorial latitudes [Bibring et al., 1990; Mustard et al., 1993] and Hubble Space Telescope observations on a near-global scale with a spatial resolution of $\sim 1^{\circ}$ pixel $^{-1}$ [Bell et al., 1999].

These observations indicated a bimodal distribution of reflectivity, with typical bright and dark values of 0.36 and 0.18 , respectively [Bell et al., 1999], and with noticable changes occurring during the past 20 years owing to variability in the atmosphere of Mars associated with the seasonal transport of dust. 

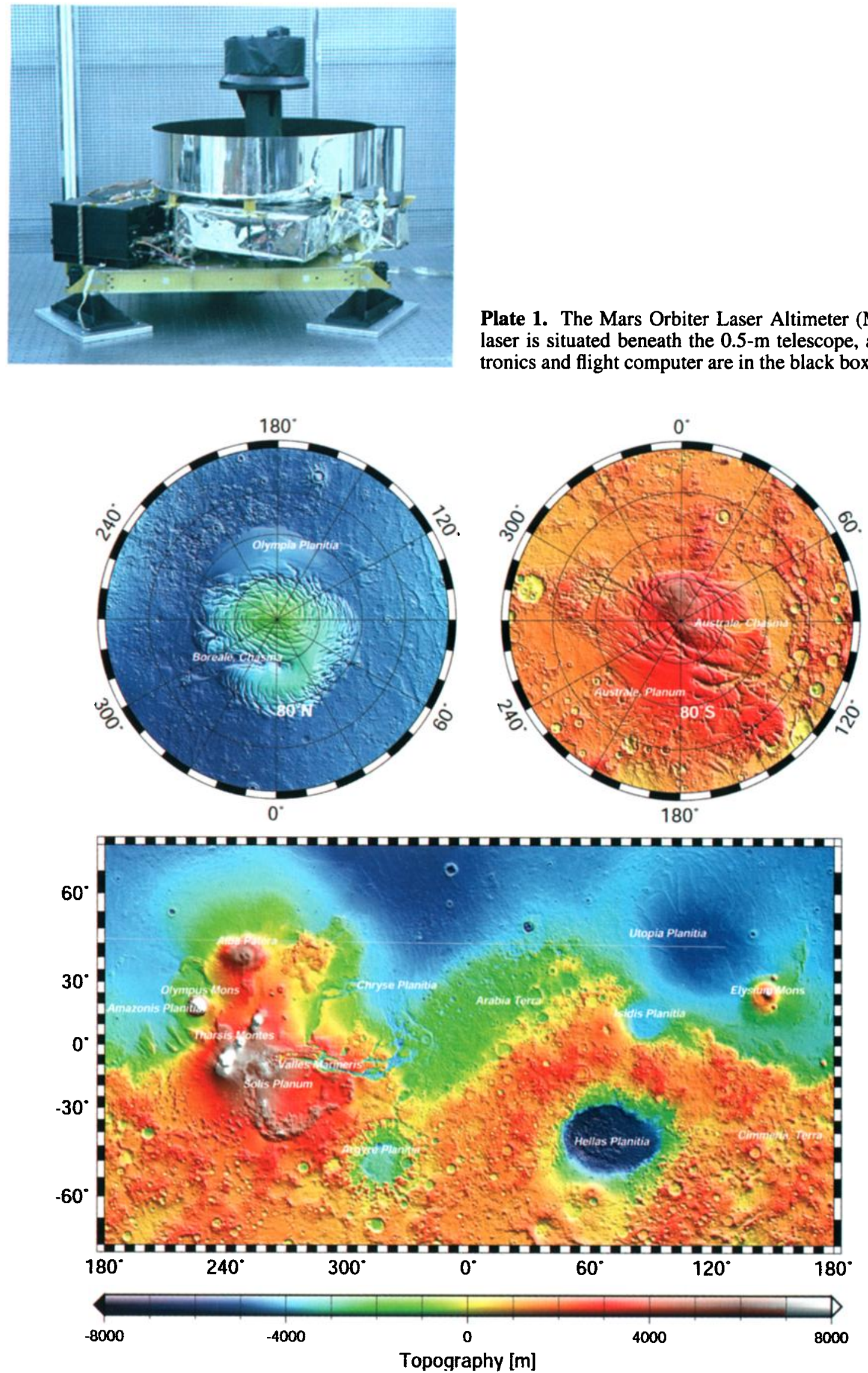

Plate 2. The topography of Mars from MOLA. The resolution of the model is $1 / 64^{\circ}$ in latitude $\times 1 / 32^{\circ}$ in longitude ( $\sim 1 \times 2 \mathrm{~km}^{2}$ at the equator). Topography is shown as color-coded elevation draped over shaded relief. Major features are labeled in white. The projection at mid-latitudes is Mercator and at high latitudes is polar stereographic. Coordinates are areocentric with an east positive longitude convention. On Mars $1^{\circ}$ is $\sim 59 \mathrm{~km}$. 
Table 1. MOLA Instrument Specifications

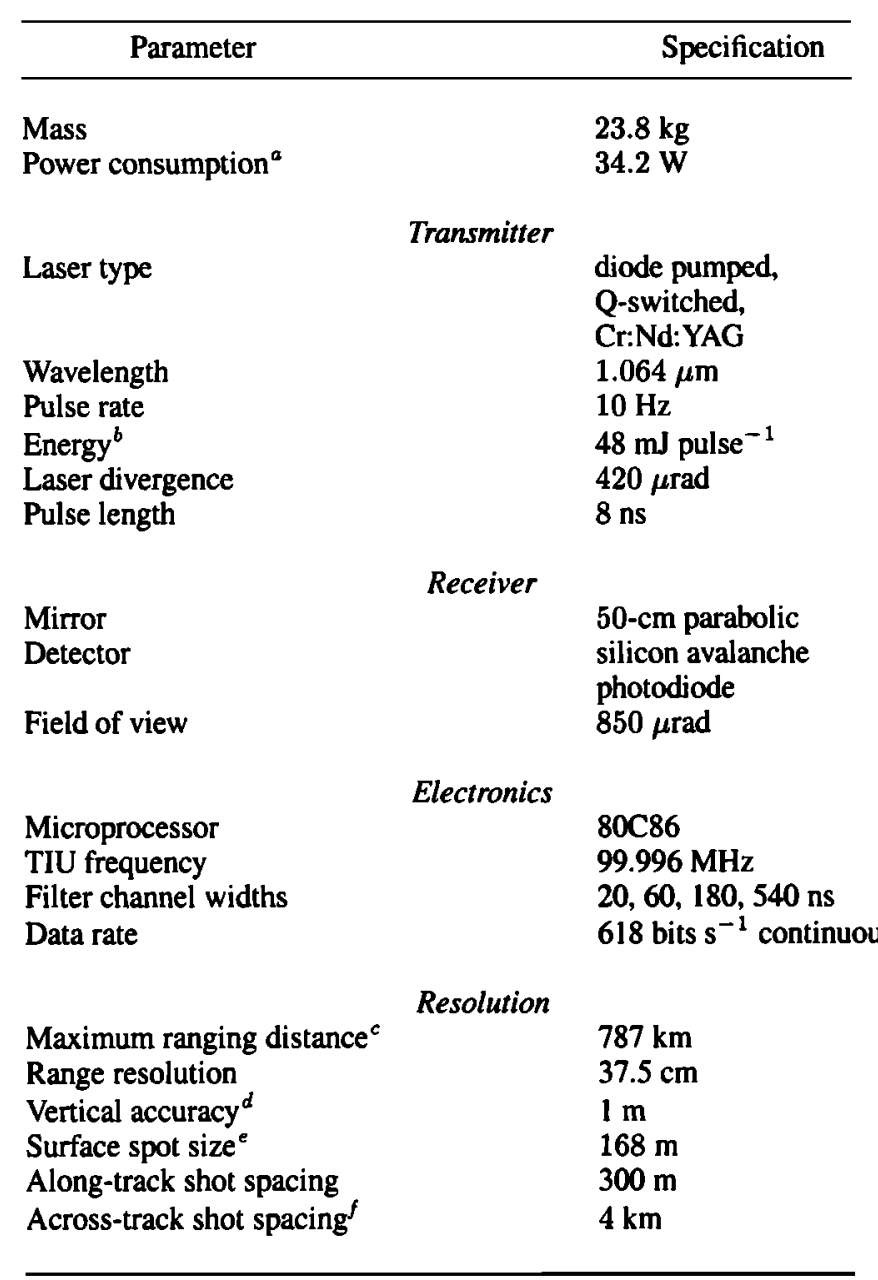

a Includes replacement heat for temperature control.

${ }^{b}$ At arrival at Mars; degrades with time.

${ }^{c}$ Hardware limited.

${ }^{d}$ Includes radial orbit error.

${ }^{e}$ In 400-km-elevation mapping orbit.

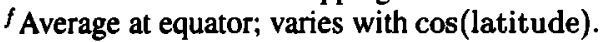

\section{Instrument Description and Operation}

\subsection{Background and Components}

The Mars Orbiter Laser Altimeter (Plate 1) was designed by the Laser Remote Sensing Branch of the Laboratory for Terrestrial Physics of NASA's Goddard Space Flight Center, with support from Goddard's Engineering Systems Analysis Branch. The designation MOLA 2 refers to the instrument flown on Mars Global Surveyor, which is a descendant of the MOLA 1 instrument [Zuber et al., 1992] that was carried aboard the ill-fated Mars Observer spacecraft.

Key instrument parameters of MOLA 2 are given in Table 1. The laser transmitter was built by McDonnell-Douglas Space Systems Division, and its detailed design and function are discussed by Afzal [1994]. The transmitter consists of a Q-switched, chromium- and neodymium-doped yttrium aluminum garnet (Cr:Nd:YAG) oscillator that is pumped by a 36-bar laser diode array. Each bar consists of $\sim 80$ alu- minum, gallium arsenide (AlGaAs) laser diodes. The laser is pulsed at a $10-\mathrm{Hz}$ rate controlled by the Q-switch and emits pulses with $\sim 8$-ns full width at half the maximum amplitude (FWHM).

The design and function of MOLA receiver components are discussed elsewhere [Sun et al., 1992; Ramos-Izquierdo et al., 1994; Abshire et al., 2000]. The optical system contains a 0.5 -m-diameter, gold-coated beryllium telescope built by the Optical Corporation of America. The optical train includes a 2.0-nm FWHM optical bandpass filter that rejects solar background and a silicon avalanche photodiode (SiAPD) detector. The receiver also contains a time interval unit (TIU), which is a binary counter that records the number of clock cycles from the threshold crossings of the transmitted and returned pulses. The clock is a temperature-controlled quartz crystal oscillator with a frequency of $99.996 \mathrm{MHz}$. A charge-to-time converter and a timer measure the pulse area (energy) between the two threshold crossing points. A similar circuit measures the pulse width at the threshold crossings. To improve range resolution, the timing electronics includes interpolators for the transmitted and returned pulses. These allow determination of threshold crossing times to one-quarter of each 10-ns clock cycle, yielding the effective 2.5 -ns timing resolution. An $80 \mathrm{C} 86$ microprocessor is used to execute the flight software.

\subsection{Ranging Function}

MOLA measures the round-trip time of flight of individual laser pulses between the MGS nadir deck and the Martian surface or atmospheric layers. When the laser fires, a small fraction of the output laser energy is coupled to a PIN photodiode through a multimode optical fiber and starts the TIU. Every $14 \mathrm{~s}$, the laser trigger pulse is time stamped with respect to the MGS spacecraft time so that the location of the laser spot on the Martian surface can be reconstructed. The time stamps have a resolution of $1 / 256 \mathrm{~s}$.

The backscattered laser pulse is only detected and recorded within a range gate, within which the surface return is expected. The purpose of the range gate is to minimize the effect of noise due to backscattered solar photons at the laser wavelength. The width of the range gate is adjustable between 20 and $80 \mathrm{~km}$ via an onboard algorithm and reduces to its minimum once the instrument locks onto the surface. The telescope serves as a photon bucket for the laser pulses scattered by terrain or clouds. The SiAPD detector outputs a voltage proportional to the rate of returning photons that have been backscattered from the Martian surface or atmosphere. When this voltage exceeds the detection threshold, the TIU is stopped and the round-trip time of flight is recorded. A separate circuit measures the pulse width that can be used to correct for range walk associated with the leading edge timing.

After passing through the SiAPD detector, MOLA's returned signal is amplified and subsequently passed through a parallel bank of four five-pole Bessel filters (Table 2). These filters increase the probability of detection by match- 
Table 2. MOLA Matched Filter Characteristics

\begin{tabular}{|c|c|c|c|c|}
\hline Characteristic & 1 & 2 & 3 & 4 \\
\hline Description & smooth & moderate & rough & clouds \\
\hline $\begin{array}{l}\text { Channel width, } \\
\text { ns }\end{array}$ & 20 & 60 & 180 & 540 \\
\hline $\begin{array}{l}\text { Terrain height } \\
\text { variation within } \\
\text { footprint, m }\end{array}$ & 3 & 9 & 27 & 81 \\
\hline $\begin{array}{l}\text { Footprint-scale } \\
\text { surface slope, } \\
\text { deg }\end{array}$ & 1.0 & 2.9 & 8.6 & 24.2 \\
\hline
\end{tabular}

ing returned pulses that have been spread in time by surface roughness within the sampled footprint or scattering by atmospheric particulates. The filter whose impulse response provides the closest match to the received pulse shape gives the highest output signal to noise ratio. However, the instrument records the laser pulse time of flight from the filter that exceeds the detection threshold and has the shortest propagation delay (i.e., the narrowest impulse response pulse width). So the filter that triggers need not be that best matched to the range spread produced by RMS surface roughness measured by MOLA's pulse width (see next section).

The detection threshold in the receiver electronics is continuously adjusted by software, such that the false alarm rate within the range gate interval is at or below the desired level of $1 \%$ [McGarry et al., 1991]. As in a radar receiver, this detection scheme maximizes the probability of detection while keeping the false alarm rate under an acceptable level. The probability of making a successful range measurement $\left(P_{\text {meas }}\right)$ is expressed [Zuber et al., 1992; Abshire et al., 2000]

$$
P_{\text {meas }}=P_{\text {det }}\left(1-P_{\mathrm{fa}}\right),
$$

where $P_{\text {det }}$ is the probability of detection and $P_{\mathrm{fa}}$ is the probability of a false alarm. The receiver design and flight software that enabled autonomous threshold adjustment in MOLA are in contrast to the designs of the Clementine [Smith et al., 1997] and Near Earth Asteroid Rendezvous (NEAR) Shoemaker [Cole et al., 1997] laser ranging devices, in which threshold settings require a command upload for adjustment.

By interpolating the spacecraft orbital trajectory to the time of the laser measurement, the distance between the spacecraft and the Martian center of mass is obtained. The range $Z_{\text {Mars }}$ from MGS to the Martian surface is related to the time of flight $t_{\text {opt }}$ of the optical pulse by

$$
Z_{\mathrm{Mars}}=\frac{c t_{\mathrm{opt}}}{2}
$$

where $c$ is the vacuum speed of light. The vector difference between the radial distance to the spacecraft from the planetary center of mass and the range to the surface provides the radius of Mars at the location of the laser spot on the surface. Equation (2) neglects the effect of the atmospheric path delay, which is only a few centimeters on Mars due to the thin Martian atmosphere. In the MGS mapping orbit the instrument's sampling rate combined with the laser beam divergence (cf. Table 1 ) results in a surface spot size of $\sim 168$ $\mathrm{m}$ with shot-to-shot spacings of $\sim 300 \mathrm{~m}$. The precision of MOLA range measurements approaches the limiting resolution of $37.5 \mathrm{~cm}$ on smooth level surfaces and may increase to as much as $\sim 10 \mathrm{~m}$ on $30^{\circ}$ slopes [Gardner, 1992; Abshire et al., 2000].

\subsection{Footprint-Scale Slopes and Surface Roughness}

The width of MOLA's backscattered laser pulse, measured at detection threshold crossings, provides a measure of the target height variance or relief. The pulse spreading contains contributions from both footprint-scale slopes and root-mean-square (RMS) roughness within the footprint. If it is assumed that pulse spreading is solely a consequence of footprint-scale slope, $\theta$, then the relationship between slope and the RMS width, $\sigma_{r}$, of the backscattered pulse is [Gardner, 1982]

$$
\sigma_{r}^{2}=\left(\sigma_{x}^{2}+\sigma_{f}^{2}\right)+\frac{4 d_{M a r s}^{2}}{c^{2}}\left[\tan ^{4} \gamma+\tan ^{2} \gamma \tan ^{2} \theta\right],
$$

where $\sigma_{x}$ is the transmitted laser pulse width, $\sigma_{f}$ is the receiver impulse response, and $\gamma$ is the laser divergence angle (i.e., the half angle at the $1 / e^{1 / 2}$ intensity point). The first term inside the brackets in (3) accounts for the effect of laser beam curvature and can often be neglected since $\gamma \ll \theta$.

In most areas of Mars, the spreading of the optical pulse is dominated by roughness rather than local slope [Garvin et al., 1999]. In such cases the width of the backscattered pulses can be used to derive roughness by correcting the returned pulse for local slopes determined from MOLA ranging [Garvin et al., 1999]. This approach has been verified from study of returned pulse widths measured for terrestrial desert surfaces by the Shuttle Laser Altimeter (SLA) [Garvin et al., 1998], which has a receiver design nearly identical to that of MOLA. Note that because the pulse width parameter is an RMS value it does not fully represent the possible local extremes of small-scale roughness.

During the initial months of the MGS global mapping mission (March 1999 to late June 1999) the received signal was unexpectedly strong, which caused saturation in the measured pulse width and area. As a consequence, resulting measurements of pulse width and pulse energy (discussed later) were unusable due to corruption of their absolute magnitudes. By raising the threshold setting for channel 1 (the channel with the shortest propagation delay) on July 2, 1999, the percentage of saturated shots decreased and more robust measurements of pulse width became possible. Since that time, the behavior of the calibrated optical pulse width parameter has been tracked and is reproducible at the $10 \%$ to $20 \%$ level in places where there are abundant crossovers, such as in high-latitude regions.

\subsection{Clouds}

MOLA also has functioned as an atmospheric lidar, providing the first quantitative characterization of the threedimensional distribution of cloud fronts on Mars [Zuber 
et al., 1998c; Pettengill and Ford, 2000, G.A. Neumann et al., Clouds detected by the Mars Orbiter Laser Altimeter after one Mars year, submitted to Journal of Geophysical Research, 2001, hereafter referred to as Neumann et al., submitted manuscript, 2001]. Clouds are diffuse targets, but MOLA's matched filters (Table 2) and the instrument's adaptive detection threshold enhance their probability of detection.

For each pulse, MOLA's leading edge detector will trigger only once. If an atmospheric reflector with sufficient opacity and backscatter crosssection is encountered within MOLA's range gate, an atmospheric reflection will register. In MOLA's nominal operating mode, only clouds within the minimum range gate width $(20 \mathrm{~km})$ of the surface will trigger. The center point of the range gate is determined autonomously on the basis of the last $14 \mathrm{~s}$ worth of laser ranges [McGarry et al., 1991]. For particularly dense clouds, such as the polar hoods over the winter pole, the instrument will sometimes lose lock on the surface and track clouds [Neumann et al., submitted manuscript, 2001].

MOLA range data are classified semiautomatically into ground and nonground returns using a stochastic tracking algorithm, followed by manual editing [Neumann et al., submitted manuscript, 2001]. If three or more non ground triggers have occurred within a 0.5 -s window, or 6 or more in a 6-s window ( $\sim 20 \mathrm{~km}$ on the ground), a nonground trigger is deemed to be a reflective "cloud," since the probability of such groups occurring by chance due to noise alone is $0.001 \%$. Nonreflective clouds also occur and are characterized by groups of 2 or more shots in a 2-s window that do not trigger on any channel, or by average reflectivitytransmittance product (as described in section 3.5 ) being less than 0.02 for the same window. Reflective clouds on channels 1 and 2, with photons arriving within 20 or $60 \mathrm{~ns}$ (Table 2), are dense, while returns from channels 3 and 4 are diffuse. Dense cloud fronts have mainly been observed on the flanks of the southern polar cap [Neumann et al., submitted manuscript, 2001].

\subsection{Surface Reflectivity}

The reflectivity of Mars, $r_{\text {Mars }}$, at the laser wavelength is determined from the ratio of received to transmitted laser energy, corrected for distance and the Lambert reflection law. The energy of the outgoing pulse, $E_{\mathrm{trans}}$, is sampled with a PIN photodiode, a charge-to-time converter, and an 8-bit counter. The energy of the received pulse, $E_{\text {rec }}$, is derived from the measured pulse width and area under the curve between two threshold crossings.

The relationship between $r_{\text {Mars }}$ and the ratio of the received/transmitted pulse energies is expressed by rearranging the laser link equation as [Abshire et al., 2000]

$$
r_{\text {Mars }}=\frac{E_{\text {rec }}}{E_{\text {trans }}} \frac{\pi Z_{\text {Mars }}^{2}}{\tau_{r} t_{\text {atm }}^{2} A_{r}},
$$

where $t_{\mathrm{atm}}$ is the one-way atmospheric transmissivity, $\tau_{r}$ is the optical transmission of the receiver, and $A_{r}$ is the aperture area of the receiving telescope. The accuracy of the reflectivity measurement after calibration is $\sim 5 \%$. In practice, $r_{\text {Mars }}$ contains contributions from the reflectivity of the terrain, $r_{\text {terr }}$, and the opacity of the atmosphere. If independent atmospheric opacity information is available, such as from the MGS Thermal Emission Spectrometer (TES) [e.g., Smith et al., 2000], then the reflectivity of the surface can be obtained using Beer's law

$$
r_{\mathrm{terr}}=\frac{r_{\mathrm{Mars}} e^{2 \tau_{\mathrm{atm}}}}{O_{p}}
$$

where $O_{p}$ is the returned signal enhancement due to the opposition effect [Hapke et al., 1998]. In using TES data a scaling factor must be applied to correct the TES 9- $\mu \mathrm{m}$ dust opacity to the MOLA wavelength of $1.064 \mu \mathrm{m}$. The scaling of dust opacity in the infrared to the MOLA wavelength may contribute up to $20 \%$ of the error in the measured surface reflectivity [Ivanov and Muhleman, 1998].

\subsection{Atmospheric Opacity}

If there is an independent estimate of the reflectivity of terrain in areas where MOLA has ranged, then the MOLA reflectivity measurement can be used to provide an estimate of the 1.064- $\mu \mathrm{m}$ opacity, $\tau_{\mathrm{atm}}$, of the Martian atmosphere. The opacity can be expressed [Ivanov and Muhleman, 1998]

$$
\tau_{\text {atm }}=-\frac{1}{2} \ln \left(\frac{r_{\text {Mars }}}{r_{\text {terr }}}\right)
$$

In a proof of concept study during the MGS science phasing orbits, radiometrically calibrated Viking color MDIMs [Eliason et al., 1992] were used to correct for the reflectivity of the Martian surface. Since the wavelength of the Viking red filter is 0.55 to $0.70 \mu \mathrm{m}$, a scaling factor was used to convert to $1.064 \mu \mathrm{m}$ [Ivanov and Muhleman, 1998].

\subsection{Data Products}

Data from MOLA are transmitted from MGS to stations of the NASA Deep Space Network, after which they are transmitted to NASA GSFC, where all processing occurs. Raw MOLA Experiment Data Records (EDRs) are processed into Precision Experiment Data Records (PEDRs) that contain profiles of all MOLA's measured and derived parameters, as well as the value of the areoid [Smith et al., 1999a] at each shot location and a flag to indicate ground returns.

The profile data are assembled into Experiment Gridded Data Products (EGDRs) of a resolution that depends on data density and distribution. The MOLA team is contractually obligated to submit for archiving grids developed from data in hand after 30 days of global mapping and at the end of the MGS mission. However, the team has so far submitted and intends to continue to submit to the NASA Planetary Data System (PDS) grids of progressively increasing resolution and vertical accuracy on a 3-month schedule.

\subsection{Differences Between MOLA 1 and MOLA 2}

In rebuilding the instrument (MOLA 2) for MGS, minor changes were implemented in order to reduce risk, several of which coincidentally also increased performance. The laser 
power-on sequence was modified in order mitigate a turnon transient and protect optical coatings from damage. Improvements in the laser diode fabrication process allowed selection of diodes that provided maximum pulse energy over a broader temperature range than MOLA 1 . The sampling of the start pulse energy was redesigned in order to measure $95 \%$ cross-sectional area of the output laser beam. This change enabled the $1.064-\mu \mathrm{m}$ measure of surface reflectivity to improve from $20 \%$ in MOLA 1 to $\sim 5 \%$ in MOLA 2. A trailing-edge detector was added so that the returned pulse width could be measured more reliably and with much finer resolution than with matched filters (Table 2). Finally, three delay lines were added to the TIU so that a clock cycle could be encoded at quarter-cycle intervals. This addition improved the range resolution from $1.5 \mathrm{~m}$ to $37.5 \mathrm{~cm}$.

\section{Geodetic Corrections}

\subsection{Orbit Determination}

Subtraction of the range to the surface from the MGS orbit, allowing for off-nadir pointing, yields measurements of the radius of Mars, $R_{\mathrm{Mars}}$, in a center-of-mass reference frame. The surface topography, $h_{\mathrm{Mars}}$, with respect to the gravitational geopotential at the laser beam footprint can be obtained from

$$
h_{\mathrm{Mars}}=R_{\mathrm{Mars}}-R_{\mathrm{areoid}},
$$

where the radius is measured with respect to Mars' center of mass as determined from MOLA, and $R_{\text {areoid }}$ is the radius of the areoid determined from the gravity field [Smith et al., 1999a].

Precision spacecraft orbits were determined using the NASA GSFC GEODYN/SOLVE orbit determination and parameter estimation system of programs [Rowlands et al., 1993; McCarthy et al., 1994]. GEODYN numerically integrates the spacecraft Cartesian state and force-model partial derivatives by employing a high order Cowell predictorcorrector model. The force modeling includes a spherical harmonic representation of the Martian gravity field, as well as point mass representations for the Sun and other planets (except Pluto). Solar radiation pressure, measurement and timing biases, and tracking station coordinates can also be also estimated. The accuracy of the laser spot location in latitude and longitude is limited by the knowledge of the spacecraft pointing at a nominal level of 1 to $3 \mathrm{mrad}$ (400 to $2000 \mathrm{~m}$ on the surface, depending on the spacecraft altitude) and absolute spacecraft position uncertainties of order 100 m.

\subsection{Altimetric Crossovers}

Errors in the gravity field model used in the computation of spacecraft orbits cause geographically correlated errors [Tapley and Rosborough, 1985] in spacecraft position that cannot be removed by including additional tracking data. Such errors have been observed for Earth-orbiting spacecraft as well as for MGS [Lemoine et al., 1999]. In the case of MGS, high-precision gravity models developed at both JPL and NASAVGSFC [Smith et al., 1999a; Lemoine et al., this issue; Yuan et al., this issue] show internal accuracies for the radial position of MGS at the submeter level. However, orbit overlap estimates do not take into account systematic errors. Comparison of these Doppler-only orbits with MOLA ranges at over 24 million altimeter crossover locations show radial errors at the 3- to 5-m level.

Orbital crossover analysis is a method for using altimetry as an observation type for nontopographic purposes. Crossovers are locations on the surface of a planet where the groundtrack of an orbit crosses over a previous track. At these locations a measure of the radius of the planet is obtainable from both orbits. The crossover observations are sensitive to orbital errors and can therefore be used as an observation of the spacecraft radial position in the orbit determination process [Shum et al., 1990]. Thus crossovers can be combined with the Doppler tracking of the spacecraft to improve knowledge of the orbit and laser beam pointing angle and, simultaneously, to estimate changes in the topography or shape of the planet due to seasonal mass redistribution between the polar caps and atmosphere, tides, and other effects.

Experience with the use of crossovers in satellite geodesy includes Earth-orbiting radar altimeter satellites, such as TOPEX [Marshall et al., 1995]. Crossovers have been used for the first time on a planetary spacecraft for MGS and have resulted in demonstrated improvements in radial, along-track, and across-track orbit components [Rowlands et al., 1999; Neumann et al., this issue].

\subsection{Geodetic Conventions}

Mars Global Surveyor utilizes a spacecraft-fixed ( $X Y Z$ ) coordinate system along whose axes the spacecraft Inertial Measurement Units (IMU) are aligned to measure the spacecraft attitude, and thus the inertial pointing of the science instruments. An instrument coordinate system is used to define the mounting of the instrument with respect to the spacecraft-fixed system. The Earth Mean Equator and Vernal Equinox 2000 (i.e., $J 2000$ ) is used as the standard inertial reference system to describe the spacecraft trajectory, planetary body ephemerides, star positions, inertial orientations of planetary body-fixed coordinate systems, inertial spacecraft attitude, and inertial instrument pointing. A series of matrix transformations relate the instrument-fixed coordinates to inertial $J 2000$ coordinates. All calculations for topography are done in a mass-centered, areocentric coordinate reference system, with longitude defined as positive eastward with the prime meridian defined according to Davies et al. [1992a]. Geodetic constants assumed in the MOLA investigation are based on the IAU9 1 reference system [Davies et al., 1992a] and are given in Table 3. The gravity field of Mars is being continuously refined through the efforts of the MGS Radio Science Team [Tyler et al., this issue]. The areoid in this analysis is based on gravity model mgm0964c20a [Lemoine et al., 1999; Smith et al., 1999a; Zuber et al., 2000a], while orbits have recently been recomputed with an updated version of the field, mgm $1004 \mathrm{~d}$ [Lemoine et al., this issue]. 
Table 3. Mars Constants Used by MOLA

\begin{tabular}{|c|c|c|c|c|}
\hline Parameter/Model & Value & Units & Reference $^{a}$ & Comments \\
\hline Reference System & & & 1 & IAU91 \\
\hline Pole, 2000 RA & $5.544579446831762 \mathrm{E}+00$ & radians & 1 & $\mathrm{~J} 2000$ \\
\hline Pole, 2000 Dec & 9.230348427839985E-01 & radians & 1 & $\mathbf{J} 2000$ \\
\hline Rotation rate & 7.088218081252292E-05 & radians $\mathrm{s}^{-1}$ & 1 & constant \\
\hline Origin, $\Omega_{o}$ & $176.868+350.8919830^{*} d$ & degrees & 1 & \\
\hline Gravity model & $\begin{array}{l}\text { mgm0964c20 } \\
\text { mgm } 1004 \mathrm{~cd}\end{array}$ & & $\begin{array}{l}2 \\
3\end{array}$ & $\begin{array}{l}\text { areoid } \\
\text { MGS orbit }\end{array}$ \\
\hline \multirow[t]{2}{*}{ GM } & $0.42828371300166 \mathrm{E}+14$ & $\mathrm{~m}^{3} \mathrm{sec}^{-2}$ & 3 & mgm0964c20a \\
\hline & $0.42828371901284 \mathrm{E}+14$ & $\mathrm{~m}^{3} \sec ^{-2}$ & 3 & mgm1004d \\
\hline \multirow[t]{2}{*}{ Mean equatorial radius } & 3396000 & $\mathbf{m}$ & 4 & topography model \\
\hline & 3397000 & $\mathrm{~m}$ & 3 & gravity models \\
\hline Planetary ephemeris & DE403 & & 5 & \\
\hline Coordinate system & planetocentric & & & east positive \\
\hline
\end{tabular}

${ }^{a}$ References: 1, Davies et al. [1992a]; 2, Smith et al. [1999a]; 3, Smith et al. [1999b]; 4, Lemoine et al. [this issue]; 5, Standish et al. [1995].

\subsection{Reference Surface}

Zero elevation on Mars from MOLA is defined as the equipotential surface (gravitational plus rotational) whose average value at the equator is equal to the mean radius as determined by MOLA (cf. Table 4). The planetary radius and a gravity model derived from MGS Doppler tracking data [Lemoine et al., this issue] with the IAU91 coordinate system parameters for Mars [Davies et al., 1992a] collectively provided the geopotential of Mars' mean equatorial radius. This equipotential surface was then extended to all latitudes as the zero-level reference for topography.

Table 4. MOLA Geodetic Parameters

Parameter $\quad$ Value/Uncertainty

$\begin{array}{lll} & \text { Geodetic Shape } \\ \text { Mean radius } & & 3389508 \pm 3 \\ \text { Mean equatorial radius } & & 3396200 \pm \\ \text { North polar radius } & & 3376189 \pm \\ \text { South polar radius } & 3382580 \pm \\ & & \\ & & \text { Triaxial ellipsoid } \\ a & & 3398627 \mathrm{~m} \\ b & & 3393760 \mathrm{~m} \\ c & 3376200 \mathrm{~m} \\ 1 / \text { flattening } & 169.8 \pm 1.0\end{array}$

$\begin{array}{lr} & \text { Directions of principal axes } \\ a & 1.0^{\circ} \mathrm{N}, 72.45^{\circ} \mathrm{E} \\ b & 0.0^{\circ} \mathrm{N}, 324.4^{\circ} \mathrm{E} \\ c & 89.0^{\circ} \mathrm{N}, 252.4^{\circ} \mathrm{E}\end{array}$

$\begin{array}{lc} & \text { Ellipsoid offset of COF from } \\ \Delta x & -233 \mathrm{~m} \\ \Delta y & -1428 \mathrm{~m} \\ \Delta z & -2986 \mathrm{~m}\end{array}$

\section{Instrument Calibration}

\subsection{Prelaunch Laser Pulse Energy Characterization}

MOLA 2 was calibrated prior to its launch on MGS by characterizing its performance over the complete range of anticipated operating conditions. The calibration also included a full flow-through system test with ranging to a target inside the clean room. The amount of energy emitted by the laser is a function of temperature [cf. Byer, 1988], so an important aspect of prelaunch testing was the characterization of the temperature dependence of the laser output energy. Laser energies measured directly by the bench check equipment were compared to pulse energies measured by MOLA.

\subsection{Timing and Range Drift}

During flight the MOLA 2 clock frequency is compared regularly with the MGS spacecraft clock, which is monitored from Earth through the spacecraft RF transmitter carrier frequency. The MOLA clock frequency is recalculated and updated for every 24-hour period during the ground data processing and the accuracy of the resultant clock frequency should be less than $5 \times 10^{-8}(<2 \mathrm{~cm}$ over the $400-\mathrm{km}$ measurement range). Figure 1 shows that during the MGS mapping orbit through May 2000, the clock frequency drifted 23 $\mathrm{cm}$ in equivalent range. By performing this comparison in combination with spacecraft pointing information provided by the quaternions, it is possible to improve knowledge of the along-track position of each laser footprint on the Martian surface.

\subsection{Laser Performance}

The postlaunch performance of the MOLA laser is consistent with the most optimistic expectations based on prelaunch testing. The performance is particularly significant considering that the instrument was operated in an un- 


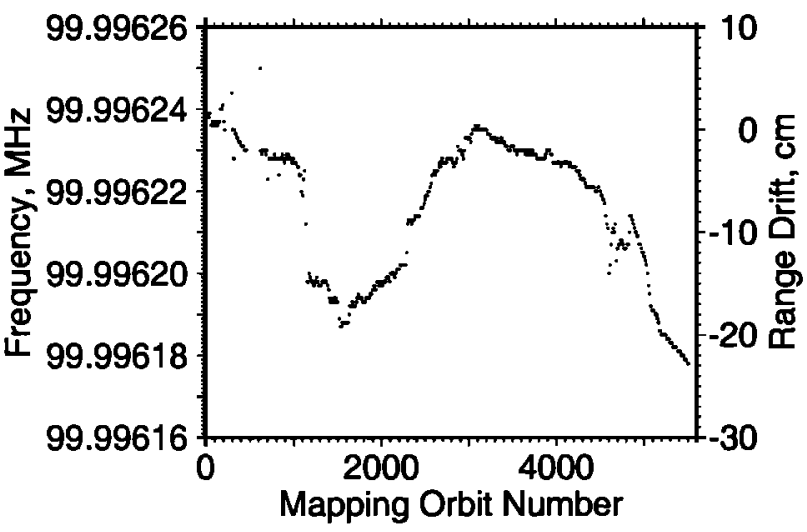

Figure 1. MOLA oscillator frequency and range drift during the MGS mapping orbit through May 2000.

intended fashion, outside its nominal operating temperature range, and switched on and off rather than run continuously, during the MGS aerobraking hiatus and science phasing orbit periods [Albee et al., this issue]. When MOLA-2 was turned off prior to Mars solar conjunction in June 2000, the laser had accumulated over $\mathbf{3 9 0}$ million pulses, of which $99 \%$ resulted in valid range measurements to the surface or atmosphere, making it by far the longest-lived laser ranging instrument that has so far flown in space. By comparison, the Clementine laser accumulated 647,000 pulses (of which $81 \%$ of the returns were noise hits) [Smith et al., 1997], and the Shuttle Laser Altimeter, an Earth-orbiting instrument built with MOLA spares, expended $\sim 3$ million pulses in two shuttle flights [Garvin et al., 1998]. The NEAR Shoemaker Laser Rangefinder [Zuber et al., 1997] accumulated 11 million pulses during the 1-year mapping mission of asteroid 433 Eros [Zuber et al., 2000b].

Even in the absence of mechanical and electrical problems and with nominal operating conditions, lasers of all kinds experience a degradation in performance with time. For solidstate lasers like that in MOLA, laser energy is expected to decrease with usage due to failure of laser diodes [Afzal, 1994]. As illustrated in Figure 2, the MOLA laser has experienced several discrete decreases in the output energy during its operation in Martian orbit. Decreasing laser energy was anticipated and factored in to MOLA's design, though prior to MOLA 2 it was expected that energy would fall off as a smooth exponential fashion rather than in discrete steps [Zuber et al., 1992; Afzal, 1994]. The laser energy drops have occurred on 60-day intervals during MOLA's continuous operation in the mapping orbit. The most likely cause of the energy decreases is the failure of individual diode bars, resulting in an $\sim 4$-mJ energy drop per failure. Monotonic increases and decreases in energy are due to temperature variations associated with the changing distance of Mars to the Sun during the Martian year.

On day 432 of 1999 (March 7, 2000) the MOLA laser briefly experienced an unusual variation in energy output due to significant unexpected variations in the temperature of the MGS nadir deck. These temperature excursions were associated with the first execution of the fixed high-gain mapping sequence [Albee et al., this issue] that was implemented to allow occultation measurements during a period when the MGS high-gain antenna obstruction prevented continuous mapping of the Martian surface. Subsequent to this event the MGS mapping sequence was modified to prevent further occurrences of this kind. Under normal operating conditions, MOLA 2 is expected to perform with full capability as long as performance exceeds $10 \mathrm{~mJ}$ in daytime and $5 \mathrm{~mJ}$ at nighttime.

\section{MGS Mission Phases and MOLA Data Collection}

Mars Global Surveyor successfully inserted into Martian orbit on September 11, 1997. The capture orbit was elliptical and near polar in inclination, with an initial period of $\mathbf{4 5}$ hours. The capture orbit was changed into a circular mapping orbit by aerobraking, utilizing repeated passes through the upper atmosphere of Mars near orbital periapsis to remove energy from the spacecraft orbit via drag on the solar panels. Aerobraking reduces the apoapsis height, eccentricity, and period. MOLA was unable to range to the surface while the MGS spacecraft was in aerobraking configuration. On September 15, 1999, prior to the initiation of aerobraking, periapse 3 of the capture orbit was designated as a period of instrument check out. During this orbit, MOLA collected its first data from Mars. The instrument sampled the Martian surface for a total of $21 \mathrm{~min}$ as the spacecraft passed through altitudes less than $787 \mathrm{~km}$, MOLA's hardware-defined maximum distance ranging limit. The ranging success rate during Pass 3 was $99.8 \%$ [Smith et al., 1998]; there were no missed shots and only $\sim 20$ false detections.

From October 14 to November 6, 1997, the periapsis height of MGS was raised out of the atmosphere to $175 \mathrm{~km}$. Aerobraking was suspended to analyze the effect of the dynamic pressures experienced during atmospheric passes on one of the solar panels that was damaged when deployed

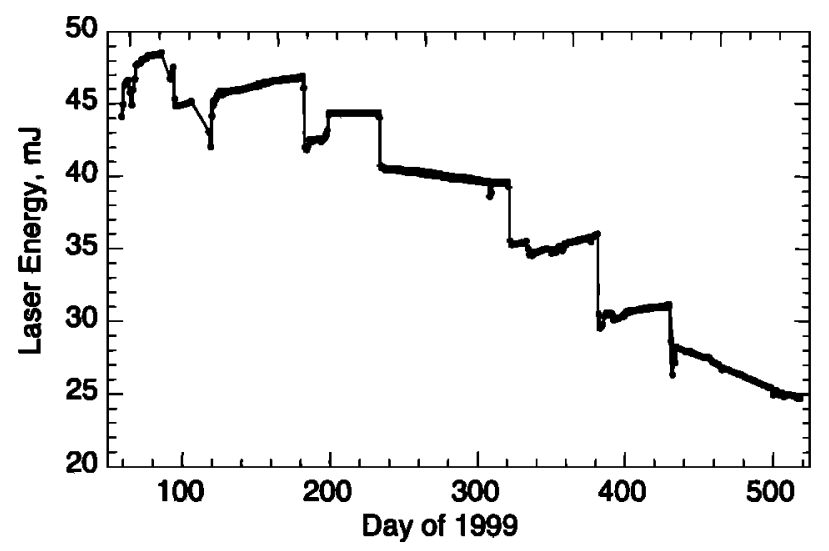

Figure 2. Daily averages of MOLA laser energy during the MGS mapping orbit. Time is given as day of 1999 , and values greater than 365 correspond to the year 2000 . 
shortly after launch. During these aerobraking hiatus orbits, 17 more MOLA profiles were collected [cf. Smith et al., 1998]. The orbital period of the aerobraking hiatus orbits was $\sim 35$ hours, and the length of the ranging pass was $\sim 22.5$ $\min$.

MGS implemented the science phasing orbits (SPO) between April and September, 1998 [Albee et al., 1998]. These science data-collecting orbits were undertaken to allow the originally planned $0200 / 1400$ UT equator-crossing times to be achieved in the MGS circular mapping orbit. The SPO had a period of 11 hours $37 \mathrm{~min}$ and an approximate periapsis altitude of $170 \mathrm{~km}$ that allowed $\sim 25$ min of laser ranging each orbit. During SPO 1 and 2, with the numbers corresponding, respectively, to periods before and after solar conjunction, MOLA collected over two million elevation measurements of Mars' northern hemisphere. The SPO orbits lasted until mid-September 1998, but MOLA was turned off on August $l$ to avoid excessive power cycling of the laser, an operation mode that had not been planned for in the instrument design.

MOLA began continuous mapping of Mars in the nearpolar, circular MGS mapping orbit on February 28, 1999. The instrument has ranged continuously to Mars at a $10-\mathrm{Hz}$ rate until June, 1999 except for a 2-week period in April 1999 when all instruments were shut off to investigate an obstruction of the MGS High Gain Antenna. In June 1999, MOLA was shut off for a 2 month period around solar conjunction, when the solar plasma induced a level of noise in the MGS X-band tracking data that translated to unacceptable errors in the spacecraft orbit and hence MOLA topographic accuracy.

\section{Global Topographic Model}

\subsection{Data and Resolution}

The topographic model, shown in Plate 2, is based on $333,689,830$ MOLA surface measurements. Data were corrected for spacecraft attitude, and for pointing angles $<6^{\circ}$ except where off-nadir ranging was performed to cover the north and south poles in areas not routinely sampled due to the $92.8^{\circ}$ inclination of the MGS orbit. To derive location coordinates and median heights, all surface measurements were projected and binned on a $1 / 64^{\circ}$ latitude $x$ $1 / 32^{\circ}$ longitude global grid. The resolution of the global grid is currently $\sim 1 \times 2 \mathrm{~km}^{2}$ at the equator, with longitudinal spacing decreasing with the cosine of latitude. More than half of the bins contained at least one observation, and usually more than three, while the remainder were interpolated by minimum-curvature-under-tension [Smith and Wes$s e l, 1990]$. Planetary radii were then projected and similarly binned, and a spherical harmonic expansion was subsequently fit to the data. The spherical harmonic solution of mass centered radii, $R_{\mathrm{Mars}}$, converted to geopotential elevation, $h_{\text {Mars }}$, by equation (7), takes the form

$$
\begin{aligned}
h_{\text {Mars }}(\phi, \lambda)=\sum_{l=1}^{N} \sum_{m=0}^{l} P_{l, m}(\sin \phi) . \\
\quad\left[C_{l, m} \cos (m \lambda)+S_{l, m} \sin (m \lambda)\right]
\end{aligned}
$$

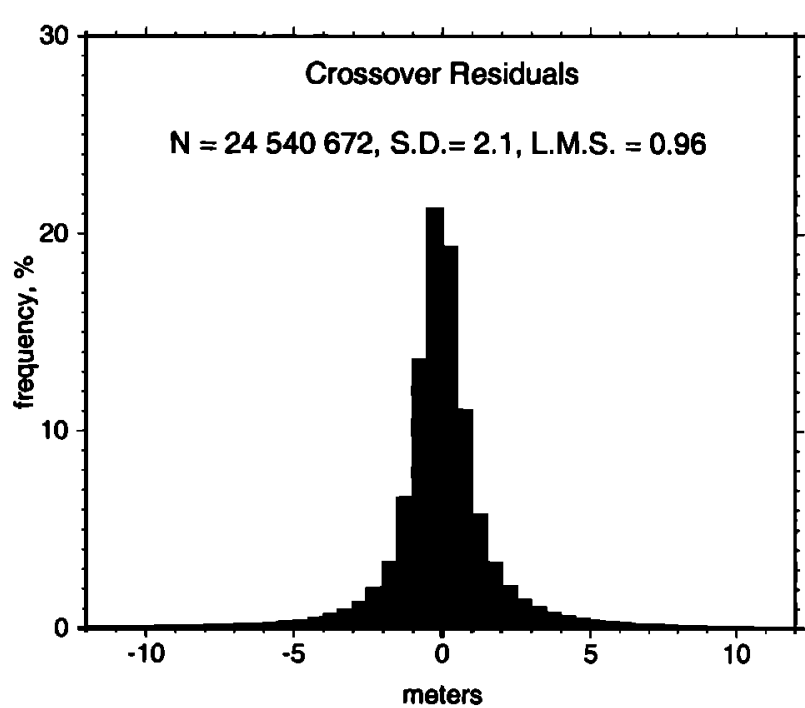

Figure 3. Histogram of orbit residuals at over 48 million altimetric crossover points. The least median of squares (LMS) misfit of $0.96 \mathrm{~m}$ is a measure of the accuracy of the global topographic model in Plate 2. No attempt has been made here to remove any time-varying height effect due to sublimation and deposition of $\mathrm{CO}_{2}$ on the polar caps.

where $\phi$ and $\lambda$ are the areocentric latitude and longitude of the surface, $P_{l, m}$ are the normalized associated Legendre functions of degree $l$ and azimuthal order $m, C_{l, m}$, and $S_{l, m}$ are the normalized spherical harmonic coefficients with units given in meters, and $N$ is the maximum degree representing the size (or resolution) of the field. The $C$ and $S$ coefficients provide information on the distribution of global topography. The current spherical harmonic model is to degree and order 1152 and has a spatial resolution of $\sim 9 \mathrm{~km}$.

The estimate of global topographic accuracy includes contributions from radial orbit error ( $0.85 \mathrm{~m}$ RMS) [Lemoine et al., this issue], instrument error ( $3 \mathrm{~m}$ RMS) [Abshire et al., 2000], and areoid error ( $\pm 5 \mathrm{~m}$ RMS) [Lemoine et al., 1999, this issue; Smith et al., 1999a]. Figure 3 demonstrates that inclusion of MOLA altimetric crossovers has reduced the misfit of topography at crossover locations to $\pm 0.96 \mathrm{~m}$ [Neumann et al., this issue], and to first order this misfit represents the accuracy of the topographic model.

\subsection{Fundamental Parameters of Shape}

Basic parameters of the shape of Mars are given in Table 4. Mars has a mean radius with respect to its center of mass of $3389508 \pm 3 \mathrm{~m}$, but the global distribution of radii shows considerable variability. The difference of $\sim 20$ $\mathrm{km}$ between the polar and equatorial radii indicates that the largest contribution to the shape is the planetary flattening, which is due primarily to the rotation of Mars. There is a $\sim 5 \%$ contribution [Folkner et al., 1997; Zuber and Smith, 1997] to the flattening from the Tharsis province, which is situated near the equator. The flattening of $1 / 169.8$ is significantly less than the value of $1 / 154.4$ [Bills and Ferrari, 1978 ] and slightly less than the ellipsoidal value of $1 / 166.53$ [Smith and Zuber, 1996] that have been used in previous geophysical analyses. 


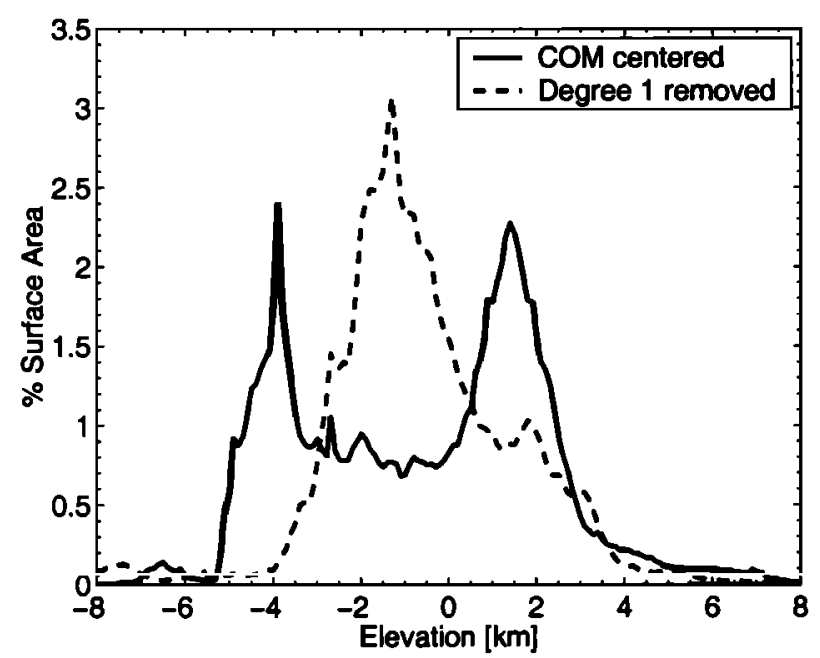

Figure 4. Hypsograms of surface elevation with respect to Mars' center of mass (solid line) and to the center of figure (dotted line).

Subtracting the gravitational potential or areoid [Smith et al., 1999a; Lemoine et al., this issue] from planetary radii measurements gives elevations in terms of geopotential topography, which eliminates the contribution due to rotation and accentuates other long-wavelength components of the shape. Figure 4 and Table 5 illustrate that the dynamic range of geopotential topcgraphy on Mars is $29.5 \mathrm{~km}$, the largest of the terrestrial planets. The major topographic excursions are due to large impact basins and shield volcanoes. Mars' thick elastic lithosphere [Turcotte et al., 1981; Banerdt et al., 1982; Comer et al., 1985; Sleep and Phillips, 1985; Banerdt et al., 1992] allows such large surface loads to be maintained (see below).

\subsection{Best Fit Ellipsoid}

A commonly used measure of the planetary shape is the reference ellipsoid. Parameters of the best fit ellipsoid, calculated with respect to a coordinate system with origin at Mars' center of mass (COM), are given in Table 4. The ellipsoid is displaced from the COM by $-2986 \mathrm{~m}$ along the $z$ axis, and represents an offset between the COM and the planet's geometric center (center of figure; $\mathrm{COF}$ ) along the polar axis. The sign of the offset indicates that the south pole has a higher elevation than the north pole (by $\sim 6.4 \mathrm{~km}$, including relief of the ice caps). The ellipsoid is also displaced by $\sim 1428 \mathrm{~m}$ along the $y$ axis in the direction of the Tharsis topographic rise.

\subsection{Geodetic Grid}

MOLA data have been used to redefine the geodetic grid of Mars and have provided up to 2 orders of magnitude improvement in knowledge of the absolute locations of latitude and longitude and 3 orders of magnitude improvement in knowledge of radius over all previous control point networks [e.g., Davies et al., 1992b]. Using geolocated positions of MOLA spots on the Martian surface [Rowlands et al., 1999; Smith et al., 1999b], the locations sampled by MOLA are now known to one MOLA footprint or approximately \pm 100 m with respect to Mars' center of mass. Vertical positions are known to the accuracy of the global topographic model, or $\sim 1 \mathrm{~m}$.

Effort is currently underway [Duxbury, 2000] to relocate into the MOLA coordinate system the Mars Mediumresolution (231-m pixel $^{-1}$ ) Mosaicked Digital Image Models (MDIMs) [Davies et al., 1992b] derived from Viking images. This process utilizes MOLA Geodetic Altimetry (MOGAL) files [Duxbury, 2000] in which MDIM's are brought into alignment with control point features, such as craters, sampled in MOLA PEDRs.

Table 5. Major Topographic Excursions on Mars

\begin{tabular}{|c|c|c|c|}
\hline Parameter & Latitude, deg & Longitude, ${ }^{\circ} \mathrm{E}$ & Elevation, $\mathbf{m}$ \\
\hline \multicolumn{4}{|c|}{ Regional Highs } \\
\hline Olympus Mons $^{a}$ & 17.3495 & 226.31 & 21287.4 \\
\hline Ascraeus Mons & 11.7082 & 255.177 & 18219.0 \\
\hline Arsia Mons & -9.12736 & 238.261 & 17780.7 \\
\hline Elysium Mons & 24.7478 & 146.437 & 14126.6 \\
\hline Pavonis Mons $^{b}$ & -0.06261 & 246.674 & 14057.4 \\
\hline Hecates Tholus & 31.8125 & 149.875 & 4853.26 \\
\hline Albor Tholus & 18.6562 & 149.875 & 3925.49 \\
\hline \multicolumn{4}{|c|}{ Regional Lows } \\
\hline Hellas $^{c}$ & -32.8132 & 62.0172 & -8180 \\
\hline Argyred $^{d}$ & -44.8192 & 315.088 & -5240.7 \\
\hline Utopia & 39.5 & 110.2 & -5050 \\
\hline Lyot $^{e}$ & 28.9277 & 50.6031 & -7036 . \\
\hline Valles Marineris & -14.2969 & 301.969 & -5679.47 \\
\hline
\end{tabular}

\footnotetext{
${ }^{a}$ Rim of small crater on south flank.

${ }^{b}$ South rim.

${ }^{c}$ Small crater.

${ }^{d}$ Hooke crater.

e Deepest basin in northern hemisphere.
} 
Table 6. Comparison of MOLA to Landing Site Elevations

\begin{tabular}{|c|c|c|c|c|c|}
\hline Landing Site & $\begin{array}{l}\text { Latitude, }^{a} \\
\text { deg }\end{array}$ & $\begin{array}{c}\text { Longitude, }^{a} \\
{ }_{\mathrm{E}}\end{array}$ & $\begin{array}{c}\text { MOLA } \\
\text { Radius, } \\
\text { m }\end{array}$ & $\begin{array}{c}\text { MOLA } \\
\text { Elevation, }^{b} \\
\mathrm{~m}\end{array}$ & $\begin{array}{c}\text { Elevation } \\
\text { MOLA - Lander, } \\
\text { m }\end{array}$ \\
\hline Viking Lander 1 & 22.2692 & 311.8113 & 3389373 & -3627. & 45 \\
\hline Viking Lander 2 & 47.6680 & 134.0430 & 3381857 & -4505 & $\mathbf{0}$ \\
\hline Pathfinder & 19.0949 & 326.5092 & 3389807 & -3682 & 94 \\
\hline
\end{tabular}

${ }^{a}$ Landing site coordinates are taken from Folkner et al. [1997]. All locations are given in the IAU1991 reference system [Davies et al., 1992a].

${ }^{b}$ MOLA radius minus 50th degree and order areoid of Lemoine et al. [this issue].

\subsection{Relationship of Topography to Atmospheric Pressure}

The relationship between surface topography and atmospheric pressure provides a measure of the mass of the atmospheric column above a particular location, which is critical in the assessment of potential future landing sites [Golombek et al., 1997a, b]. The average atmospheric pressure on Mars is $\sim 6.1$ mbars, which is close to the triple point of water. Early topographic models of Mars [e.g., $W u, 1991]$ were referenced to this atmospheric pressure surface. The use of a pressure surface as a reference introduced considerable error into estimates of elevation because of temporal variability in the height of the pressure surface due to seasonal variations in $\mathrm{CO}_{2}$ content and dynamical motions of the atmosphere. Because of the importance of understanding surface pressure for models of circulation of the Martian atmosphere and for landing-site assessment, MOLA elevations, which are referenced to a static areoid, have been related to the $6.1-\mathrm{mbar}$ atmospheric pressure surface.

To relate surface topography to atmospheric pressure, it is necessary to first compare planetary radii obtained from spacecraft occultations to those derived from MOLA. The occultations yield a measure of both planetary radius and atmospheric pressure and thereby provide a unique linkage between these quantities [Kliore et al., 1973; Lindal et al., 1979; Hinson et al., 1999]. MOLA radii, which are considerably more accurate than radii obtained by occultations, can then be related to occultation-derived surface pressures. By comparing MOLA radii to Viking and Mariner 9 occultations, Smith and Zuber [1998] showed that the zero point of MOLA topography corresponds to an atmospheric pressure of $\sim 5.2$ mbars at $L_{s}=0^{\circ}$. ( $L_{s}$ is the seasonal parameter on Mars and runs from $0^{\circ}$ to $360^{\circ}$ over the course of the Martian year; $L_{s}=0^{\circ}$ corresponds to the vernal equinox in the northern hemisphere.) The 6.1-mbar pressure level occurs at approximately $-1600 \mathrm{~m}$ relative to the zero reference of MOLA topography for $L_{s}=0^{\circ}$. However, the height of the 6.1-mbar surface needs to be adjusted, depending on the date. Seasonal variations in atmospheric pressure associated with the exchange of $\mathrm{CO}_{2}$ between the atmosphere and polar caps is expected to produce vertical variations in the height of the 6.1-mbar surface of 1.5 to $2.5 \mathrm{~km}$ over the course of a Martian year [Smith and Zuber, 1998].

\subsection{Comparison to Landing Site Elevations}

The Viking and Pathfinder landers contained sensors that measured atmospheric pressure directly and thus provided local estimates of surface elevation. A pre-MGS comparison of Viking lander site elevations with corresponding locations on the USGS DEM shows the heights to disagree by $\sim 2 \mathrm{~km}$, with the DEM locations in the wrong relative direction with respect to each other as compared to the lander sites [Kieffer et al., 1992]. In contrast, a comparison of MOLA altimetry with the locations of the landing sites shows good agreement (Table 6), considering the spatial differences in sampling. The differences between MOLA and lander-derived

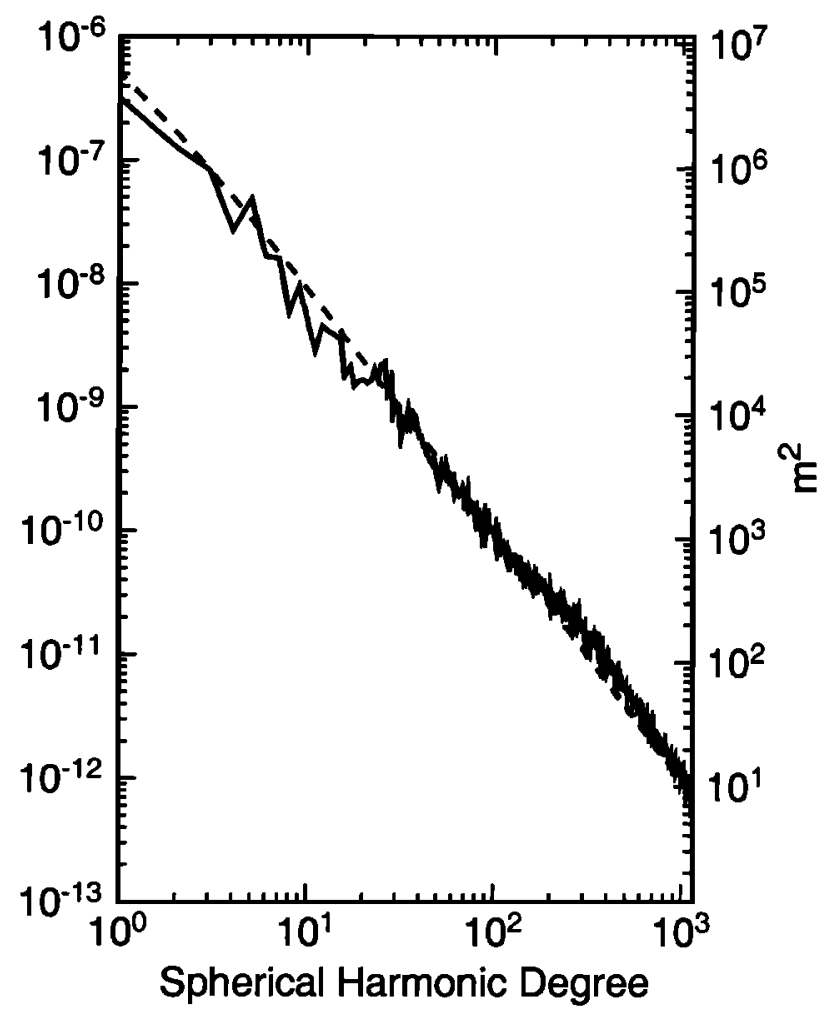

Figure 5. Power spectrum of Martian topography to degree and order 1152 (maximum resolution $9 \mathrm{~km}$ ). The left axis plots degree variance normalized by the square of the planetary radius, and the right axis plots unnormalized variance. The dashed line is a best fit power law (equation (9)). 
elevations of the landing sites are likely due to actual RMS variations of local topography and (for MOLA) errors in the geoid of Mars that are decreasing as gravity models are continually refined.

\subsection{Power Spectrum}

The power spectrum for Martian topography is obtained from the degree variance of spherical harmonic coefficients [e.g., Bills and Ferrari, 1985]. Figure 5 shows a variance $(V)$ spectrum to degree and order 1152, which corresponds to a spatial scale of $9 \mathrm{~km}$. A power law of

$$
V=8.2815 l^{-1.9346} \mathrm{~km}^{-2}
$$

provides a best fit to the spectrum. Figure 5 indicates that Martian topography has less power than the power law from degrees $10-25$ (spatial scales $\sim 10^{3} \mathrm{~km}$ ), due probably to the flat northern hemisphere (discussed later). The increase in power between degrees 100 and 1000 is thought to arise from the cratered southern highlands. At 10-km spatial scale (degree 1000), a $10-\mathrm{m}^{2} \mathrm{RMS}$ variance of topography is observed. The power law cannot simply be extrapolated to estimate the RMS variance of surface roughness at landing-site scales. On a $100-\mathrm{m}$ spatial scale only centimeters of roughness would be expected from extrapolation of the power law (Figure 5).

\section{Scientific Accomplishments}

\subsection{Global Physiography}

8.1.1. COM/COF offset and the pole-to-pole slope. The 3-km offset along the $z$ axis between Mars' COM and COF (cf. Table 4) results in a non-zero $C_{1,0}$ term in the spherical expansion of topography (equation (8)). Similarly, the 1.4-km offset in the direction of Tharsis is reflected in the $C_{1,1}$ and $S_{1,1}$ terms in the harmonic expansion. In practice, the term is sinusoidal in latitude rather than linear, so the hemispheric-scale elevation change is more complicated than a constant linear function. If the offset along the polar axis is interpreted in terms of a long-wavelength tilt, then it corresponds to an average global-scale south-to-north tilt of $0.036^{\circ}$ directed along lines of longitude [Smith et al., 1999b]. As illustrated in Plate 3, the progressive decrease in elevation from south to north is best observed at longitudes near $0^{\circ} \mathrm{E}$, away from the influence of Tharsis and Hellas. While this zonal elevation change is complicated by both large- and regional-scale topographic features, it is apparent that this fundamental aspect of Martian topography has controlled the surface and subsurface flow of volatiles and sediments throughout much of Martian history. As discussed more below, the global-scale elevation change associated with the $C_{1,0}$ term of the topography field resulted in the northern hemisphere becoming a global-scale sink for transported material. As discussed by Zuber et al. [1998b], the COM/COF offset in the direction of Tharsis also causes a tilt in the east-west direction, though deflections associated with the membrane response to Tharsis loading complicate the pattern [Phillips et al., 2001].
8.1.2. Hemispheric dichotomy. The striking difference in global physiography between the northern and southern hemispheres is termed the hemispheric dichotomy [Mutch et al., 1976; Carr, 1981]. The southern hemisphere is heavily cratered and older, whereas the northern hemisphere is more lightly cratered and younger, and was probably resurfaced by volcanism [Scott and Tanaka, 1986; Greeley and Guest, 1987] and sedimentation [Zuber et al., 2000a] early in Martian history. Much of the northern lowlands is composed of the Late Hesperian-aged Vastitas Borealis Formation and Amazonian-aged Arcadia Formation [Tanaka et al., 1992], which are tilted subtly north and are smooth at scales ranging from $\sim 100 \mathrm{~m}$ (Plate 5) to baselines of hundreds of kilometers [Kreslavsky and Head, 1999; Aharonson et al., this issue]. In the southern hemisphere, Noachian-aged ridged plains form locally flat intercrater deposits, whereas younger Hesperian-aged ridged plains dominate in some regions. The boundary between the northern and southern hemispheres in many places is characterized by complex terrain [Sharp et al., 1971; Sharp, 1973], as well as regional elevation changes of up to $4 \mathrm{~km}$ over distances of 300 to $1300 \mathrm{~km}$ [Frey et al., 1998]. Regions where the elevation change is relatively steep (e.g., longitudes $100^{\circ}$ to $220^{\circ}$; see Plate 2 ), comprise the dichotomy boundary scarp.

The dichotomy is characterized by both an elevation difference (Plate 2) as well as a difference in surface geology and macroscale roughness (Plate 5), but it is not yet clear if these features share the same mechanism of formation. Hypotheses to explain the hemispheric dichotomy have included thinning of the northern hemisphere crust by mantle convection [Lingenfelter and Schubert, 1973; Wise et al., $1979 \mathrm{a}, \mathrm{b}$ ], an early period of tectonic plate recycling [Sleep, 1994], and a massive impact or impacts in the northern hemisphere [Wilhelms and Squyres, 1984; Frey and Schultz, 1988]. The global distribution of elevations from MOLA has some bearing on the nature of the hemispheric elevation difference. Figure 4 shows global hypsograms of elevation with respect to the COM and COF. In a mass-centered coordinate system the elevation difference between the southern highlands and northern lowlands is apparent, while in a figure-centered system the distribution of elevations is unimodal. A planet-scale distribution of topography that contains a discrete elevation contrast in a mass-centered system may, in principle, appear unimodal when referenced to the COF [Aharonson et al., this issue]. However, on Earth, with elevated continents and deep ocean basins, the hypsogram of topography is bimodal whether viewed from mass- or figure-centered systems. This comparison indicates that the dichotomy boundary scarp contributes less to the COM/COF offset on Mars than the continental-oceanic crustal transition does on Earth [Aharonson et al., this issue].

It has now been established that both the topographic expression [Smith et al., 1999b] and crustal thickness distribution [Zuber et al., 2000a] of the dichotomy boundary are noncircular, and there is no evidence preserved that would support a hemispheric-scale single impact such as previously proposed [Wilhelms and Squyres, 1984]. Formation of the elevation difference by multiple smaller impacts has also 


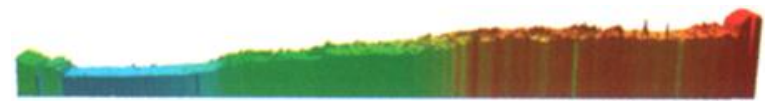

Plate 3. MOLA pole-to-pole downhill slice along longitude $0^{\circ} \mathrm{E}$. The south pole is on the right, and the north pole is on the left. Apparent is the quasi-monotonic decrease in elevation from south to north (apart from the north polar deposits) as well as the distinctive contrast in roughness between the southern highlands and northern plains.

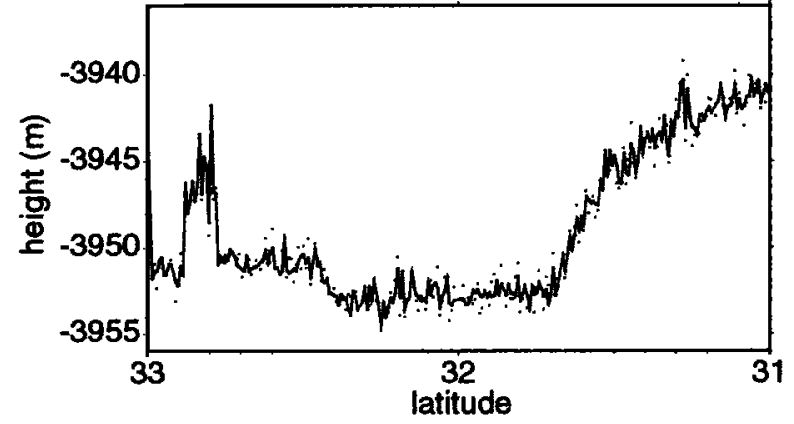

Plate 4. MOLA Pass 31, which traverses Amazonis Planitia, shows the flat northern hemisphere of Mars. The line connects range returns and the dots show the topography that would be obtained without the instrument's timing interpolator. This plate, in which height is in meters and latitude is in degrees, demonstrates the submeter performance of MOLA 2 over gently sloping surfaces. (a)

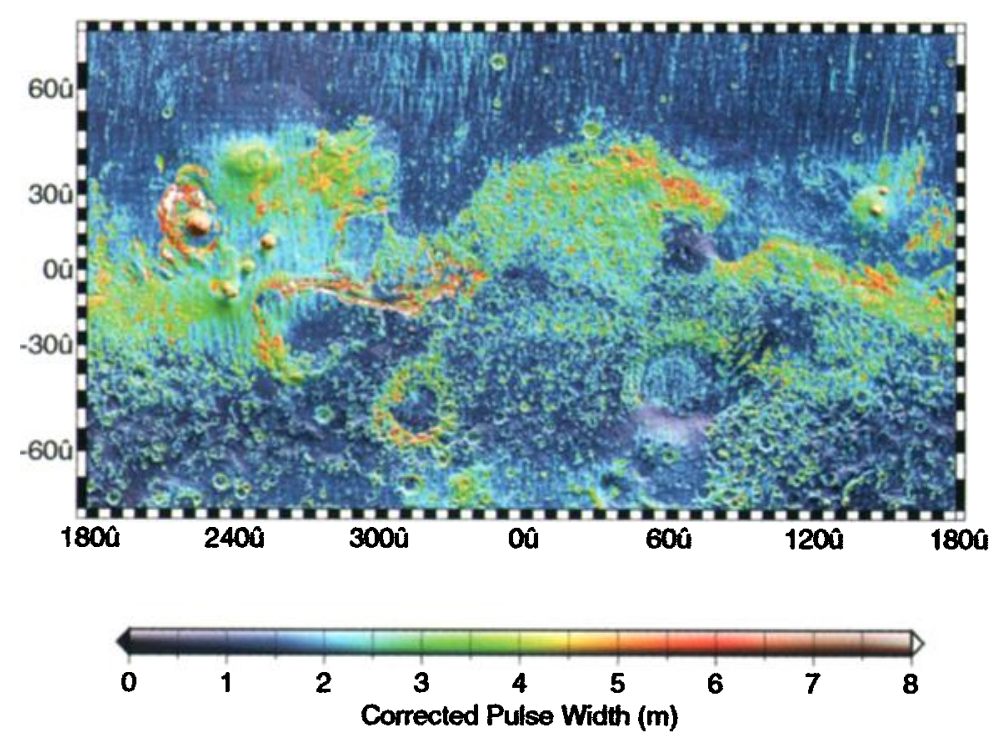

(b)

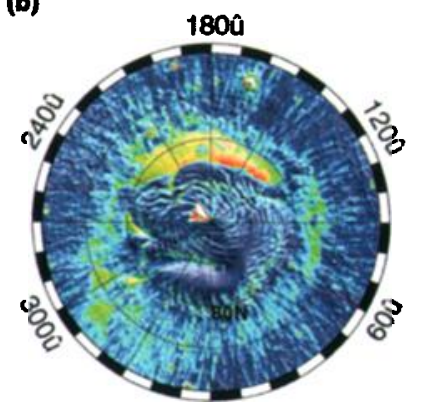

(c)

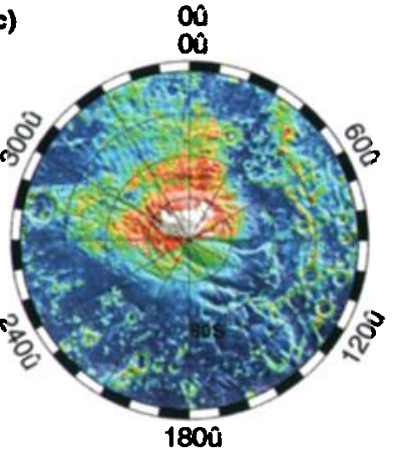

Plate 5. Vertical roughness of Mars in meters at the scale of 100-m from MOLA's optical pulse width. Pulse widths have been corrected for the effect of local slopes as described by Garvin et al. [1998]. Map projection and other attributes are as for Plate 2. 
been suggested [Frey and Schultz, 1988]. Beyond Utopia, however, no circular structures of comparable scale are apparent in the topography of the northern plains or from gravity [Smith et al., 1999a], although it is possible that such structures could have been masked by processes that occurred subsequent to formation. In any case a process or processes other than impact must be invoked to explain the preserved physiographic difference between the hemispheres.

8.1.3. The northern lowlands and evidence for a possible ancient ocean. The northern lowlands display a lower crater density than the southern highlands (cf. Plate 2) due to hemispheric-scale resurfacing that, prior to MGS, had generally been viewed as mainly volcanic [Greeley and Spudis, 1981; Greeley and Guest, 1987; Scott and Tanaka, 1986; McEwen et al., 1999], with a thin sedimentary cover in some areas. Analysis of MGS gravity and topography now suggests a significant sedimentary component to the northern hemisphere resurfacing [Zuber et al., 2000a]. The northern latitudes outside of the Tharsis rise are now known to be extremely flat, sloping gently downward to the north [Smith et al., 1998; Zuber et al., 1998b; Smith et al., 1999b] (cf. Plate 3). The flatness of the upper latitudes of the northern hemisphere extends across all longitudes and for over 2000 $\mathrm{km}$ in north-south extent. In the northern lowlands the topography varies by only $\pm 50 \mathrm{~m}$ to $\pm 400 \mathrm{~m}$ about a mean sloping surface [Aharonson et al., 1998]. The flatness is observed over a range of topographic baselines [Aharonson et al., 1998, this issue; Kreslavsky and Head, 1999, 2000], and flatness is documented down to the $100-\mathrm{m}$ scale (discussed later). Of particular interest is Amazonis Planitia (Plate 4), west of the Tharsis rise, that has been established as the flattest large-scale surface in the solar system [Aharonson et al., 1998]. Amazonis exhibits an RMS variance of $\sim 2$ $\mathrm{m}$ over scales up to $10^{2} \mathrm{~km}$ and is comparable in smoothness to the Earth's oceanic abyssal plains [Aharonson et al., 1998].

Prior to MGS, the northern lowlands were proposed to have been the site of an ancient ocean, with two geological contacts ("1" and "2") hypothesized on the basis of analyses of Viking images as possible shorelines [Parker et al., 1993]. MOLA data were used to test the predictions of the hypothesis of standing bodies of water in the northern lowlands [Head et al., 1998a, 1999; Hiesinger and Head, 2000; Garvin et al., 2000a]. Evidence in support of the hypothesis includes the following: the correspondence of Contact 2 with an approximate equipotential surface (the $\sim-3700 \mathrm{~m}$ elevation contour); enhanced topographic smoothness and distinctive simple crater properties inside Contact 2 ; terraces in the vicinity of Contact 2 that in places are oriented nearparallel to the contact; and a volume within Contact $2(\sim 100$ $\mathrm{m}$ global equivalent layer) consistent with estimates of the amount of water that conceivably could have been available on early Mars [Carr, 1996]. An ocean that filled to Contact 2 would have had an average depth of $570 \mathrm{~m}$ but would have achieved a depth of over $3 \mathrm{~km}$ within Utopia.

While the evidence from MOLA data is consistent with a past standing body of water, none yet reported uniquely requires such a genesis. Complicating factors include: observations of Contact 2 by the Mars Orbiter Camera that do not show evidence for paleoshorelines [Malin and Edgett, 1999]; tectonic ridge-like morphology of proposed shoreline terrace features north of Alba Patera and the deviation of these structures from an equipotential surface [Montesi and Zuber, 2001; Withers and Neumann, 2001]; statistical analysis of topography that shows that Amazonis and other northern lowland regions cannot be derived from simply smoothing heavily cratered terrain [Aharonson et al., this issue]; and the apparent absence of surficial carbonate in the northern plains noted by the MGS TES instrument [Christensen et al., this issue].

8.1.4. Tharsis. Plate 2 shows the vast volcano-tectonic Tharsis province to consist of a rise that extends from $220^{\circ} \mathrm{E}$ to $300^{\circ} \mathrm{E}$ and from $50^{\circ} \mathrm{S}$ to $10^{\circ} \mathrm{N}$, and spans $\sim 10^{7} \mathrm{~km}^{2}$ by area. The complex structure of the province revealed by MOLA indicates that most of Tharsis was formed by volcanic construction [Solomon and Head, 1981], with likely contributions from both extrusive and intrusive magmatism. The topographic map also shows that Tharsis consists of a main rise that contains contains the Tharsis Montes (Ascraeus, Pavonis, and Arsia) and a northern rise that essentially comprises the Alba Patera volcanic structure and its surroundings. The possible contribution to Tharsis topography from structural uplift, whose signature could conceivably have been masked by subsequent volcanism, has yet to be quantitatively assessed.

Unlike all previous topography models, Olympus Mons is not associated with Tharsis proper but rather is situated off the western edge [Smith et al., 1999b]. However, the volcanic construct likely has a genetic relationship to Tharsis.

MOLA data show that the Thaumasia region that defines southernmost Tharsis is not topographically distinct from the main lobe of the Tharsis rise. High-standing ridges in this region, proposed to be a consequence of lithospheric folding [Schultz and Tanaka, 1994], appear to have escaped resurfacing by younger Tharsis volcanic flows due to their high elevation. These elevated ancient terrains can be a consistent with an origin by either volcanic construction or uplift and further modeling and structural analysis will be required to distinguish the two possibilities.

Previous models for the origin of Tharsis based on gravity and topography analyses supported by the spatial and temporal distribution of tectonics [Banerdt et al., 1982, 1992; Tanaka et al., 1991] are currently undergoing revision [Banerdt and Golombek, 2000]. Contrary to previous conclusions based on lower-resolution Viking data [Banerdt et al., 1982, 1992], it is not necessary to invoke a period of purely isostatic support in Tharsis' history. Nor is it necessary to resort to complex representations of Tharsis' mechanical structure, such as an upper crust detached from the upper mantle [Tanaka et al., 1991], though such a lithospheric configuration may have once existed and may explain certain aspects of Tharsis tectonics, such as differences in ridge spacing between Hesperian ridged plains and the northern lowlands [Montesi and Zuber, 2001]. Instead, mod- 
eling shows that most structures around Tharsis can be explained by a flexural loading model [Banerdt and Golombek, 2000].

Phillips et al. [2001] showed that the membrane response to Tharsis loading has a global-scale effect that can explain a number of salient features on Mars. These include the negative gravity ring around Tharsis [Smith et al., 1999a; Phillips et al., 2001], the elevation of certain terrains in Arabia Terra, and the apparent asymmetry of the Utopia basin rim.

\subsection{Slopes and Surface Roughness}

8.2.1. Slopes. MOLA data have been used to calculate surface slopes on baselines from $300 \mathrm{~m}$ to $1000 \mathrm{~km}$ [Kreslavsky and Head, 1999, 2000; Aharonson et al., this issue]. With the high accuracy of the global data set, slopes on hemispheric-scale baselines $\left(10^{3} \mathrm{~km}\right)$ can be measured to several parts in $10^{5}$. On the $100-\mathrm{km}$ baselines the predominant tilts are south to north [Aharonson et al., this issue] and are generally consistent with the mapped distribution of valley networks and outflow channels [Williams, 2000; Phillips et al., 2001].

A useful measure is the RMS slope, which is generally analogous to the RMS roughness from radar observations [Simpson et al., 1992], though the former measure is influenced by isolated high slopes associated with structures such as craters within the window. RMS slopes in a $35-\mathrm{km}$ running window show an average of $3^{\circ}-10^{\circ}$ in the southern highlands and $0.2^{\circ}-0.8^{\circ}$ in the northern lowlands [Aharonson et al., this issue]. There is a general agreement between RMS slopes from MOLA with those measured by Earthbased radar [Christensen, 1986; Christensen and Moore, 1992], though there are significant disagreements in some regions such as Amazonis Planitia, likely reflecting different RMS slope properties at different length scales [Aharonson et al., this issue].

Median slopes are likely more typical of the average Martian surface, as they are not sensitive to window width and outliers within a window. They are generally smaller than RMS slopes, reflecting the contribution of local-scale structure. For both RMS and median slopes the smoothest units on Mars are Amazonis Planitia and certain parts of the polar caps, while the steepest areas are the walls of Valles Marineris, the Olympus Mons aureole, the dichotomy boundary east of $30^{\circ} \mathrm{E}$, and the rims of Argyre and Hellas.

8.2.2. Roughness. At shorter spatial scales, MOLA optical pulse widths provide a measure of the 100 -m-scale roughness of Mars. Results show a mean 100-m-scale global roughness of $2.1 \pm 2.0 \mathrm{~m}$ RMS [Garvin et al., 1999]. The roughness distribution is bimodal with the primary mode at $1.5 \mathrm{~m}$ RMS. Less than $1 \%$ of all values occur in excess of $10 \mathrm{~m}$, and these are restricted to the flanks of the uplands, canyons, and some larger crater rims. The north and south polar latitudes (i.e., areas north or south of $65^{\circ}$ latitude) display a mean roughness of $2.0 \mathrm{~m}$ RMS, similar to that for Mars as a whole.

Plate 5, which plots slope-corrected pulse widths, indicates five global roughness units [Garvin et al., 1999], ex-
Table 7. Global Roughness Units From Optical Pulse Widths

\begin{tabular}{|c|c|}
\hline $\begin{array}{l}\text { RMS } \\
\text { Roughness, m }\end{array}$ & Example Regions \\
\hline 0.3 to 1.1 & $\begin{array}{l}\text { northern plains, Vastitis Borealis, } \\
\text { southern hemisphere intercrater plains }\end{array}$ \\
\hline 1.3 to 1.7 & $\begin{array}{l}\text { northem volcanic plains, } \\
\text { Amazonis, Elysium, }\end{array}$ \\
\hline 2.0 & $\begin{array}{l}\text { Sinal and Lunae Planum } \\
\text { crater ejecta blankets, } \\
\text { inner crater cavity walls }\end{array}$ \\
\hline $\begin{array}{l}2.1 \text { to } 2.5 \\
>3.0\end{array}$ & $\begin{array}{l}\text { Tharsis, Olympia Planitia } \\
\text { hemispheric dichotomy boundary, } \\
\text { Olympus Mons aureole, } \\
\text { interior of Valles Marineris }\end{array}$ \\
\hline
\end{tabular}

amples of which are given in Table 7. The smoothest units include much of the Vastitis Borealis formation and some parts of the northern polar cap. The roughest areas are clustered in a few distinctive areas, including some parts of the hemispheric dichotomy boundary, the interior of Valles Marineris, and the Olympus Mons aureole.

An interesting aspect of the global roughness distribution is a transition that occurs within the northern lowland plains. Pulse-width-derived roughness correlates with the $-\mathbf{3 7 0 0} \mathrm{m}$ elevation contour (Contact 2) for $60 \%$ of the boundary, and follows the crustal dichotomy boundary equally well. More than $50 \%$ of the lowermost roughness values on Mars fall within the northern lowland plains, although outcroppings of this unit are also observed in southern mid-latitudes. Another striking regional boundary separates the crustal dichotomy region from the lowland plains to the north from Arabia to Daedalia Planum.

There is possible evidence for a temporal dependence to surface roughness. The pulse width measurements used in Plate 5 were obtained during southern winter, and the high roughness values on the south polar cap may be at least in part due to the presence of $\mathrm{CO}_{2}$ frost or snow. However we do not rule out data issues such as might occur when using unsaturated pulse widths but saturated pulse energies. Further analysis is underway.

\subsection{Impact Craters and Basins}

8.3.1. Major basins. MOLA data have established the Hellas impact structure (Plate 6) as the deepest known topographic depression in the solar system, with relief of over $9 \mathrm{~km}$ (Table 5). The basin is topographically asymmetric, which to first order is consistent with the suggestion of an oblique impact [Wichman and Schultz, 1989], but may also reflect localized surface modification (Plate 2). In terms of size, morphology, and topographic expression, Hellas has significant similarities to the South Pole-Aitken basin on the far side of the Moon [Spudis et al., 1994; Zuber et al., 1994; Head et al., 1998d]. These impact structures have similar diameters and volumes, as well as ejecta distributions. Plate 6 illustrates the concentric nature of material around the basin, 
which has an elevation above its surroundings of $2 \mathbf{~ k m}$ and accounts for a significant amount of the high-standing topography of the southern hemisphere. Material excavated from Hellas represents a major redistribution of the Martian crust [Zuber et al., 2000a], contributing in part to the surficial expression of topography along part of the dichotomy boundary [Smith et al., 1999b]. Plate 7 shows the unusual distribution of macroscale roughness around Hellas; the southwestern rim is much smoother than the rest of the rim or the surrounding southern hemisphere highlands. This smoothed region has been proposed to be an area of glaciation on the basis of morphology revealed in images [Kargel and Strom, 1992]. Elevation data reveal that basin floor deposits, previously proposed to be a consequence of fluvial, lacustrine, or aeolian deposition [e.g., Wichman and Schultz, 1989], are volumetrically significant.

Precise topography also permits quantitative characterization of both morphometry and unusual aspects of other major impact basins. For example, the MOLA topography now shows a continuous flow route from the Argyre basin to the Chryse outflow region that follows the $0.036^{\circ}$ slope, therefore constraining the period in Martian history when transport occurred [Williams, 2000]. Isidis shows a complex floor structure that has no counterpart in images and may reflect distinctive evolution associated with the basin's unique position at the geological dichotomy boundary [Frey et al., 2000b].

8.3.2. Buried and degraded basins. MOLA has verified the existence of the Utopia basin, buried beneath the northern plains. The basin, centered at $45^{\circ} \mathrm{N}, 110^{\circ} \mathrm{E}$ (Plate 2), was proposed originally as an impact feature on the basis of geological evidence [McGill, 1989] but was not resolved in earlier topographic maps of Mars. Utopia has a similar diameter to Hellas, but its depth is only $2.5 \mathrm{~km}$. Since basin depth scales with diameter, the relief of Utopia indicates that the thickness of resurfacing of the northern hemisphere in the vicinity of Utopia, accounting for uncertainties associated with settling, isostatic adjustment, and Hellas fill, is 5 to $10 \mathrm{~km}$.

MOLA's high-resolution global grid has also resolved a number of suble, degraded, previously unrecognized impact basins [Frey et al., 1999, 2000a]. There is no MOLA topographic expression [Smith et al., 1999b], however, nor evidence from gravity [Smith et al., 1999a], for some impacts proposed prior to MGS to lie beneath northern hemisphere plains [Frey and Schultz, 1988; Schultz and Frey, 1990].

8.3.3. Impact crater geometry. MOLA observations have been used to construct three-dimensional digital elevation models of over 5000 impact craters larger than $7 \mathrm{~km}$ in diameter planet [Garvin et al., 2000b]. These measurements include apparent crater depth, as derived from the mean floor elevation and the mean relief of the rim. Additional measurements include crater cavity and ejecta slopes, cavity and apparent ejecta volumes, cavity shapes, central uplift volumes, and many other parameters. The observations have relevance to understanding the role of target properties, including volatiles, in the impact cratering process [e.g., Carr et al., 1977; Barlow and Bradley, 1990], as well as the influences of crater modificational processes [Melosh, 1989].

A particularly useful geometric relationship is the ratio of depth $(d)$ to diameter $(D)$, usually plotted for morphologically distinct crater classes that scale with size. The progressive shoaling of depth relative to diameter as the latter increases reflects the influence of gravity and target strength in the cratering process. For topographically fresh complex craters in the diameter range 7 to $100 \mathrm{~km}$, the weighted power law function that best fits the data is [Garvin et al., 2000a]

$$
d=0.33 D^{0.53 \pm 0.03},
$$

where $d$ and $D$ are measured in kilometers. The behavior of complex craters is similar, on a global basis, to results reported by Pike [2000] that were derived on the basis of shadow measurements, but there are significant differences for many individual craters. The result suggests substantial infilling as part of the modification stage, which is consistent with slumping and other effects documented by Mars Orbiter Camera images [Malin and Edgett, 2000].

Equation (10) represents a general shoaling of apparently fresh impact landforms with increasing diameter and hence kinetic energy. However, there are exceptions, in particular in the higher latitudes on Mars where nonimpact-related in-
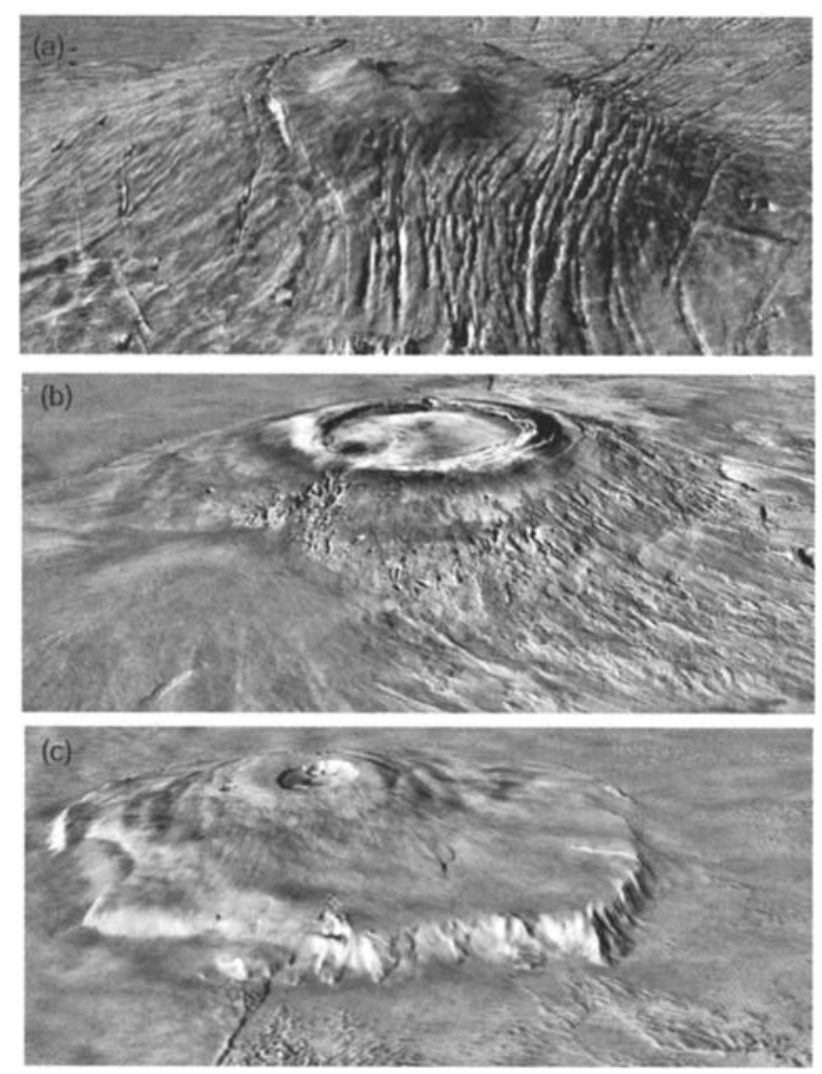

Figure 6. MOLA topography draped over Viking MDIMs for three volcanic shields: (a) Alba Patera, (b) Arsia Mons, and (c) Olympus Mons. The vertical exaggeration in each frame is 10:1. 
Table 8. Relief and Volumes of Major Volcanoes

\begin{tabular}{lcccccc}
\hline Volcano & $\begin{array}{c}\text { Latitude, } \\
\text { deg }\end{array}$ & $\begin{array}{c}\text { Longitude, } \\
{ }^{\circ} \mathrm{E}\end{array}$ & $\begin{array}{c}\text { Maximum Elevation, } \\
\mathrm{m}\end{array}$ & $\begin{array}{c}\text { Basal Elevation, } \\
\mathrm{m}\end{array}$ & $\begin{array}{c}\text { Relief, } \\
\mathrm{m}\end{array}$ & $\begin{array}{c}\text { Edifice Volume, } \\
\times 10^{6} \mathrm{~km}^{3}\end{array}$ \\
\hline Alba Patera & 40.5056 & 248.110. & 6769.6 & $\mathbf{8 2 7}$ & 5942.6 & 2.1 \\
Arsia Mons & -9.12736 & 238.261 & 17780.7 & 5823. & 11957.7 & 1.5 \\
Ascraeus Mons & 11.7082 & 255.177 & 18219.0 & 3401. & 14818.0 & 1.1 \\
Elysium Mons & 24.7478 & 146.437 & 14126.6 & 1793. & 12333.6 & 0.2 \\
Olympus Mons & 17.3495 & 226.31 & 21287.4 & -378. & 21665.4 & 2.7 \\
Pavonis Mons & -0.0626096 & 246.674 & 14057.4 & 5807. & 8250.4 & 0.4 \\
\hline
\end{tabular}

\footnotetext{
${ }^{a}$ Volumes were calculated by estimating the position of the base of the volcano (usually a break in topographic slope, and including the prominent flank eruption deposits on the Tharsis Montes) circumferentially around the edifice, determining the average elevation of this surface, and calculating the volume above this average elevation. No correction was made for the influence of lithospheric flexure or of infilling of flexural moats by flows or slide material [McGovern and Solomon, 1993, 1997].
}

filling processes have operated [Garvin et al., 2000b]. The MOLA data have also established a distinctive shoaling of depth at the complex crater/basin transition [Garvin et al., 2000a], similar to that observed for the Moon from Clementine altimetry [Williams and Zuber, 1998].

Because the $d / D$ ratio is sensitive to target properties, it can also be used as an indicator of the shallow subsurface structure. Garvin et al. [2000a] analyzed craters within Contact 2 [Parker et al., 1993] and showed that the $d / D$ relationship for simple craters is statistically different from that for the rest of Mars, while that for complex craters shows no notable difference from that for the rest of Mars. This observation suggests that shallow target properties within Contact 2 are different from those outside the contact.

\subsection{Volcanism}

MOLA data have provided accurate three-dimensional descriptions of a wide range of volcanic edifices (cf. Figure 6) and flows [Head, 1998; Smith et al., 1999b]. Measurements such as absolute heights, relief, and volumes (cf. Table 5 and Table 8) and the distribution of flank slopes are providing information on volcanic style, composition, and source depth [cf. Wilson and Head, 1994]. These data are showing evidence for changes in the characteristics of edifices as a function of geologic time [Head et al., 1998c]. They also are revealing the unusual characteristics of edifices such as Alba Patera, where tectonic structures have been shown to be arrayed asymmetrically around the edifice, and the edifices to extend to much greater distances than previously thought [e.g., Jager et al., 1999; McGovern et al., this issue]. MOLA data also provide important information on caldera depths, volumes and caldera wall structure [Smith et al., 1998], showing the relationships between different morphologic styles and permitting an assessment of their mode of formation and relation to magma reservoirs at depth [e.g., Head et al., 1998b]. Analysis of morphometry has led to the firm identification of an edifice resembling a stratovolcano in the Aeolis region and the development of criteria for the recognition of degraded equivalents in the older heavily cratered terrain on Mars [Stewart and Head, this issue].
Even with high-resolution topography, evidence for flexural loading by volcanic constructs that would provide constraints on lithospheric thickness and heat flow at the time of loading has been largely ambiguous [Solomon et al., 1998]. The lack of any discernible flexural signatures around major structures such as Arsia Mons and Alba Patera implies that any flexural depressions must be filled by some combination of volcanic flows and landslide material from the volcano flanks.

Detailed measurements of lava flow thicknesses, roughness, levee characteristics, and regional slopes are similarly yielding important information on styles of emplacement and rheological properties of lava [Hulme, 1974; Wilson and Head, 1994]. Kreslavsky and Head [1999, 2000] have used MOLA data to characterize the regional and global roughness characteristics of lava flow units and deposits and have found distinct differences between units and trends in roughness characteristics with time. Analysis of individual MOLA profiles has been undertaken as a tool for estimating the rheological properties and silica content of lava flows [e.g., Thomson and Head, 2000]. Analysis of the geometric properties of craters at high latitude has yielded topographic evidence for geologically recent volcanism in the north polar region [Garvin et al., 2000c].

\subsection{Tectonics}

8.5.1. Valles Marineris. MOLA topography has clarified the regional context of the Valles Marineris canyon system, particularly its relationship to the Tharsis province. Valles Marineris is now shown to lack a regional dome, which indicates that the canyon system was a consequence of passive rifting [Sengor and Burke, 1978] associated with stresses due to the formation of the Tharsis rise [Smith et al., 1999b], rather than an active rift formed above a localized mantle plume. The canyon system dips to the east away from Noctis Labyrinthus, reaching a maximum depth of $\sim 11 \mathrm{~km}$ below the surrounding Hesperian-aged plains. The easternmost segments of Valles Marineris tilt westward and are situated a kilometer below Chryse, where outflow channels suggest water from Valles Marineris and other southern hemisphere 


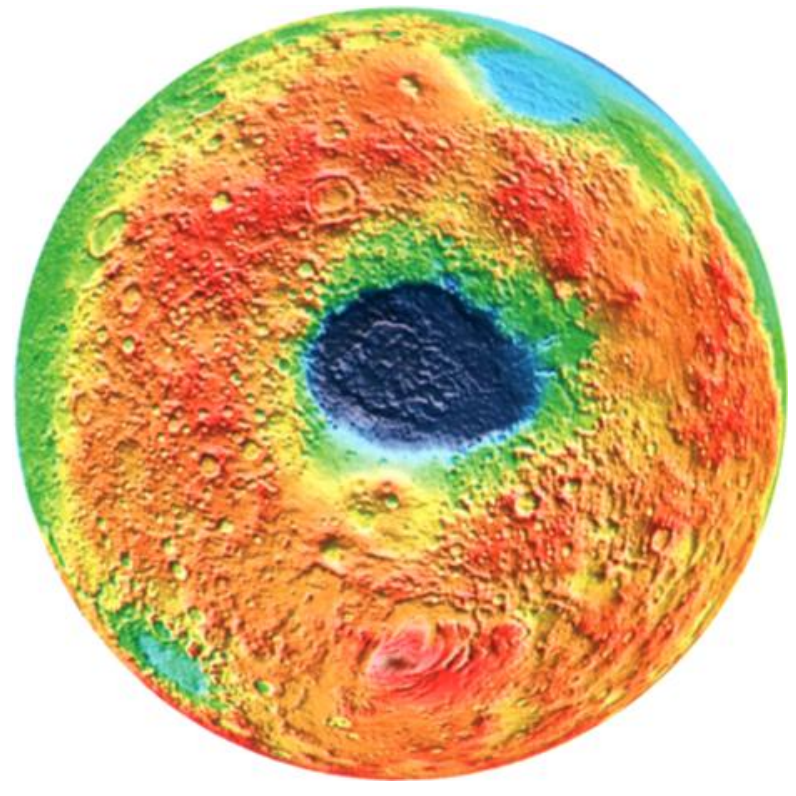

Plate 6. Orthographic projection of Martian topography centered on $45^{\circ} \mathrm{S}, 65^{\circ} \mathrm{E}$ illustrates the annular nature of high terrain (in red) around the Hellas impact basin (at center, in purple). North is to the top; the south polar layered terrains are at bottom center.

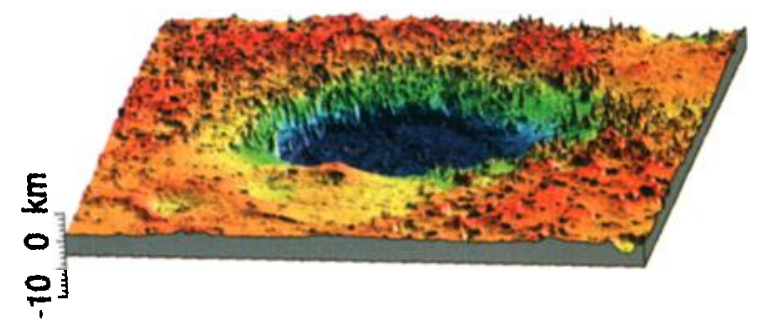

Plate 7. Three-dimensional view of the Hellas impact basin showing the unusually smooth southwest rim. The vertical exaggeration is $20: 1$. View is from the south.

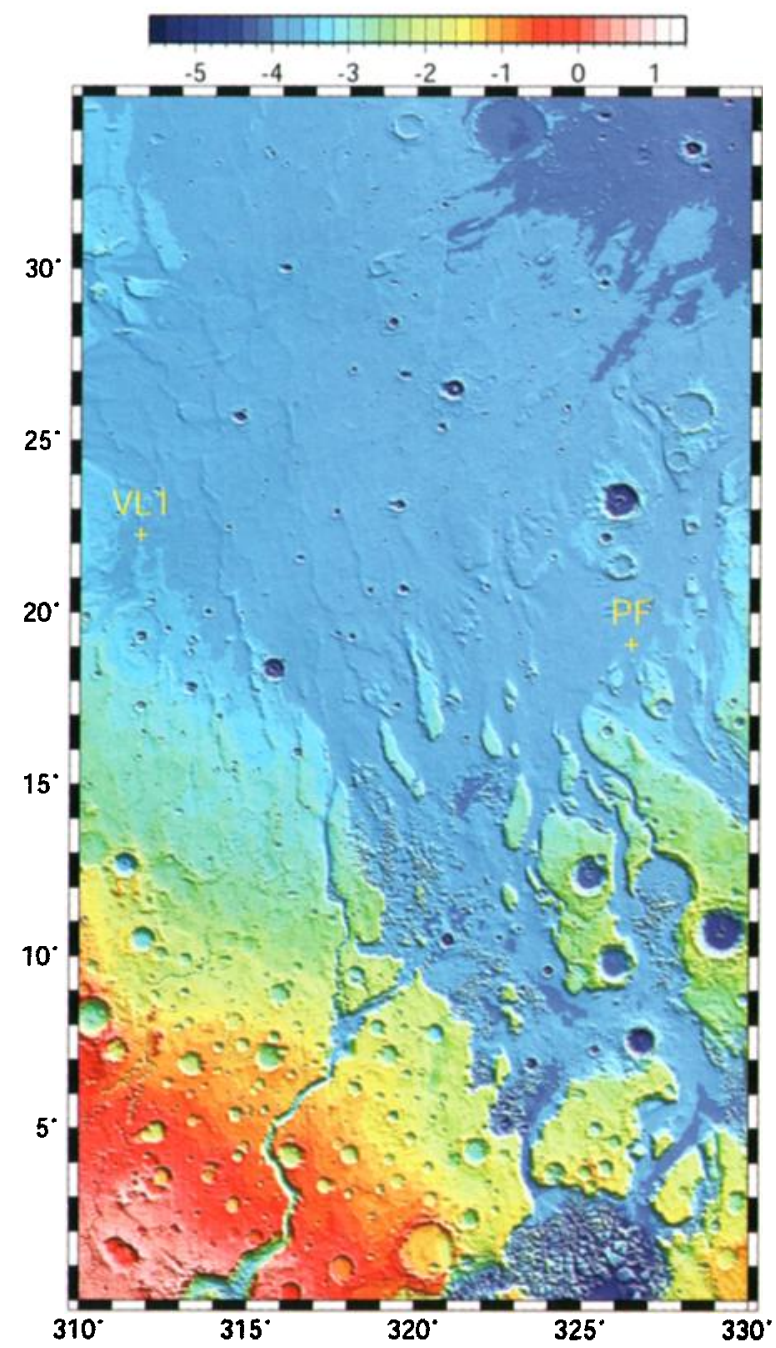

Plate 8. High-resolution regional topographic grid showing detailed evidence for past transport of water in the Chryse region. Locations of the Viking 1 and Pathfinder landers are shown for reference. The unit of elevation is kilometers.

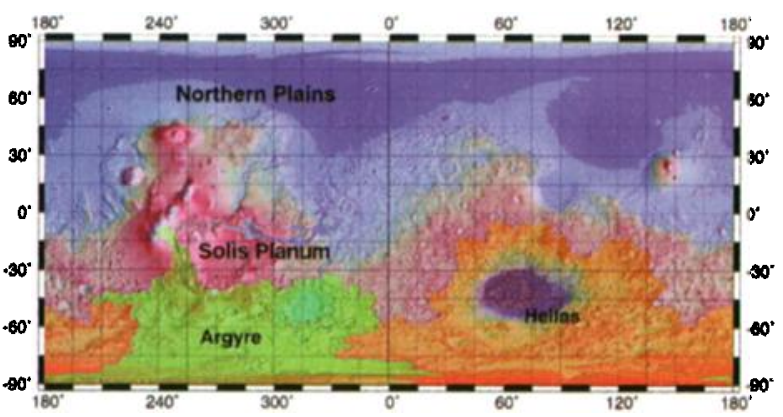

Plate 9. Drainage basins and watersheds on Mars for the three largest closed basins based on present-day topography. The northern plains basin is dark blue, and its watershed is pink. The Hellas basin is purple, and its watershed is orange. The Argyre basin is turquoise, and its watershed is green. For limited amounts of fill the high-standing Solis Planum region would be a separate basin. 
regions once debouched. The westward tilt initiates at the intersection of the canyon with an outcropping of Noachian material surrounding Solis Planum and predates the formation of the canyon, suggesting that the westward tilt has existed since the canyon formed [Smith et al., 1999b]. The topographic configuration of the eastern canyon could be consistent with the transport of significant quantities of water in earlier periods [Smith et al., 1999b]. The canyon walls exhibit a duality of slopes from top to bottom such that the upper wall sections are steeper than their lower counterparts [Aharonson et al., 1998]. Such a slope distribution indicates extensive mass wasting related to the slumping and erosion of material from the upper walls.

8.5.2. Graben. MOLA profiles have been used to estimate Tharsis-related tectonic extension in the Tempe Terra region in eastern Tharsis. The results for extension in small graben are generally consistent with earlier work [e.g., Golombek et al., 1996] based on scarp widths and assumed scarp slopes. However, MOLA-derived extension in large rifts is less, because measured slopes are now known to be less [Harrington et al., 1999] than estimated in previous work.

8.5.3. Wrinkle ridges. MOLA profiles and gridded data have elucidated the nature of wrinkle ridges, are compressive structures characterized by linear, asymmetric topographic highs that are preferentially found in volcanic plains. A long-standing question has been the subsurface structure of the ridges, their depth penetration, and the contributions of faulting versus folding in accommodating strain [e.g., Plescia and Golombek, 1986; Watters, 1993; Zuber, 1995]. MOLA topography shows that the preponderance of ridges exhibit an elevation offset [Golombek et al., this issue], a result that appears most consistent with the presence of a subsurface fault with significant depth penetration, a style of faulting also termed "thick-skinned" deformation. The topography also shows that, at least in parts of the Tharsis region, the elevated side of grouped ridges is consistently on the same side, which may be a consequence of heterogeneities in the stress field or lithospheric structure of Tharsis at the time of ridge formation [Montesi and Zuber, 2001].

\subsection{Internal Structure}

8.6.1. Crustal structure. MOLA topography, in combination with gravity [Smith et al., 1999a; Lemoine et al., this issue] from the MGS Radio Science experiment [Tyler et al., 1992, this issue], has permitted determination of the global crust and upper mantle structure of Mars [Zuber et al., 2000a; Zuber, 2001]. In inversions for crustal structure based on a uniform-density crust [Zuber et al., 2000a; $\mathrm{Zu}$ ber, 2001], the planet displays two distinct crustal zones that do not, at least in the present day, correlate in a global sense with the geologic expression of the hemispheric dichotomy. One crustal province consists of a region of crust that thins progressively from the south polar region toward the north, and encompasses much of the southern highlands and Tharsis province. The second province constitutes a region of approximately uniform crustal thickness that includes the northern lowlands and Arabia Terra. While the boundary between crustal provinces lacks correspondence to the geological dichotomy boundary, it does show some correlation to distinctive global-scale compositional units mapped by the MGS TES instrument [Bandfield et al., 2000]. On a regional scale the model shows thinning of the crust beneath major impact basins and a complex crustal structure beneath Tharsis indicative of pervasive accumulation of volcanic materials. As for terrestrial rift zones, the crust beneath Valles Marineris is thinned along the central axis. The Elysium and Solis Planum provinces appear to be crustal plateaus with crustal roots, while Tempe Terra is a topographic dome that lacks a root.

The mean thickness of the global crustal model ( $~ 50$ $\mathrm{km}$ ) is constrained by calculations of the minimum value of lower-crustal viscosity that allows the long-wavelength crustal structure to be maintained [Zuber et al., 2000a; Nimmo and McKenzie, 2001]. The results are inconsistent with alternative models that suggest an average crustal thicknesses of 100-250 km on the basis of the geochemistry of Martian meteorites [Sohl and Spohn, 1997] or inappropriate isostatic assumptions [Yuan et al., this issue].

8.6.2. Lithosphere structure. MGS topography and gravity have also been used to map the thickness of the elastic lithosphere on Mars, which is a measure of the inverse of the thermal gradient, and thus of heat flow from the interior [Solomon and Head, 1990]. Prior to MGS, Martian lithosphere thickness was estimated from the flexural deflection of the lithosphere in response to loading, but analyses were limited by the resolution and quality of the topography, and to a lesser extent, gravity fields. Earliest estimates of the thickness of the elastic lithosphere on Mars were derived from the radial distances of circumferential graben inferred to be the result of flexural stresses from near-axisymmetric loads [Comer et al., 1985], or from the absence of graben around a known load [Comer et al., 1981].

Independent inversions and forward models [Simons et al., 1997, 2000; McGovern et al., this issue] have been performed for effective elastic thickness $T_{e}$, regarded as the depth to an isotherm $\left(\sim 650^{\circ} \mathrm{C}\right)$ beneath which the Martian interior is too weak to support stresses over geologicallylong $\left(\sim 10^{8}\right.$ year) intervals. Results indicate considerable spatial variability in lithosphere structure. For example, the southern highlands, including the Hellas impact basin, show a best fit $T_{e}$ ranging from 0 to $20 \mathrm{~km}$, while the Utopia basin in the northern plains gives a value of $\sim 100 \mathrm{~km}$. The Alba Patera volcano displays $T_{e}=50 \mathrm{~km}$, while Olympus Mons and the other Tharsis volcanoes are characterized by $T_{e}>100 \mathrm{~km}$. Within the southern highlands, the Terra Cimmeria region of prominent linear magnetic anomalies revealed by the MGS magnetometer experiment [Acuna et al., 1999; Connerney et al., 1999] shows $T_{e}=20 \mathrm{~km}$.

The lithospheric thickness distribution is explained if, as on Earth [Watts et al., 1980], elastic thickness reflects the thermal state of the Martian lithosphere at the time of loading [Zuber et al., 2000a]. The southern highlands have the oldest surface ages, and the $T_{e}$ values are consistent with 
crustal stabilization and loading earliest in Martian history. Next youngest are the northern lowlands, and the lithosphere thicknesses derived reflect the thermal state during the period of northern hemisphere resurfacing. The lithospheric thicknesses determined for large areas of the southern lithosphere indicate a heat flow on early Mars, however, that is considerably less than the global averages suggested by many thermal evolution models [Schubert and Spohn, 1990, 1998]. If this difference is valid, then much of the early heat loss must have been localized elsewhere on Mars, in a region or regions where lithosphere thicknesses at the earliest times cannot be determined because values in such regions reflect the thermal state at times of subsequent geological activity. On areal grounds, the northern hemisphere was the most likely locus of any such early high heat flow. Such an inference could be consistent with an early episode of plate tectonics [Sleep, 1994], a period of degree-one mantle dynamics [Zhong and Zuber, 2001], or perhaps some other global-scale geodynamical phenomenon that results in significant early heat loss from the deep interior [Nimmo and McKenzie, 2000; Stevenson, 2001].

\subsection{Past Transport of Water}

8.7.1. Channels. Martian outflow channels represent compelling evidence for the transport of significant quantities of water during earlier evolutionary epochs on the planet [Carr, 1996]. However, significant questions remain regarding the amount, duration, and possible episodicity of flow, and the residence time of liquid water on the early Martian surface [Carr and Clow, 1981; Baker et al., 1991; Baker, 2001]. Such questions bear significantly on the nature of Mars' early climate [Fanale et al., 1992; Squyres and Kasting, 2001; Jakosky and Phillips, 2001]. MOLA altimetry has permitted precise characterization of local and regional slopes as well as channel cross sections that are enabling past estimates of flow rate and discharge [cf. Komar, 1979; Komatsu and Baker, 1997] to be refined [Smith et al., 1998].

Thus far, high-resolution profiles and regional topographic maps, such as shown in Plate 8 for the Chryse outflow region, have yielded evidence for sustained flow and multiple flooding events [Williams et al., 2000]. In addition a global analysis of the geometric properties of valley networks has revealed a correlation of channel depth with latitude [Williams, 2000] that may have implications for the volatile source depth. These observations, combined with the recognition of linear gravity deficits that emanate from major outflow regions and may represent the subsurface continuation of channels in Chryse and Kasei Valles [Zuber et al., 2000a]. These proposed buried channels collectively have implications for the early transport of water, in terms of the mechanism for liberating liquid water, the duration of flow, and the nature of filling of a proposed early ocean.

8.7.2. Watersheds. While it is not possible to confidently reconstruct past pathways of water on Mars from present topography, MOLA data can be used to trace current transport directions and sinks. There is reason to believe that Mars has not undergone major vertical motions for much of its history [Banerdt and Golombek, 2000; Williams et al., 2000; Williams, 2000], so such analysis may also have significant relevance for the nature of surface and subsurface hydrological transport that occurred in an early environment when liquid water was stable at the surface.

Flow directions and watersheds based on the present topography have been calculated globally for Mars [Smith et al., 1999b]. Plate 9 indicates that there are at present, and probably for much of Martian history, four major closed basins that can act as sinks for the surficial flow of water or ice. The low-lying northern plains is by far the largest of these basins. Table 9 shows that its watershed, the basin along with the remaining area of the planet that would drain into it, constitutes three-quarters of Mars' surface area. Table 9 also shows watershed characteristics for Contacts 1 ($1700 \mathrm{~m})$ and $2(-3750 \mathrm{~m})$, defined by Parker et al. [1993] as possible locations of ancient shorelines. Note that the volume estimate for Contact 1 can only be considered approximate because it deviates significantly from a constant elevation [Head et al., 1999].

The other basins are Hellas, Argyre, and Solis Planum, all in the southern hemisphere. Hellas is much smaller in area than the northern plains, but its great depth gives it a volume that approaches that of the much shallower northern basin, though volume ultimately depends on the amount of water available for fill. The highest closed contour of the Hellas drainage basin is $1250 \mathrm{~m}$, at which level it breaches into the Isidis basin and into the northern lowlands. However, Hellas' drainage area is relatively small. The volume of Argyre is only $8 \%$ that of Hellas, but its drainage area is about half as large. Argyre's watershed breaches into Chryse Planitia through a well-developed set of flood-carved channels that may have removed a significant volume of surficial material

Table 9. Mars Watershed Characteristics

\begin{tabular}{lcccccc}
\hline Basin & $\begin{array}{c}\text { Drainage } \\
\text { Area, } \\
10^{6} \mathrm{~km}^{2}\end{array}$ & $\begin{array}{c}\text { Basin } \\
\text { Volume, } \\
10^{6} \mathrm{~km}^{3}\end{array}$ & $\begin{array}{c}\text { Flooded } \\
\text { Area, } \\
10^{6} \mathrm{~km}^{2}\end{array}$ & $\begin{array}{c}\text { Overflow } \\
\text { Elevation, } \\
\mathrm{m}\end{array}$ & $\begin{array}{c}\text { Maximum } \\
\text { Depth, } \\
\mathrm{m}\end{array}$ & $\begin{array}{c}\text { Average } \\
\text { Depth, } \\
\mathrm{m}\end{array}$ \\
\hline Northern Plains (above $-3750 \mathrm{~m})$ & 110.85 & 14.05 & 24.82 & N/A & 3215 & 570 \\
Northern Plains (above -1700 m) & 110.85 & 93.21 & 51.00 & N/A & 5165 & 1830 \\
Hellas & 22.34 & 27.24 & 10.61 & 1245 & 9465 & 2570 \\
Argyre & 11.41 & 2.27 & 1.48 & 185 & 5140 & 1530 \\
Solis Planum & 2.89 & 0.36 & 0.79 & 3310 & 1800 & 460 \\
& & & & & & \\
\hline
\end{tabular}




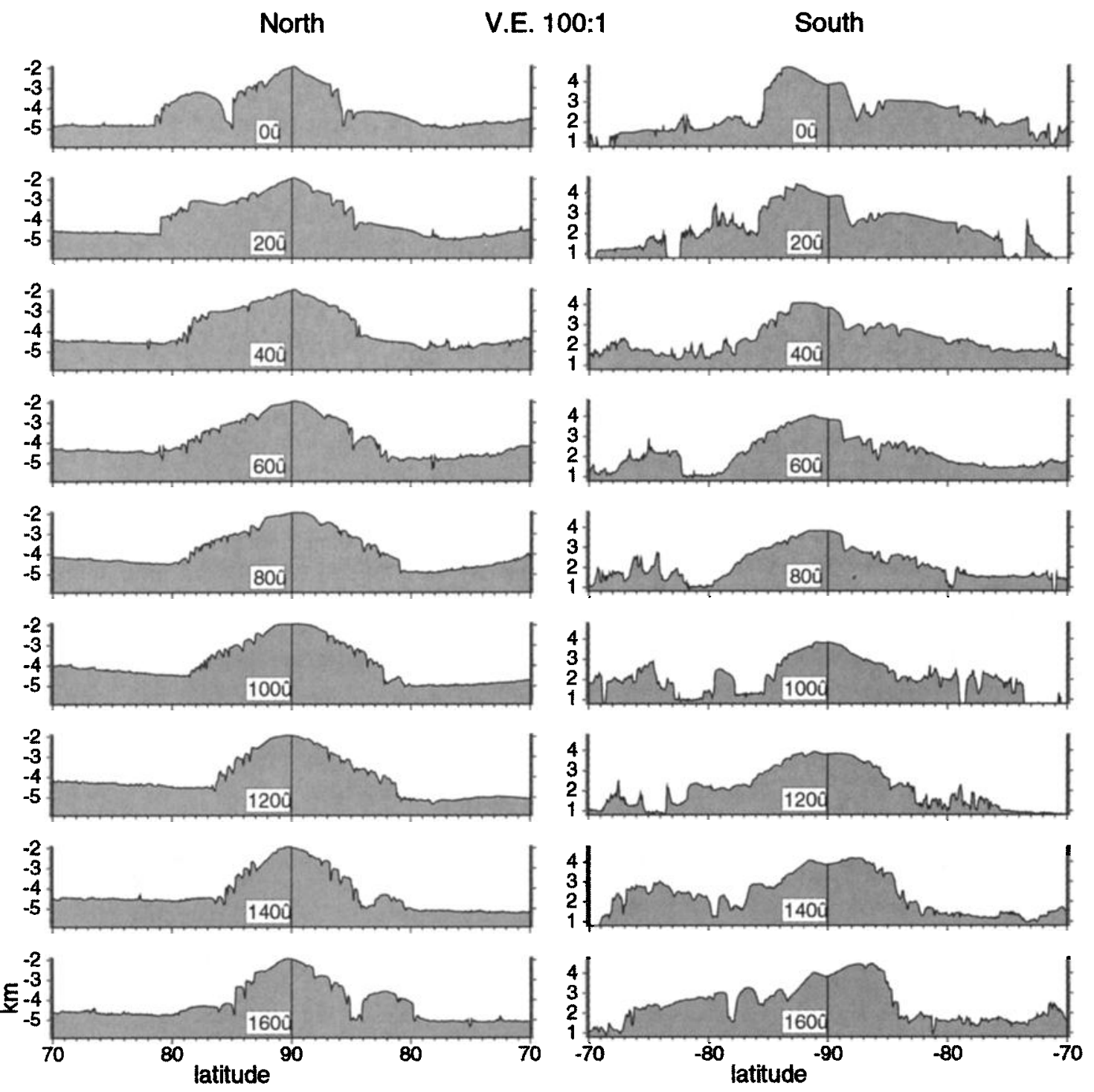

Figure 7. Profiles from the MOLA global grid across the (left) northern and (right) southern polar caps at $20^{\circ}$ longitude intervals. Apparent are the general planform of the layered terrains as well as the spiral chasms, surrounding terrain, outliers, and impact craters. The vertical exaggeration is 100:1.

from the highlands [Hynek and Phillips, 2001]. The high elevation $(3300 \mathrm{~m})$ and shallow depth $(\sim 500 \mathrm{~m})$ of the Solis Planum watershe dictate that given sufficient fill it may have breached and combined with Argyre [Williams, 2000].

\subsection{Polar Regions}

8.8.1. North polar cap. The north polar cap (Plate 2) stands $\sim 3 \mathrm{~km}$ above the surrounding terrain but lies within an $\sim 5-\mathrm{km}$-deep hemispheric-scale depression that is contiguous with the northern lowland regions [Zuber et al., 1998c]. The regional setting of the northern cap clarifies the nature of solar insolation [Ward, 1974; Arrell, 2000] and provides a quantitative basis for model of the global cycling of water [Clifford, 1993] throughout Martian history. Observations from Viking showed a water-ice composition for the residual north polar cap [Paige et al., 1994]. Both ablation and viscoplastic flow have been shown to be consistent with broad-scale aspects of the overall shape [Zuber et al., 1998a; Ivanov and Muhleman, 2000; Zwally and Saba, 1999].

The northern cap displays complex structure, including deep spiral chasms that penetrate in some cases to the level of surrounding terrains (cf. Figure 7). MOLA reflectivity measurements verify that these chasms are a sink for windblown dust [Zuber et al., 1998c]. Small-scale layering visible at the margins of the cap from high-resolution imaging [Thomas et al., 2000] is not resolved in MOLA altimetry. Large areas of the ice cap are extremely smooth, with regional slopes over many tens of kilometers of order $0.2^{\circ}$. Topography on spatial scales of kilometers has been observed in some areas to be smooth at the meter scale at $100-\mathrm{m} \mathrm{spa-}$ tial resolution (Plate 5). Deposits outward of the main cap show regional slopes that are comparable to those observed 


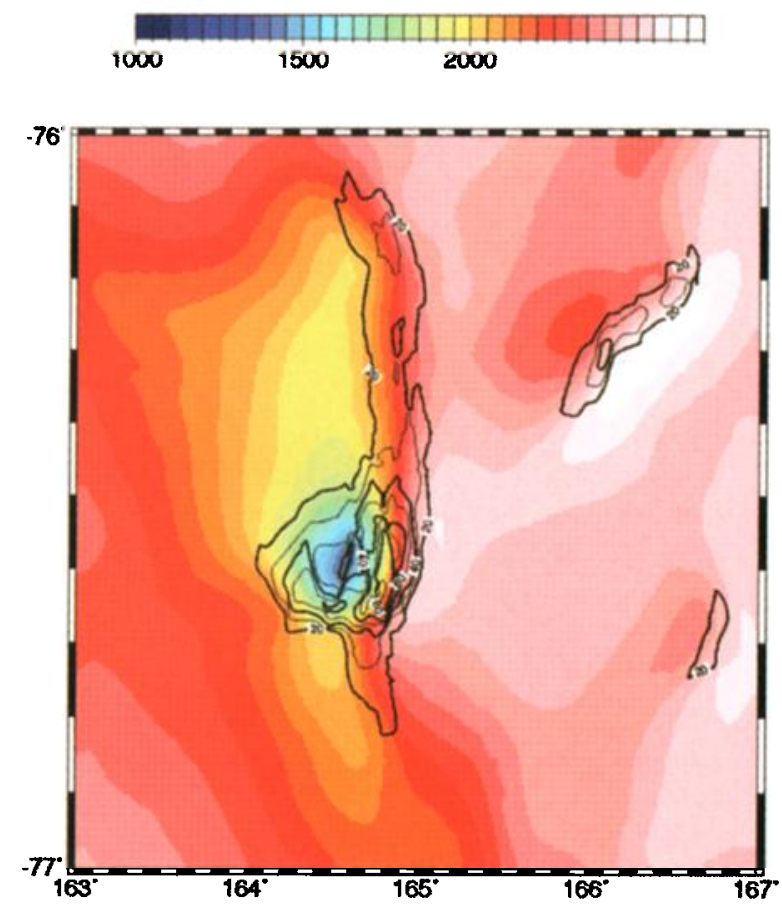

Plate 10. Topography (color shaded contours) and 100-m-scale roughness (line contours) of the Mars Polar landing region. The most likely landing point is $\left(76.5^{\circ} \mathrm{S}, 165^{\circ} \mathrm{E}\right)$ [Casani et al., 2000].

(a)

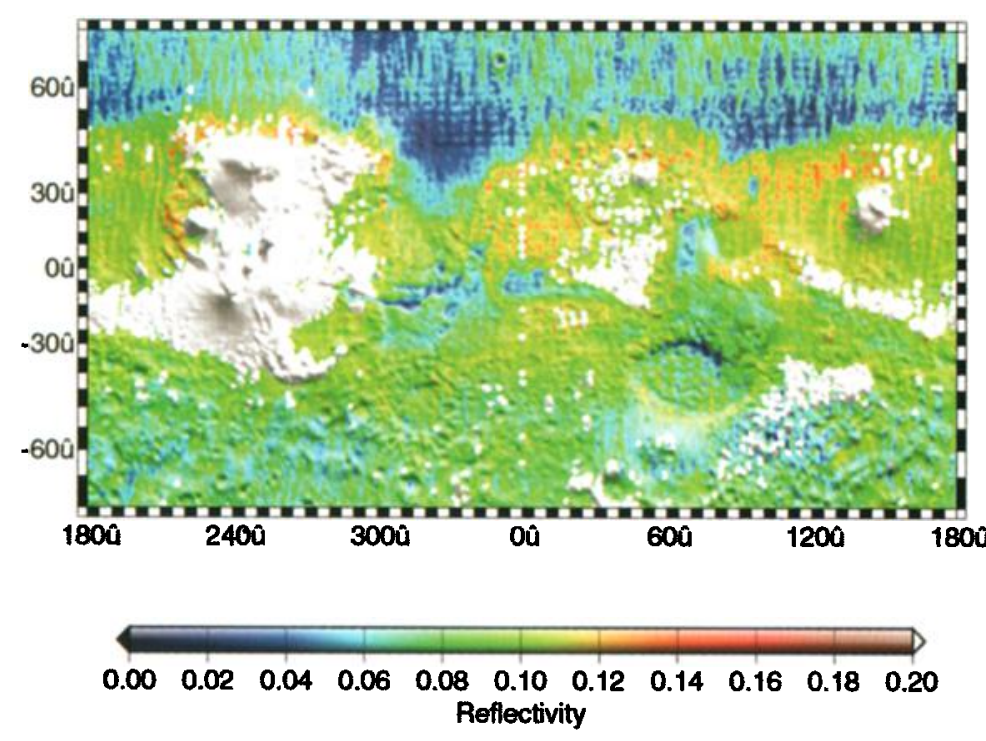

(b)

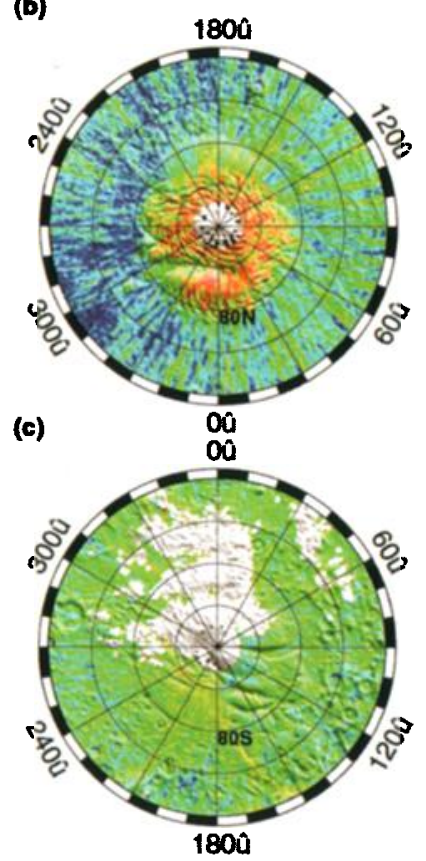

Plate 11. Composite 1.064- $\mu \mathrm{m}$ reflectivity of Mars at the scale of $100-\mathrm{m}$ from MOLA's ratio of received to transmitted laser energy measured during the mapping orbit [Ivanov, 2000]. White represents saturated pulse returns, and black corresponds to no data. Each point on the map is an average reflectivity observed over the period $L_{s}=100^{\circ}$ to $360^{\circ}$. Attenuation of the laser power due to extinction from atmospheric aerosols has not been taken into account. The map resolution is $0.5^{\circ} \times 0.5^{\circ}$. The map projection and other attributes are as for Plate 2. 
Table 10. Polar Layered Terrains

\begin{tabular}{lll}
\hline \multicolumn{1}{c}{ Parameter } & North & South \\
\hline Maximum elevation (m) & $-1905.2^{a}$ & $4802.5^{b}$ \\
Maximum relief, m & $2744.8^{c}$ & $3052.5^{d}$ \\
Mean elevation, m & 1015 & 783.3 \\
Area, $\times 10^{6} \mathrm{~km}^{2}$ & 1.12 & 1.16 \\
Volume, no flexure, & $1.14^{c}$ & $1.20^{d}$ \\
$\times 10^{6} \mathrm{~km}^{3}$ & & \\
Volume, with flexure $^{e}$ & $1.505^{f}$ & $1.66^{g}$ \\
$\times 10^{6} \mathrm{~km}^{3}$ & & \\
$\rho_{\text {cap }}=1000 \mathrm{~kg} \mathrm{~m}^{-3}$ & & $2.70^{g}$ \\
Volume, with flexure & & \\
$\times 10^{6} \mathrm{~km}^{3}$ & & \\
$\rho_{\text {cap }}=2000 \mathrm{~kg} \mathrm{~m}^{-3}$ & $2.34^{f}$ & \\
\hline
\end{tabular}

${ }^{a}\left(89.7353^{\circ} \mathrm{N}, 220.366^{\circ} \mathrm{E}\right)$.

b $\left(87.1362^{\circ} \mathrm{S}, 348.116^{\circ} \mathrm{E}\right)$.

${ }^{c}$ Above $-4650 \mathrm{~m}$.

${ }^{d}$ Above $1750 \mathrm{~m}$.

eThe total volume is assumed to be the topography above the basal surface plus the material filling the flexural depression calculated as in McGovern and Solomon [1997].

${ }^{f}$ Assumes $T_{e}=50 \mathrm{~km}$ after Zuber et al. [2000a].

${ }^{g}$ Assumes $T_{e}=30 \mathrm{~km}$ after Zuber et al. [2000a].

in association with the central cap deposits, but the outer terrains exhibit more small-amplitude variation than the central cap deposits. Such topographic variance may be indicative of stagnant ice in the outlying deposits. Gravity anomalies do not correlate well with the northern polar deposits [Smith et al., 1999a], suggesting either a nearly compensated load or complex subsurface structure [Johnson et al., 2000].

Impact craters in high-latitude terrains that surround the north polar cap display unusual geometric and reflective properties that collectively constitute evidence for ice fill [Garvin et al., 2000b], attesting to the significant volatile content of the substrate at high latitudes.

Spiral chasms are observed to penetrate into the massive Olympia Planitia dune field, which supports the suggestion that this region was once a part of the polar cap and subsequently lost volatiles. Topography and statistical analysis of correlation length [Aharonson et al., this issue] indicates that the Olympia Planitia dune field is unique on Mars in terms of its regularity in wavelength structure. The volume of the dune deposit is $10,000 \pm 3000 \mathrm{~km}^{3}$, with the accuracy limited by the uncertainty of the position of the basal surface [Zuber et al., 1998c].

8.8.2. South polar cap. The southern ice cap (Plate 2) lies at an elevation $\sim 6-\mathrm{km}$ higher than the northern cap due to the 3-km offset between Mars' COF and COM [Smith and Zuber, 1996; Smith et al., 1999b]. The southern cap is visually much smaller than in the north, although south polar layered deposits extend much farther from the ice cap and exhibit a more asymmetric distribution than their northern counterparts [Zuber et al., 1998c]. The residual ice, which persists throughout the seasonal cycle, is offset from the present rotational pole toward $35^{\circ}-40^{\circ} \mathrm{E}$ such that the pole does not fall within the residual ice deposits. The topography is highest in the south polar region within the residual ice deposits $\left(87^{\circ} \mathrm{S}, \sim 10^{\circ} \mathrm{E}\right)$, where a broad dome is present at one end of the cap (cf. Figure 7). The relief of the southern polar cap is comparable to that of the northern cap (Table 10).

The topography indicates that the area of probable ice-rich material greatly exceeds the region of residual ice that is apparent from images. This conclusion is based first on the existence of distinctive plateau regions that correlate with layered terrain units, as would be expected if the layers were deposited on cratered terrain [Vasavada and Herkenhoff, 1999]. Unlike the situation in the north, a well-defined gravity anomaly correlates with the southern layered deposits, indicating that the southern layered terrains are uncompensated [Smith et al., 1999b].

Impact craters within the layered terrains share unusual geometric properties with counterparts in the north polar region [Garvin et al., 2000b] that are observed to have formed in an ice-rich substrate. This similarity suggests that significant portions of the south polar ice cap may be buried beneath mantling dust deposits.

The detection by Viking of $\mathrm{CO}_{2}$ within south polar residual deposits during summer seasons [Paige and Keegan, 1994] suggested a dominant $\mathrm{CO}_{2}$ composition. However, topographic cross sections across the northern and southern caps (Figure 7) show a correspondence in shape that combined with recent results on the rheology of solid $\mathrm{CO}_{2}$ [Durham et al., 1999], suggests that the southern cap may have a significant water ice component [Nye et al., 2000].

8.8.3. Present volumes and past history. The polar caps represent one of the two major reservoirs of present-day volatiles on Niars, with the other being the subsurface regolith [Carr, 1996]. The layered terrains are the only reservoir whose volume can be realistically estimated on the basis of current observations. Best estimates for volumes, taking into account the possible effect of lithospheric flexure due to loading of the polar deposits [Smith et al., 1999b; Johnson et al., 2000], are given in Table 10. To determine upper limits of the volume, the models use elastic plate thicknesses, $T_{e}$, determined by Zuber et al. [2000a], which reflect the mechanical structure of the lithosphere at an earlier epoch. At such time the elastic lithosphere would have been thinner than at present and greater flexural deflection would have occurred in response to loading. Lower limits of volume were determined from the limit of an infinitely thick lithosphere, with no flexural deflection and where the volume consists of material above the basal surface. For all flexural models, $\Delta \rho=\rho_{\text {mantle }}-\rho_{\text {cap }}$, where $\rho_{\text {cap }}$ ranges from $1000 \mathrm{~kg}$ $\mathrm{m}^{-3}$ to $2000 \mathrm{~kg} \mathrm{~m}^{-3}$, with the former value corresponding to pure water ice and the latter to an ice/dust mixture. Uncertainties in the volume include uncertainties in the densities of the polar layered deposits and in the lithosphere thickness, as well as the extent of ice-rich material, particularly in the south. Densities of the polar deposits can be calculated from the gravitational load, but such estimates are model dependent because they require knowledge of the position of the basal surface and the compensation state of the load. In ad- 
dition, estimates of the polar deposit load from gravity alone do not take into account the possible effect of lithospheric loads beneath the caps, which appear to be present at least in the north polar region [Smith et al., 1999b; Johnson et al., 2000]. The combined northern and southern layered terrain volumes can be expressed in terms of a global equivalent layer (GEL) of water. This estimate of the present-day surface water inventory is obtained from the "no-flexure" lower limit and from the flexural estimates assuming purely waterice $\left(\rho_{\text {cap }}=1000 \mathrm{~kg} \mathrm{~m}^{-3}\right)$ caps. The results yields a GEL of 16 to $22 \mathrm{~m}$, which is at the low end of estimates for the amount of water believed to have been present early in Martian history [Carr, 1996].

There is evidence that both polar caps were once larger than at present. "Outliers" of high-albedo material detached from the northern cap are now shown to exhibit up to a kilometer of relief and represent massive volatile-rich deposits [Zuber et al., 1998c]. These structures are distributed quasisymmetrically around the present cap and may delineate the bounds of a larger cap earlier in Martian history [Fishbaugh and Head, 2000].

Regional-scale topography in the distal region of the southern layered deposit reveals evidence for a volatile-rich layer of Hesperian age. The morphology suggests the possibility of sub-glacial meltback and possible drainage of liquid water into surrounding lows, including the Argyre basin, in middle Martian history [Head, 2000].

The age of formation of the polar caps is not well constrained given the small number of preserved impact craters, though crater counts [Cutts et al., 1976; Plaut et al., 1988] and morphology [Thomas et al., 2000] suggest that the upper surfaces of the south are older than that of the north. Analysis of MOLA topography over the north polar cap has resulted in an increase in the number of craters and an increase in the upper limit of its relative surface age [Sakimoto and Garvin, 1999], but such analysis is limited in interpretability as it does not yet take into account the obliteration and relaxation of these structures. It is not yet understood whether the difference in apparent compensation states between the southern and northern layered terrains [Smith et al., 1999a] is due to differences in lithosphere structure, age of loading, or the composition of the load (e.g., a higher dust content in the southern cap).

\subsection{Mars ' 98 Landing Site}

In anticipation of the Mars Polar landing in December 1999 , the MOLA team provided to the Mars ' 98 Project information on surface topography, landing site pressure, and local slopes of the landing region $\left(70^{\circ} \mathrm{S}\right.$ to $80^{\circ} \mathrm{S} ; 130^{\circ} \mathrm{E}$ to $210^{\circ} \mathrm{E}$ ) to be used in landing site assessment. Subsequent to a planned loss of signal prior to the atmospheric entry phase of the terminal descent to the surface, communication with the lander was never re-established. During attempts to locate the lander, updated MOLA information was provided to the Mars '98 Project, and additional information on local slopes and surface roughness was later provided to the
Mars Polar Lander Failure Board [Casani et al., 2000] for their evaluation of environmental factors that may have contributed to the failure.

Plate 10 shows the topography in the vicinity of the most likely landing area $\left(76.5^{\circ} \mathrm{S} ; 165^{\circ} \mathrm{E}\right)$ based on a post-landing reconstruction developed from the best available navigation information and atmosphere models. The elevation of the likely landing site is $2424 \mathrm{~m}$, and at the time of the landing $\left(L_{s}=256^{\circ}\right)$ the atmospheric pressure is estimated to have been $\sim 5$ mbar, well within acceptable limits [Casani et al., 2000]. Plate 10 shows that most of the area is smooth relative to most of Mars. Within the landing region, however, there is a large depression. This structure is characterized by $300-\mathrm{m}$ baseline slopes that are mostly less than $5^{\circ}$, within acceptable landing limits. However, $\sim 1 \%$ of the area has slopes greater than $10^{\circ}$, in excess of the design specifications for landing.

The contours in Plate 10 show the 100 -m-scale RMS roughness derived from MOLA's returned optical pulse widths. These roughness values have been corrected for the effects of local slopes [Garvin et al., 1999]. Over most of the landing zone, the pulse width correlates well with the largerscale slopes, behavior contrary to the norm for most of Mars (cf. Plate 5). This result indicates that the pulse spread is most likely due to the regional slope and that the surface at 100-m-scale is smoother than for most of Mars. This interpretation is consistent with recently reanalyzed thermal inertia results [Vasavada and Herkenhoff, 1999] that suggest that the landing area is dominated by a dust-covered surface with minimal to no rock cover [Casani et al., 2000].

\subsection{The 1.064- $\mu \mathrm{m}$ Reflectivity}

Plate 11 shows the composite reflectivity of the Martian surface and atmosphere at $1.064 \mu \mathrm{m}$ from MOLA. The map shown is a time-averaged value at each grid point. When the TES investigation produces corrected opacity data, it will be possible to produce a global map of $1.064 \mu \mathrm{m}$ reflectivity for the surface alone. In practice, the reflectivity of the surface changes with the seasons due to the advance and retreat of the polar frosts and because of dust re-distribution.

In the current composite map the Tharsis region is the brightest on the planet and lacks significant atmospheric aerosols, so most of the laser returns in that region are saturated. The north polar ice cap is unsaturated primarily because of extinction in extensive cloud formations that existed over the cap during northern fall and winter. However, the north polar signature became largely saturated during periods when the atmosphere was clear. The darkest places on the planet are Acidalia Planitia, Utopia Planitia, and the floor of Valles Marineris. Acidalia and Utopia are well-known dark albedo features. Returns from the dark floor of Valles Marineris are also attenuated by the dust within the canyons [Ivanov and Muhleman, 1998]. Overall, there is a good correlation of the reflectivity with dark and bright albedo features on the surface of Mars. 

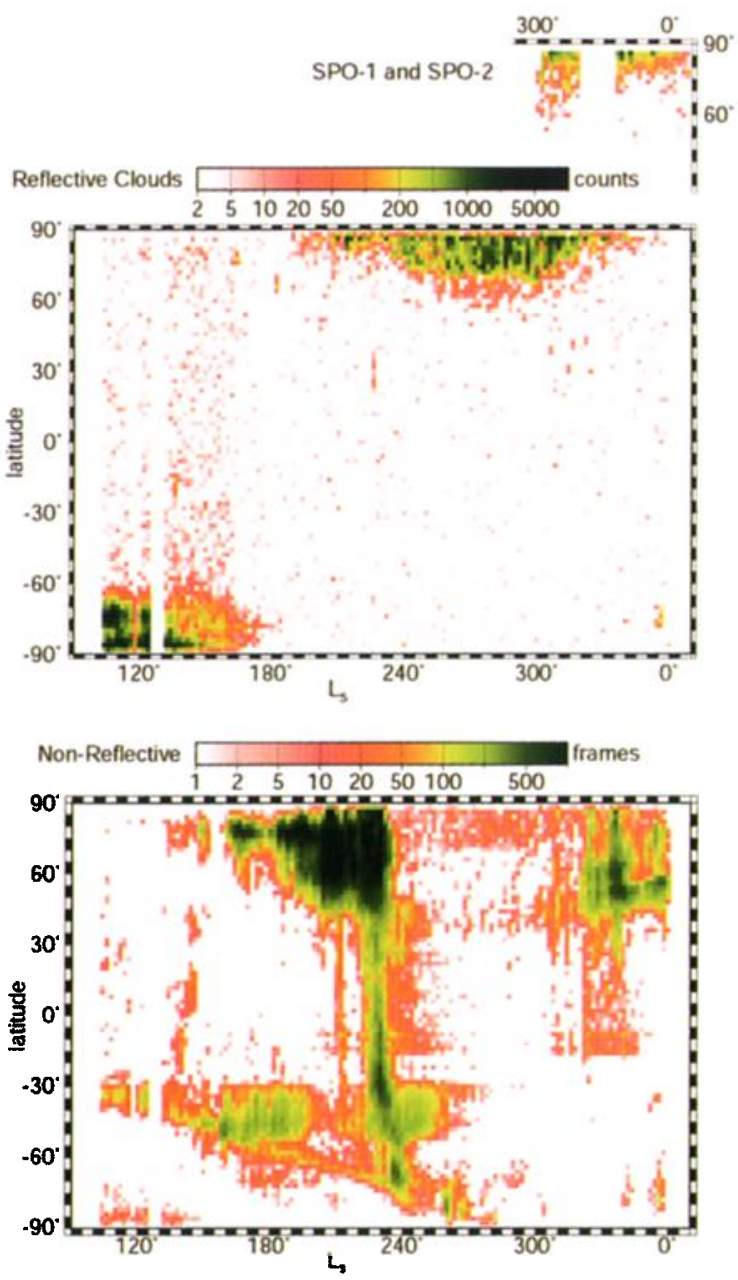

Plate 12. Zonal plots of number of frames in which (a) reflective and $(b)$ nonreflective clouds have been observed within a $2^{\circ}$ window of latitude and a $2^{\circ}$ window of season $\left(L_{s}\right)$ during the MGS mapping orbit. Reflective clouds detected during the SPO mission phase are shown as an outset above the mapping figure. Because of the sensitivity of returned signal strength to spacecraft orbit geometry, nonreflective clouds are not easily identifiable during SPO. From Neumann et al. [submitted manuscript, 2001].

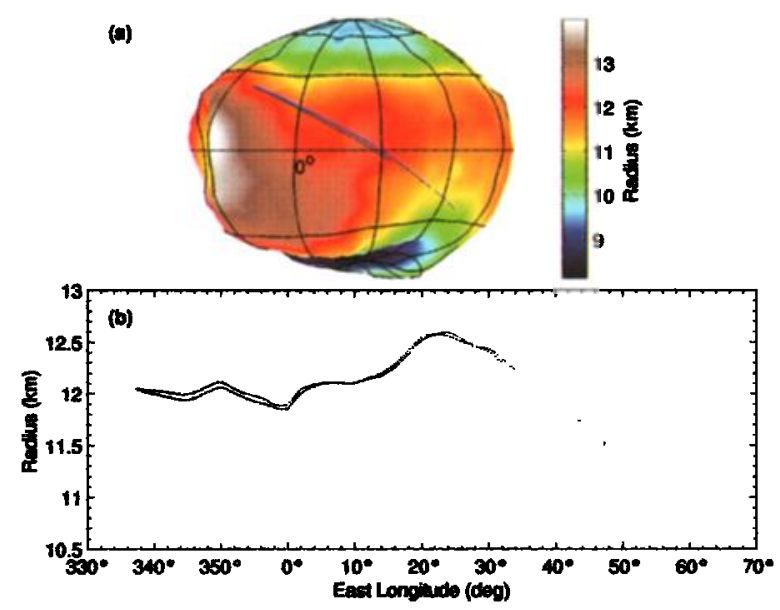

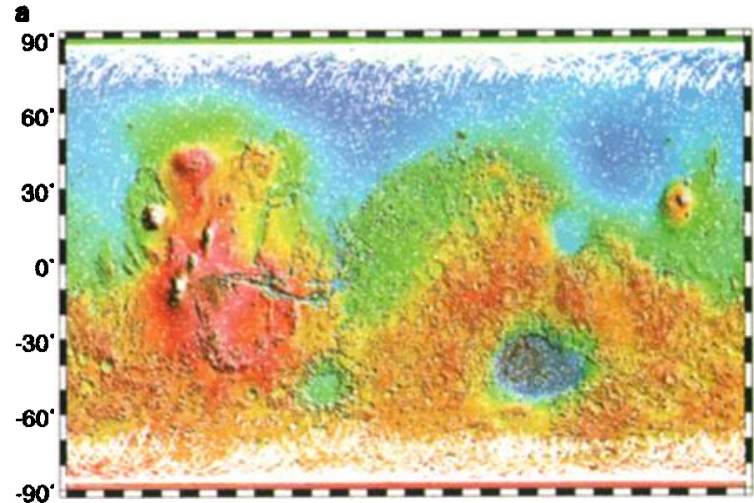

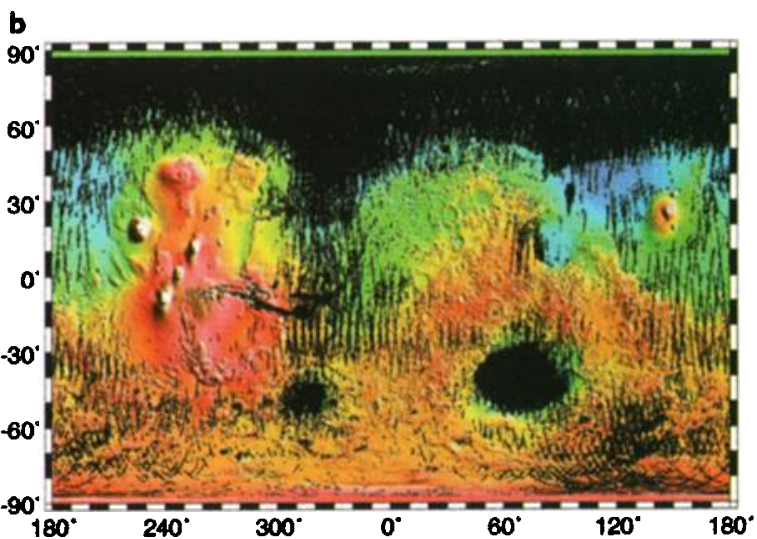

Plate 13. Spatial distributions of number of frames in which (a) reflective (white dots) and (b) nonreflective (black dots) clouds were observed by MOLA. Both plots represent temporal averages of mapping orbit observations. From $\mathrm{Neu}$ mann et al. [submitted manuscript, 2001].

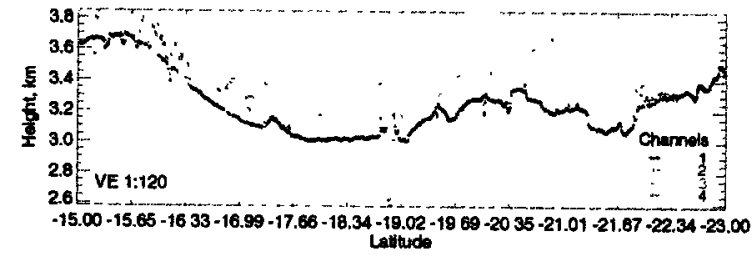

Plate 14. Part of MOLA profile P10769b showing returns south of the Valles Marineris during a regional dust storm in Noachis Terra. The many channel 4 returns (in blue) from the atmosphere indicate that dust is distributed diffusely with altitude.

Plate 15. (a) Location of MOLA profile of Phobos plotted on the shape model of Duxbury [1989]. (b) Profile plotted as radius from Phobos' center of mass. 


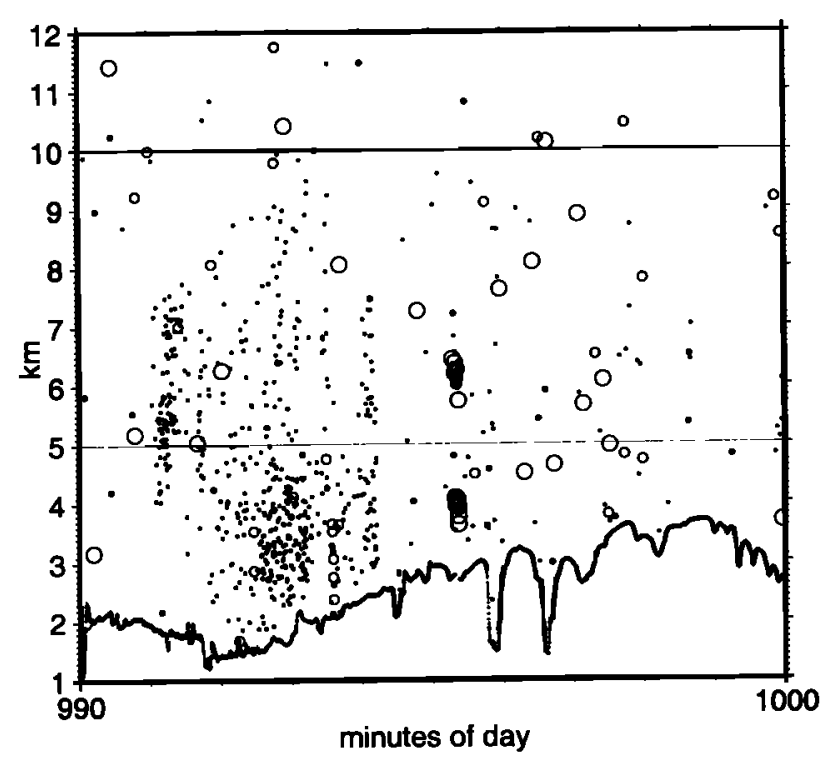

Figure 8. $\mathrm{CO}_{2}$ snow condensing out of the Martian atmosphere. This profile is over the south polar region during southern hemisphere winter during the first day MOLA turned on in the mapping orbit. The filled circles correspond to channel 1 and 2 returns and the small and large open circles correspond to channel 3 and 4 returns.

\subsection{Clouds and Snow}

Volatile clouds detected by MOLA are generally of two types: bright or reflective structures that are sufficiently backscattering that they result in detections, and dark or absorptive features so opaque that no returned signal is obtained [Neumann et al., submitted manuscript, 2001]. Clouds detected by MOLA are typically denser than telescopically observed hazes, although they often coincide [Ivanov and Muhleman, 1998]. Zonal plots of the temporal distributions of reflective and nonreflective or absorptive clouds are shown in Plate 12.

Observations of reflective clouds by MOLA began just after orbit insertion with limited coverage of the north polar hood during late northern winter, $L_{s}=305^{\circ}$. As shown in Plate $12 a$, reflective clouds in the north polar region begin to develop in northern autumn $\left(L_{s} \sim 200^{\circ}\right)$, peaking in density and southward extent by $L_{s}=280^{\circ}$. They then recede poleward, dissipating prior to the beginning of spring. At the commencement of global mapping during southern winter $\left(L_{s}=104^{\circ}\right)$, reflective clouds appeared high over the southern pole (e.g., Figure 8), with low, dense clouds flanking the pole at $70^{\circ} \mathrm{S}$. As for the north, these clouds disappeared by the beginning of spring.

Plate 12 suggests that the north polar reflective clouds may have persisted longer in the 1998 winter season than they did in 2000 . Observations were limited to twice a day during elliptical orbit mapping, yet overall more clouds were seen around $L_{s}=350^{\circ}$ in 1998 than during the mapping orbit in 2000 , when observations were about six times more frequent. However, the data have not been scrutinized for possible temporal effects of pulse energy and other factors, so the data warrant further review.
Plate $12 b$ shows a much different distribution of absorptive clouds. In the northern polar regions absorptive clouds developed during northern autumn and trace the north polar frost line. Their occurrence decreases during northern winter, during which time the reflective clouds dominate. The number of cloud frames increases again during late winter. In the southern hemisphere, a separate dark cloud front formed north of the polar frost line. As southern winter ended, the cloud line migrated southward toward the pole, clearing by southern summer solstice. As for the north, dark clouds are not observed in areas where reflective clouds are seen over the southern polar deposits.

During southern hemisphere summer at about $L_{s}=220^{\circ}$ through $250^{\circ}$, nonreflective clouds became globally distributed. During this period there were major dust storms that were also observed by the TES [Smith et al., 2000; Conrath et al., 2000] and MOC [Malin et al., 1998] instruments.

Plate 13 shows that the spatial distribution of clouds is geographically and topographically controlled [Neumann et al., submitted manuscript, 2001]. There are many more nonreflective clouds than reflective ones, with the former located mostly in topographic lows, along the seasonal frost lines, and in association with dust storms, and the latter found mostly in the polar regions. Both bright and dark northern winter clouds are concentrated in the Borealis basin, and the dark clouds penetrate southward into Chryse. Cloud fronts, with unusually sharp returns (mainly channel 1 ), are distributed broadly over the southern cap in winter. Many craters show clouds closely associated with their rims. Atmospheric reflections have also been observed to obscure periodically some high-latitude craters that have bright floors indicating the presence of frost or ice [cf. Garvin et al., 2000b]. Absorptive clouds are seen in the Hellas Basin $\left(50^{\circ}\right.$ to $\left.80^{\circ} \mathrm{E}\right)$ almost year-round. Equatorial clouds have also been observed within the Valles Marineris and Noctis Labyrinthus canyons.

Cloud echoes have been observed at elevations as high as $15 \mathrm{~km}$ above the surface [Pettengill et al., 2000; Neumann et al., submitted manuscript, 2001]. Because of the typical width of the MOLA range gate $(20 \mathrm{~km})$, the maximum elevations observed by the instrument likely do not correspond to actual maximum heights. Clouds are sometimes observed to have sloping tops that are interpreted as propagating phase fronts of gravity or buoyancy waves [Zuber et al., 1998c; Pettengill and Ford, 2000]. These waves are likely generated by the heat of fusion associated with the condensation of $\mathrm{CO}_{2}$ or by polar geostrophic winds. Also observed are lee waves generated by the impingement of polar vortex winds [Zurek et al., 1992] on topographic discontinuities such as the margins of polar layered terrains.

Early theoretical considerations and general circulation model calculations [Geirasch and Goody, 1968; Leovy and Mintz, 1969] first addressed possibility of $\mathrm{CO}_{2}$ condensation in the Martian atmosphere. Subsequent IR spectral measurements of the atmosphere [Forget et al., 1995; Bell et al., 1996; Klassen et al., 1999] and polar caps [Paige et al., 1994; Paige and Keegan, 1994] supported this possibility. The reflective clouds detected by MOLA condense during 
the winter night and sublimate in sunlight. The observation of visible-IR phase fronts dictates that the condensing volatile is almost certainly solid $\mathrm{CO}_{2}$. Thus these reflective clouds represent the first height detections of dry ice snow in the Martian atmosphere. The observations indicate that the atmospheric lapse rate follows a "wet" $\mathrm{CO}_{2}$ adiabat of 0.85 ${ }^{\circ} \mathrm{km}^{-1}$ [Zuber et al., 1998c; Pettengill and Ford, 2000].

As shown in Plate 14, MOLA has also observed regional dust clouds. These optically thick clouds form at low altitudes (within $1 \mathrm{~km}$ of ground) in localized areas at equatorial and low southern latitudes. Dust clouds, which have been independently imaged/detected by the MGS MOC [Malin et al., 1998] and TES [Christensen et al., this issue] instruments, have been observed by MOLA to obscure the floors of Valles Marineris and the Hellas basin. Given the forward-scattering properties of dust, clouds such as shown in Plate 14 observed during a dust storm in Noachis Terra and during dusty atmospheric periods in Figure $12 \mathrm{~b}$ may correspond to water ice clouds condensed on dust grains.

Increases in atmospheric opacity have also been observed from MOLA's reflectivity measurement during the SPO mission phase [Ivanov and Muhleman, 1998]. Higher than average atmospheric opacity was observed within the Valles Marineris and at high northern latitudes. Given the preliminary nature of the analysis it was not possible to distinguish whether the increase was due to dust or $\mathrm{CO}_{2}$, though this should be possible in the future by joint analysis of MOLA observations with TES [Christensen et al., this issue] and IRTM [Kieffer et al., 1977] data.

\subsection{Phobos}

On September 12, 1998, MGS encountered the Martian moon Phobos at a distance of $265 \mathrm{~km}$, which was well within the MOLA ranging distance. A scheme was developed to maximize the ranging time to the moon by overtaking the trailing rim with the spacecraft slew while at a distance $(\sim 530 \mathrm{~km})$ such that the apparent motion of Phobos was less than $0.3^{\circ} \mathrm{s}^{-1}$. As the track crossed Phobos and the distance decreased, the increase in apparent motion slowed and eventually reversed the track before the entire disk was traversed. The track then recrossed the trailing rim at a range of $\sim 350$ $\mathrm{km}$ (Plate 15). This operation resulted in the first successful active laser ranging to a small body, with nearly $70 \mathrm{~s}$ of time on the target and 627 valid ranging measurements along two nearly coincident but slightly offset tracks [Banerdt and Neumann, 1999]. These tracks cross Phobos' Mars-facing hemisphere and span a distance of $\sim 120^{\circ}$ of arc. At these distances the laser footprint varied in size from 130 to $200 \mathrm{~m}$ near the reversal point to a few hundred meters near the limb. Successful returns were obtained for emission angles up to $80^{\circ}$. Plate 15 shows that the MOLA profile sampled a variety of craters and provided information on laser performance when ranging near the limb of a body of finite size. The MOLA ranging observations also indicated a 4-km offset of Phobos relative to the expected position [Banerdt and Neumann, 1999] and have been used to improve the ephemeris of the body.

\section{Conclusions}

MOLA has successfully mapped the global topography of Mars with a horizontal resolution a couple of kilometers and a vertical accuracy of $\sim 1 \mathrm{~m}$. In addition, the instrument has provided global information on surface roughness, 1.064- $\mu \mathrm{m}$ reflectivity, and the spatial and temporal distribution of clouds and snow. In the rest of the MGS mapping mission the goals of the MOLA investigation are to fill in and further refine the global map in terms of spatial resolution and vertical accuracy. In addition, there will be increased effort to produce high-resolution regional topographic grids (e.g., Plate 8), and to improve measurements of optical pulse width and reflectivity. During the extended mission, MOLA's primary goals will be to attempt to resolve time variations in the elevation due to the seasonal exchange of $\mathrm{CO}_{2}$ between the atmosphere and polar caps, as well as to monitor changes in the atmosphere due to $\mathrm{CO}_{2}$ and dust transport. Finally, the generation of high-resolution local grids of topography, slope, and surface roughness to assist in the identification and assessment of potential future landing sites will be a high priority.

Acknowledgments. The MOLA investigation is supported by the NASA Mars Exploration Program. We recognize significant contributions from R. B. Follas, J. J. Frawley, S. K. Fricke, P. L. Jester, S. Pratt, J. Quigley, J. H. Roark, J. C. Schott, B. Webb, and $M$. Wong. In addition, we acknowledge the MOLA instrument engineers, the laser engineers at McDonnell-Douglas, and the Mars Global Surveyor spacecraft and mission operation teams at the Jet Propulsion Laboratory and Lockheed-Martin Astronautics for their contributions to the success of MOLA. Data and further information about the MOLA investigation can be found at http://ltpwww.gsfc.nasa.gov/tharsis/mola.html.

\section{References}

Abshire, J. B., X. Sun, and R. S. Afzal, Mars Orbiter Laser Altimeter: Receiver model and performance analysis, Appl. Opt., 39, 2440-2460, 2000.

Acuna, M. H., et al., Global distribution of crustal magnetization discovered by the Mars Global Surveyor MAG/ER experiment, Science, 284, 790-793, 1999.

Afzal, R. S., Mars Observer Laser Altimeter: Laser transmitter, Appl. Opt., 33, 3184-3188, 1994.

Aharonson, O., M. T. Zuber, G. A. Neumann, D. E. Smith, and J. W. Head, Mars: Northern hemisphere slopes and slope distributions, Geophys. Res. Lett., 25, 4413-4416, 1998.

Aharonson, O., M. T. Zuber, and D. H. Rothman, Statistics of Mars' topography from MOLA: Slopes, correlations and physical models, J. Geophys. Res., this issue.

Albee, A. A., F. D. Palluconi, and R. E. Arvidson, Mars Global Surveyor Mission: Overview and status, Science, 279, 16711672, 1998.

Albee, A. A., R. E. Arvidson, F. D. Palluconi, and T. Thorpe, Overview of the Mars Global Surveyor mapping mission, J. Geophys. Res., this issue.

Arrell, J. R., Implications of Martian polar insolation levels on the climatic cycling of volatiles, MSc. thesis, Mass. Inst. of Tech., 2000.

Baker, V. R., Water and the Martian landscape, Nature, 412, 228236, 2001.

Baker, V. R., R. G. Strom, V. C. Gulick, J. S. Kargel, G. Komatsu, and V.S. Kale, Ancient oceans, ice sheets, and the hydrological cycle on Mars, Nature, 352, 589-594, 1991. 
Bandfield, J. L., V. Hamilton, and P. R. Christensen, A global view of Martian surface composition from MGS-TES, Science, 287, 1626-1630, 2000.

Banerdt, W. B., and M. P. Golombek, Tectonics of the Tharsis regions of Mars: Insights from MGS topography and gravity, $\mathrm{Lu}$ nar Planet. Sci. Conf., XXXI, abstract 2038, 2000.

Banerdt, W. B., and G. A. Neumann, The topography (and ephemeris) of Phobos from MOLA ranging, Lunar Planet. Sci. Conf., XXX, abstract 2021, 1999.

Banerdt, W. B., R. J. Phillips, N. H. Sleep, and R. S. Saunders, Thick shell tectonics on one-plate planets: Applications to Mars, J. Geophys. Res., 87, 9723-9733, 1982.

Banerdt, W. B., M. P. Golombek, and K. L. Tanaka, Stress and tectonics on Mars, in Mars, edited by H. H. Kieffer, B. M. Jakosky, C. W. Snyder, and M. S. Matthews, pp. 249-297, Univ. of Ariz. Press, Tucson, 1992.

Barlow, N. G., and T. L. Bradley, Martian impact craters: Correlations of ejecta and interior morphologies with diameter, latitude, and terrain, Icarus, 87, 156-179, 1990.

Bell, J. F., W. M. Calvin, M. E. Ockert-Bell, D. Crisp, J. B. Pollock, and J. Spencer, Detection and monitoring of $\mathrm{H}_{2} \mathrm{O}$ and $\mathrm{CO}_{2}$ ice clouds on Mars, J. Geophys. Res., 101, 9227-9237, 1996.

Bell, J. F., M. J. Wolf, T. C. Daley, D. Crisp, P. B. James, S. W. Lee, J. T. Trauger, and R. W. Evans, Near-infrared imaging of Mars from HST: Surface reflectance, photometric properties and implications for MOLA data, Icarus, 138, 25-35, 1999.

Bibring, J., et al., ISM observations of Mars and Phobos: First results, Proc. Lunar Planet. Sci. Conf., 20th, 461-471, 1990.

Bills, B. G., and A. J. Ferrari, Mars topography harmonics and geophysical implications, J. Geophys. Res., 83, 3497-3508, 1978.

Bills, B. G., and A. J. Ferrari, Venus topography: A harmonic analysis, J. Geophys. Res., 90, 827-836, 1985.

Byer, R. L., Diode laser-pumped solid state lasers, Science, 239 , 742-747, 1988.

Carr, M. H., The Surface of Mars, Yale Univ. Press, New Haven, Conn., 1981.

Carr, M. H., Water on Mars, p. 229, Oxford University Press, New York, 1996.

Carr, M. H., and G. D. Clow, Martian channels and valleys: Their characteristics, distribution and age, Icarus, 48, 91-117, 1981.

Carr, M. H., L. S. Crumpler, J. A. Cutts, R. Greeley, J. E. Guest, and H. Masursky, Martian impact craters and emplacement of ejecta by surface flow, J. Geophys. Res., 82, 4055-4065, 1977.

Casani, J. R., et al., Report on the loss of the Mars Polar Lander and Deep Space 2 missions, Rep. JPL-D18709, Jet Propul. Lab., Pasadena, Calif., 2000.

Christensen, P. R., Regional dust deposits on Mars: Physical properties, age, and history, J. Geophys. Res., 91, 3,533-3,545, 1986.

Christensen, P. R., and H. J. Moore, The Martian surface layer, in Mars, edited by H. H. Kieffer, B. M. Jakosky, C. W. Snyder, and M. S. Matthews, pp. 686-729, Univ. of Ariz. Press, Tucson, 1992.

Christensen, P. R., et al., Mars Global Surveyor Thermal Emission Spectrometer experiment: Investigation description and surface science results, J. Geophys. Res., this issue.

Clifford, S. M., A model for the hydrologic and climatic behavior of water on Mars, J. Geophys. Res., 98, 10,973-11,016, 1993.

Cole, T. D., M. T. Boies, A. F. C. A. S. El-Dinary, M. T. Zuber, and D. E. Smith, The Near Earth Asteroid Rendezvous laser altimeter, Space Sci. Rev., 82, 217-253, 1997.

Comer, R. P., S. C. Solomon, and J. W. Head, The Olympus Mons paradox: Why hasn't the martian lithosphere failed under the load?, Lunar Planet. Sci. Conf., XI, 171-173, 1981.

Comer, R. P., S. C. Solomon, and J. W. Head, Mars: Thickness of the lithosphere from the tectonic response to volcanic loads, Rev. Geophys, 23, 61-72, 1985.

Connemey, J. E. P., et al., Magnetic lineations in the ancient crust of Mars, Science, 284, 794-798, 1999.

Conrath, B. R., Curran, R. Hanel, V. Kunde, W. M. J. Pearl, J. Pir- raglia, J. Welker, and T. Burke, Atmospheric and surface properties of Mars obtained by infrared spectroscopy on Mariner $9, J$. Geophys. Res., 78, 4267-4278, 1973.

Conrath, B. R., J. C. Pearl, M. D. Smith, W. C. Maguire, P. C. Christensen, S. Dason, and M. S. Kaerberer, Mars Global Surveyor Thermal Emission Spectrometer (TES): Atmospheric temperatures during aerobraking and science phasing, J. Geophys. Res., 105, 9509-9519, 2000.

Cutts, J. A., K. R. Blasius, G. A. Briggs, M. H. Carr, R. Greeley, and $H$. Masursky, North polar region of Mars: Imaging results from Viking 2, Science, 194, 1329-1337, 1976.

Davies, M. E., and F. Y. Katayama, The 1982 control network of Mars, J. Geophys. Res, 88, 7503-7504, 1983.

Davies, M. E., F. . Y. Katayama, and J. A. Roth, Control net of Mars, February 1978, RAND Rept. R-2309-NASA, 1978.

Davies, M. E., V. K. Abalakin, A. Brahic, M. Bursa, B. H. Chovitz, J. H. Lieske, P. K. Seidelmann, A. T. Sinclair, and Y. S. Tjuflin, Report of the IAU/IAG/COSPAR working group on cartographic coordinates and rotational elements of the planets and satellites: 1991, Cel. Mech. and Dynam. Astron, 53, 377-397, 1992a.

Davies, M. E., R. M. Batson, and S. S. C. Wu, Geodesy and cartography, in Mars, edited by H. H. Kieffer, B. M. Jakosky, C. W. Snyder, and M. S. Matthews, pp. 321-342, Univ. of Ariz. Press, Tucson, $1992 \mathrm{~b}$.

Downs, G. S., R. M. Goldstein, R. R. Green, and G. A. Morris, Mars radar observations, a preliminary report, Science, 174 , 1324-1327, 1971.

Downs, G. S., P. E. Reichley, and R. R. Green, Radar measurements of Martian topography and surface properties: The 1971 and 1973 oppositions, Icarus, 26, 273-312, 1975.

Downs, G. S., P. E. Reichley, and R. R. Green, Radar studies of the Martian surface at centimeter wavelengths: The 1975 opposition, Icarus, 33, 441-453, 1978.

Downs, G. S., P. J. Mouginis-Mark, S. H. Zisk, and T. W. Thompson, New radar-derived topography for the northern hemisphere of Mars, J. Geophys. Res., 87, 9747-9754, 1982.

Durham, W. B., S. H. Kirby, and L. S. Stern, Steady-state rheology of solid $\mathrm{CO}_{2}$ : Preliminary results, Geophys. Res. Lett., 26, 34933496, 1999.

Duxbury, T. C., The figure of Phobos, Icarus, 78, 169-180, 1989.

Duxbury, T. C., Preliminary cartographic analysis of the Pathfinder landing site using Viking Orbiter images, in Mars Pathfinder Landing Site Workshop II: Characteristics of the Ares Vallis region and field trips in the channeled scabland, Washington, edited by M. P. Golombek, K. S. Edgett, and J. W. Rice, vol. LPI Tech. Report 95-01, Part 2, pp. 35-36, Lunar and Planet. Inst., Houston, Tex., 1995.

Duxbury, T. C., An improved geodetic grid for Mars from the Mars Orbiter Laser Altimeter (MOLA), Jet Prop. Lab., Report of the Mars Geodesy and Cartography Working Group, 2000.

Eliason, E., A. McEwen, A. Allison, R. Batson, L. Soderblom, and M. Martin, Introduction to the Mars Mosaicked Digital Model (MDIM) CDROM volumes, U.S. Geol. Surv. Tech. Rep., 1992.

Esposito, P. B., W. B. Banerdt, G. F. Lindal, W. L. Sjogren, M. A. Slade, B. G. Bills, D. E. Smith, and G. Balmino, Gravity and topography, in Mars, edited by H. H. Kieffer, B. M. Jakosky, C. W. Snyder, and M. S. Matthews, pp. 209-248, Univ. of Ariz. Press, Tucson, 1992.

Fanale, F. P., S. E. Postawko, J. B. Pollack, M. H. Carr, and R. O. Pepin, Mars: Epochal climate change and volatile history, in Mars, edited by H. H. Kieffer, B. M. Jakosky, C. W. Snyder, and M. S. Matthews, pp. 1135-1179, Univ. of Ariz. Press, Tucson, 1992.

Fishbaugh, K. E., and J. W. Head, North polar region of Mars: Topography of circumpolar deposits from Mars Orbiter Laser Altimeter (MOLA) data and evidence for asymmetric retreat of the polar cap, J. Geophys. Res., 105, 22,455-22,486, 2000.

Folkner, W. M., C. F. Yoder, D. N. Yuan, and R. A. P. E. M. Standish, Interior structure and seasonal mass redistribution of Mars 
from radio tracking of Mars Pathfinder, Science, 178, 17491751, 1997.

Forget, F., G. B. Hansen, and J. B. Pollack, Low brightness temperatures of Martian polar caps: $\mathbf{C O}_{2}$ clouds or low surface emissivity?, J. Geophys. Res., 100, 21,219-21,234, 1995.

Frey, H. V., and R. A. Schultz, Large impact basins and the megaimpact origin for the crustal dichotomy on Mars, Geophys. Res. Lett., 15, 229-232, 1988.

Frey, H., S. E. Sakimoto, and J. H. Roark, The MOLA topographic signature of the crustal dichotomy boundary zone on Mars, Geophys. Res. Lett., 25, 4409-4412, 1998.

Frey, H., S. E. H. Sakimoto, and J. H. Roark, Discovery of a 450-km-diameter, multiring basin on Mars through analysis of MOLA topographic data, Geophys. Res. Lett., 26, 1657-1660, 1999.

Frey, H., L. Hutchinson, S. E. H. Sakimoto, and J. H. Roark, A large population of possible buried impact basins on Mars revealed by MOLA topographic data, Lunar Planet. Sci. Conf., $X X X I$, abstract 1736,2000 a.

Frey, H., J. H. Roark, and S. E. H. Sakimoto, Detailed topographic structure of the Isidis impact basin from MOLA data, Lunar Planet. Sci. Conf., XXXI, abstract 1748, 2000 b.

Gardner, C. S., Target signatures for laser altimeters: An analysis, Appl. Opt., 21, 448-453, 1982.

Gardner, C. S., Ranging performance of satellite laser altimeters, IEEE Trans. Geosci. Remote Sens., 30, 1061-1072, 1992.

Garvin, J. B., J. L. Bufton, J. B. Blair, D. Harding, S. B. Luthcke, J. J. Frawley, and D. D. Rowlands, Observations of the Earth's topography from the Shuttle Laser Altimeter (SLA): Laser pulse echo recovery measurements of terrestrial surfaces, Phys. Chem. Earth, 23, 1053-1068, 1998.

Garvin, J. B., J. J. Frawley, and J. B. Abshire, Vertical roughness of Mars from the Mars Orbiter Laser Altimeter, Geophys. Res. Lett., 26, 181-184, 1999.

Garvin, J. B., S. E. Sakimoto, J. J. Frawley, and C. Schnetzler, Geometric properties of Martian impact craters: An assessment from the Mars Orbiter Laser Altimeter (MOLA) digital elevation modes, Lunar Planet. Sci. Conf., XXXI, abstract 1619, 2000a.

Garvin, J. B., S. E. H. Sakimoto, J. J. Frawley, and C. Schnetzler, North polar region craterforms on Mars: Geometric characteristics from the Mars Orbiter Laser Altimeter, Icarus, 144, 329$352,2000 \mathrm{~b}$.

Garvin, J. B., S. E. H. Sakimoto, J. J. Frawley, C. C. Schnetzler, and H. M. Wright, Topographic evidence for geologically recent near-polar volcanism on Mars, Icarus, 145, 648-652, 2000c.

Geirasch, P. J., and R. Goody, A study of the thermal and dynamical structure of the Martian lower atmosphere, Planet. Space Sci., 16, 615-646, 1968.

Goldstein, R. M., W. G. Melbourne, G. A. Morris, G. S. Downs, and D. A. O'Handley, Preliminary radar results of Mars, Radio Sci., 70, 475-478, 1970.

Golombek, M. P., K. L. Tanaka, and B. J. Franklin, Extension across Tempe Terra, Mars, from measurements of fault scarp widths and deformed craters, J. Geophys. Res., 101, 26,11926,130, 1996.

Golombek, M. P., R. A. Cook, H. J. Moore, and T. J. Parker, Selection of the Mars Pathfinder landing site, J. Geophys. Res., 102, 3967-3988, 1997a.

Golombek, M. P., F. S. Anderson, and M. T. Zuber, Martian wrinkle ridge topography: Evidence for subsurface faults from MOLA, J. Geophys. Res., this issue.

Golombek, M. P., et al., Overview of the Mars Pathfinder mission and assessment of landing site predictions, Science, 278, 1743$1748,1997 \mathrm{~b}$.

Greeley, R., and J. E. Guest, Geologic map of the eastern equatorial region of Mars, scale 1:15,000,000, U.S. Geol. Surv. Map I-I802-B, 1987.

Greeley, R., and P. D. Spudis, Volcanism on Mars, Rev. Geophys., 19, 13-41, 1981.
Hapke, B., R. Nelson, and W. Smythe, The opposition effect of the Moon: Coherent backscatter and shadow hiding, Icarus, 133, 89-97, 1998.

Harmon, J. K., and S. J. Ostro, Dual-polarization radar observations with extended coverage, Icarus, 62, 110-128, 1985.

Harmon, J. K., D. B. Campbell, and S. J. Ostro, Dual-polarization radar observations of Mars: Tharsis and environs, Icarus, 52, 171-187, 1982.

Harrington, B., R. J. Phillips, and M. P. Golombek, Extension across Tempe Terra. Mars from MOLA topographic measurements, Fifth Int. Conf. on Mars, abstract 6130, 1999.

Head, J. W., Detection of lava flow unit thicknesses and characteristics on Mars: First results from Mars Orbiter Laser Altimeter (MOLA) data, Lunar Planet. Sci. Conf., XXIX, abstract 1324, 1998.

Head, J. W., Extensive south polar cap in middle Mars history? Tests using MOLA data, Lunar Planet. Sci. Conf., XXX, abstract $1119,2000$.

Head, J. W., M. Kreslavsky, H. Hiesinger, M. Ivanov, S. Pratt, N. Seibert, D. E. Smith, and M. T. Zuber, Oceans in the past history of Mars: Tests for their presence using Mars Orbiter Laser Altimeter (MOLA) data, Geophys. Res. Lett., 25, 4401-4404, $1998 \mathrm{a}$.

Head, J. W., N. Seibert, S. Pratt, D. Smith, M. Zuber, J. B. Garvin, P. J. McGovern, and the MOLA Science Team, Volcanic calderas on Mars: Initial views using Mars Orbiter Laser Altimeter (MOLA) data, Lunar Planet. Sci. Conf., XXIX, abstract 1488, $1998 \mathrm{~b}$.

Head, J. W., N. Seibert, S. Pratt, D. Smith, M. Zuber, S. Solomon, P. J. McGovern, J. B. Garvin, and the MOLA Science Team, Characterization of major volcanic edifices on Mars using Mars Orbiter Laser Altimeter (MOLA) data, Lunar Planet. Sci. Conf., $X X I X$, abstract 1322, 1998c.

Head, J. W., et al., Lunar impact basins: New data for the westem limb and farside (Orientale and South Pole-Aitken basins) from the first Galileo flyby, J. Geophys. Res., 98, 17,149-17,181, $1998 d$.

Head, J. W., H. Hiesinger, M. A. Ivanov, M. A. Kreslavsky, S. Pratt, and B. J. Thomson, Possible oceans on Mars: Evidence from Mars Orbiter Laser Altimeter data, Science, 286, 2134-2137, 1999.

Hiesinger, H., and J. W. Head, Characteristics and origin of polygonal terrain in southem Utopia, Mars: Preliminary results from the Mars Orbiter laser Altimeter (MOLA) and Mars Orbiter Camera (MOC) data, J. Geophys. Res., 105, 11,999-12,022, 2000.

Hinson, D. P., R. A. simpson, J. D. Twicken, and G. L. Tyler, Cinitial results from radio occultation measurements with Mars Global Surveyor, J. Geophys. Res., I04, 26,997-27,012, 1999.

Hord, C. W., Mariner 6 and 7 ultraviolet spectrometer experiment: Photometry and topography of Mars, Icarus, 17, 443-456, 1972.

Hulme, G., The interpretation of lava flow morpholgy, Geophys. J. R. Aston. Soc., 39, 361-383, 1974.

Hynek, B., and R. J. Phillips, Evidence for extensive denudation of the Martian highlands, Geology, 29, 407-410, 2001.

Ivanov, A. B., Some aspects of the Martian climate from the Mars Orbiter Laser Altimeter Investigation, Ph.D. thesis, Calif. Inst. of Technol., Pasadena, 2000.

Ivanov, A. B., and D. O. Muhleman, Opacity of the Martian atmosphere from Mars Orbiter Laser Altimeter (MOLA) observations, Geophys. Res. Lett., 25, 4417-4420, 1998.

Ivanov, A. B., and D. O. Muhleman, The role of sublimation for the formation of the northern ice cap: Results from the Mars Orbiter Laser Altimeter, Icarus, 144, 436-448, 2000.

Jager, K. M., J. W. Head, B. J. Thomson, P. J. McGovern, and S. C. Solomon, Alba Patera, Mars: Characterization using Mars Orbiter Laser Altimeter (MOLA) data and comparison with other volcanic edifices, Lunar Planet. Sci. Conf., XXX, abstract 1915, 1999. 
Jakosky, B. M., and R. J. Phillips, Mars' volatile and climate history, Nature, 4I2, 237-244, 2001.

Johnson, C. L., S. C. Solomon, J. W. Head, R. J. Phillips, D. E. Smith, and M. T. Zuber, Lithospheric loading by the north polar cap of Mars, Icarus, 144, 313-328, 2000.

Kargel, J. S., and R. G. Strom, Ancient glaciation on Mars, Geology, 20, 3-7, 1992.

Kieffer, H. H., T. Z. Martin, A. R. Peterfreund, B. M. Jakosky, E. D. Miner, and F. D. Palluconi, Thermal and albedo mapping of Mars during the Viking primary mission, J. Geophys. Res., 82, 4249-4291, 1977.

Kieffer, H. H., P. A. Davis, and L. A. Soderblom, Mars' global properties: Maps and applications, Proc. Lunar Planel. Sci. Conf., 12, 1395-1417, 1981.

Kieffer, H. H., B. M. Jakosky, and C. W. Snyder, The planet Mars: From antiquity to present, in Mars, edited by H. H. Kieffer, B. M. Jakosky, C. W. Snyder, and M. S. Matthews, pp. 1-33, Univ. of Ariz. Press, Tucson, 1992.

Klassen, D. R., J. F. Bell, R. R. Howell, P. E. Johnson, W. Golisch, C. D. Kaminski, and D. Griep, Infrared spectral imaging of Martian clouds and ices, Icarus, 138, 36-48, 1999.

Kliore, A. J., D. L. Cain, G. S. Levy, V. R. Eshleman, G. Fjeldbo, and F. D. Drake, Occultation experiment: Results of the first direct measurement of Mars' atmosphere and ionosphere, Science, 149, 1243-1248, 1965.

Kliore, A. J., D. L. Cain, G. Fjeldbo, B. L. Seidel, and M. J. Sykes, The atmosphere of Mars from Mariner 9 radio occultation measurements, Icarus, 17, 484-516, 1972.

Kliore, A. J., F. J. Fjeldbo, B. L. Seidel, M. J. Sykes, and P. M. Woiceshyn, S-band radio occultation measurements of the atmosphere and topography of Mars with Mariner 9: Extended mission coverage of the polar and intermediate latitudes, J. Geophys. Res., 78, 4331-4351, 1973.

Komar, P. D., Comparisons of the hydraulics of water flows in Martian outflow channels with flows of similar scale on Earth, Icarus, 37, 156-181, 1979.

Komatsu, G., and V. R. Baker, Paleohydrology and flood geomorphology of Ares Vallis, J. Geophys. Res., 102, 4151-4160, 1997.

Kreslavsky, M. A., and J. W. Head, Kilometer-scale slopes on Mars and their correlation with geologic units: Initial results from Mars Orbiter Laser Altimeter (MOLA) data, J. Geophys. Res., 104, 21,911-21,924, 1999.

Kreslavsky, M. A., and J. W. Head, Kilometer-scale roughness of Mars: Results from MOLA data analysis, J. Geophys. Res., 105, 26,695-16,711, 2000.

Lemoine, F. G., D. D. Rowlands, D. E. Smith, D. S. Chinn, D. E. Pavlis, S. B. Luthcke, G. A. Neumann, and M. T. Zuber, Orbit determination for Mars Global Surveyor during mapping, AIAA Pap., pp. 99-328, 1999.

Lemoine, F. G., D. D. Rowlands, D. E. Smith, D. S. Chinn, D. E. Pavlis, S. B. Luthcke, G. A. Neumann, and M. T. Zuber, An improved solution of the gravity field of Mars (GMM-2B) from Mars Global Surveyor, J. Geophys. Res., this issue.

Leovy, C. B., and Y. Mintz, Numerical simulation of the atmospheric circulation and climate of Mars, J. Atmos. Sci., 26, $1167-$ $1190,1969$.

Lindal, G. F., H. B. Hotz, D. N. Sweetnam, Z. Shippony, J. P. Brenkle, G. V. Hartsell, R. T. Spear, and W. H. J. Michael, Viking radio occultation measurements of the atmosphere and topography of Mars: Data acquired during 1 Martian year of tracking, $J$. Geophys. Res., 84, 8443-8456, 1979.

Lingenfelter, R. E., and G. Schubert, Evidence for convection in planetary interiors from first-order topography, Moon, 7, 172$180,1973$.

Lorell, J., et al., Gravity field of Mars from Mariner 9 tracking data, Icarus, 18, 304-316, 1973.

Malin, M. C., and K. S. Edgett, Oceans or seas in the Martian northern lowlands: High-resolution imaging tests of proposed coastlines, Geophys. Res. Lett., 26, 3049-3052, 1999.
Malin, M. C., and K. S. Edgett, Evidence for recent groundwater seepage and surface runoff on Mars, Science, 288, 2330-2335, 2000.

Malin, M. C., et al., Eary views of the Martian surface from the Mars Orbiter Camera of Mars Global Surveyor, Science, 279, 1681-1685, 1998.

Marshall, J. A., N. P. Zelensky, S. M. Klosko, D. S. Chinn, S. B. Luthcke, K. E. Rachlin, and R. G. Williamson, The temporal and spatial characteristics of TOPEX/POSEIDON radial orbit error, J. Geophys. Res., I00, 25,331-25,352, 1995.

McCarthy, J. J., S. Rowton, D. Moore, S. Luthcke, D. E. Pavlis, L. S. Tsaoussi, D. D. Rowlands, and J. A. Marcshall, Geodyn systems descriptions and operations manuals, contractor report, NASA Goddard Space Flight Cent., 1994.

McEwen, A. S., M. C. Malin, L. Keszthelyi, P. Lanagan, R. Beyer, and W. K. Hartmann, Recent and ancient flood lavas on Mars, Lunar Planet. Sci. Conf., XXX, abstract 1829, 1999.

McGarry, J. F., L. K. Pacini, J. B. Abshire, and J. B. Blair, Design and performance of an autonomous tracking for the Mars Observer Laser Altimeter, Conf. Lasers Electro-Optics, 10, CThR27, 1991.

McGill, G. E., Buried topography of Utopia, Mars: Persistence of a giant impact depression, J. Geophys. Res., 94, 2753-2759, 1989.

McGovern, P. J., and S. C. Solomon, State of stress, faulting, and eruption characteristics of large volcanoes on Mars, J. Geophys. Res., 98, 23,553-23,579, 1993.

McGovern, P. J., and S. C. Solomon, Filling of flexural moats around large volcanoes on Venus: Implications for volcano structure and global magmatic flux, J. Geophys. Res., 102, 16,30316,318, 1997.

McGovern, P. J., S. C. Solomon, J. W. H. III, D. E. Smith, M. T. Zuber, and G. A. Neumann, Extension and uplift at Alba Patera, Mars: Insight from MOLA observations and loading models, $J$. Geophys. Res., this issue.

Melosh, H. J., Impact Cratering: A Geologic Process, Oxford Univ. Press, New York, 1989.

Montesi, L. G. J., and M. T. Zuber, Crustal thickness control on Martian wrinkle ridge spacing, Lunar Planet. Sci. Conf., XXXII, abstract 1879, 2001.

Mustard, J. F., S. Erard, J.-P. Bibring, J. W. Head, S. Hurtrez, Y. Langevin, C. M. Pieters, and C. J. Sotin, The surface of Syrtis Major: Composition of the volcanic substrate and mixing with altered dust and soil, J. Geophys. Res., 98, 3387-3400, 1993.

Mutch, T. A., R. E. Arvidson, J. W. Head, K. L.Jones, and R. S. Saunders, The Geology of Mars, Princeton Univ. Press, Princeton, N.J., 1976.

Neumann, G. A., D. D. Rowlands, F. G. Lemoine, D. E. Smith, and M. T. Zuber, Crossover analysis of Mars Orbiter Laser Altimeter data, J. Geophys. Res., this issue.

Nimmo, F., and D. McKenzie, Influence of early plate tectonics on the thermal evolution and magnetic field of mars, $J$. Geophys. Res., 105, 11,969-11,979, 2000.

Nimmo, F., and D. McKenzie, Estimates of Martian crustal thickness from viscous relaxation of topography, J. Geophys. Res., 106, 5085-5098, 2001.

Nye, J. F., W. B. Durham, P. M. Schenk, and J. M. Moore, The instability of a south polar cap on Mars composed of carbon dioxide, Icarus, 144, 449-455, 2000.

Paige, D. A., and K. D. Keegan, Thermal and albedo mapping of the polar regions of Mars using Viking thermal mapper observations, 2, South polar region, J. Geophys. Res., 99, 25,99326,013, 1994.

Paige, D. A., J. E. Bachman, and K. D. Keegan, Thermal and albedo mapping of the polar regions of Mars using Viking thermal mapper observations, 1, North polar region, J. Geophys. Res., 99, 25,959-25,991, 1994.

Parker, T. J., D. S. Gorsline, R. S. Saunders, and D. M. Schneeberger, Coastal geomorphology of the Martian northern plains, J. Geophys. Res., 98, 11,061-11,078, 1993. 
Pettengill, G. H., and P. G. Ford, Winter clouds over the north Martian polar cap, Geophys. Res. Lett., 27, 609-612, 2000.

Pettengill, G. H., C. C. Counselman, L. P. Rainville, and I. I. Shapiro, Radar measurements of Martian topography, Astron. J., 74, 461-482, 1969.

Pettengill, G. H., A. A. E. Rogers, and I. I. Shapiro, Martian craters and a scarp as seen by radar, Science, 174, 1321-1324, 1971.

Pettengill, G. H., I. I. Shapiro, and A. A. E. Rogers, Topography and radar scattering properties of Mars, Icarus, 18, 22-28, 1973.

Phillips, R. J., et al., Ancient geodynamics and global-scale hydrology on Mars, Science, 291, 2587-2591, 2001.

Pike, R. J., Control of crater morphology by gravity and target type: Mars, Earth, Moon, Proc. Lunar Planet. Sci. Conf., 11, 2159 2189, 2000.

Plaut, J. J., R. Kahn, E. A. Guiness, and R. E. Arvidson, Accumulation of sedimentary debris in the south polar region of Mars and implication for climate history, Icarus, 75, 357-377, 1988.

Plescia, J. B., and M. P. Golombek, Origin of planetary wrinkle ridges based on the study of terrestrial analogs, Geol. Soc. Am. Bull., 97, 1289-1299, 1986.

Pollack, J. B., R. M. Haberle, and J. Schaeffer, Simulations of the general circulation of the Martian atmosphere, 1, Polar processes, J. Geophys. Res., 95, 1447-1473, 1990.

Ramos-Izquierdo, L., J. L. Bufton, and P. Hayes, Optical system design and integration of the Mars Observer Laser Altimeter, Appl. Opt., 133, 307-322, 1994.

Rogers, A. E. E., M. E. Ash, C. C. Counselman, I. I. Shapiro, and G. H. Pettengill, Radar measurements of the surface topography and roughness of Mars, Radio Sci., 5, 465-473, 1970.

Roth, L. E., G. S. Downs, R. S. Saunders, and G. Schubert, Radar altimetry of south Tharsis, Mars, Icarus, 42, 287-316, 1980.

Rowlands, D. D., J. A. Marshall, J. J. McCarthy, S. C. Rowton, D. Moore, D. E. Pavlis, and S. B. Lutchke, Geodyn II system description, contractor report, NASA Goddard Space flight Cent., 1993.

Rowlands, D. D., D. E. Pavlis, F. G. Lemoine, G. A. Neumann, and S. B. Lutchke, The use of crossover constraint equations derived from laser altimetry in the orbit determination of Mars Global Surveyor, Geophys. Res. Lett., 26, 1191-1194, 1999.

Sakimoto, S. E. H., and J. B. Garvin, Topography of impact craters on the northern polar cap of Mars, Lunar Planet. Sci. Conf., XXX, 1999.

Schubert, G., and T. Spohn, Thermal history of Mars and the sulfur content of its core, J. Geophys. Res., 95, 14,095-14,104, 1990.

Schubert, G., and T. Spohn, Thermal convection in a volumetrically heated, infinite Prandtl number fluid with strongly temperaturedependent viscosity: Implications for planetary thermal evolution, J. Geophys. Res., 103, 18,171-18,181, 1998.

Schultz, R. A., and H. V. Frey, A new survey of multiring basins on Mars, J. Geophys. Res., 95, 14,175-14,189, 1990.

Schultz, R. A., and K. L. Tanaka, Lithospheric-scale buckling and thrust structures on Mars: The Coprates rise and south Tharsis ridge belt, J. Geophys. Res., 99, 8371-8385, 1994.

Scott, D. H., and K. L. Tanaka, Geologic map of the western equatorial region of Mars, Scale 1:15,000,000, U.S. Geol. Survey Map I-I802-A, 1986.

Sengor, A. M. C., and K. Burke, Relative timing of rifting and volcanism on earth and its tectonic implications, Geophys. Res. Lett., 5, 419-421, 1978.

Sharp, R. P., Mars: Fretted and chaotic terrains, J. Geophys. Res., 78, 4073-4083, 1973.

Sharp, R. P., L. A. Soderblom, B. C. Murray, and J. A. Cutts, More on the dichotomy boundary, J. Geophys. Res., 76, 331$341,1971$.

Shum, C. K., B. H. Zhang, B. E. Schutz, and B. D. Tapley, Altimeter crossover methods for precision orbit determination and the mapping of geophysical parameters, J. Astronaut. Sci., 38, 355-368, 1990.

Simons, F. J., M. T. Zuber, and J. Korenaga, Isostatic response of the Australian lithosphere: Estimation of effective elastic thickness and anisotropy using multitaper spectral analysis, J. Geophys. Res., 105, 19,163-19,184, 2000.

Simons, M. A., S. C. Solomon, and B. H. Hager, Localization of gravity and topography: Constraints on the tectonics and mantle dynamics of Venus, Geophys. J. Int., 131, 24-44, 1997.

Simpson, R. A., J. K. Harmon, S. H. Zisk, T. W. Thompson, and D. O. Muhleman, Radar determination of Mars surface properties, in Mars, edited by H. H. Kieffer, B. M. Jakosky, C. W. Snyder, and M. S. Matthews, pp. 652-685, Univ. of Ariz. Press, Tucson, 1992.

Sleep, N. H., Martian plate tectonics, J. Geophys. Res., 99, 5639$5655,1994$.

Sleep, N. H., and R. J. Phillips, Gravity and lithospheric stress on the terrestrial planets with reference to the Tharsis region on Mars, J. Geophys. Res., 90, 4469-4489, 1985.

Smith, D. E., and M. T. Zuber, The shape of Mars and the topographic signature of the hemispheric dichotomy, Science, 271, 184-188, 1996.

Smith, D. E., and M. T. Zuber, The relationship between MOLA northern hemisphere topography and the 6.1-mbar atmospheric pressure surface of Mars, Geophys. Res. Lett., 25, 4397-4400, 1998.

Smith, D. E., M. T. Zuber, G. A. Neumann, and F. G. Lemoine, Topography of the Moon from the Clementine lidar, J. Geophys. Res., 102, 1591-1611, 1997.

Smith, D. E., et al., Topography of the northern hemisphere of Mars from the Mars Orbiter Laser Altimeter (MOLA), Science, 279, 1686-1692, 1998.

Smith, D. E., W. L. Sjogren, G. L. Tyler, G. Balmino, F. G. Lemoine, and A. S. Konopliv, The gravity field of Mars: Results from Mars Global Surveyor, Science, 286, 94-96, 1999a.

Smith, D. E., et al., The global topography of Mars and implications for surface evolution, Science, 284, 1495-1503, 1999 b.

Smith, M. D., J. C. Pearl, B. J. Conrath, and P. R. Christensen, Mars Global Surveyor Thermal Emission Spectrometer (TES) observations of dust opacity during aerobraking and science phasing, J. Geophys. Res., 105, 9539-9552, 2000.

Smith, W. H. F., and P. Wessel, Gridding with continuous curvature splines in tension, Geophys., 55, 293-305, 1990.

Soderblom, L. A., The composition and surface mineralogy of the Martian surface from spectroscopic observations: $0.3 \mu \mathrm{m}$ to 50 $\mu \mathrm{m}$, in Mars, edited by H. H. Kieffer, B. M. Jakosky, C. W. Snyder, and M. S. Matthews, pp. 557-593, Univ. of Ariz. Press, Tucson, 1992.

Soderblom, L. A., and D. B. Wenner, Possible fossil $\mathrm{H}_{2} \mathrm{O}$ liquid-ice interfaces in the Martian crust, Icarus, 34, 622-637, 1978.

Sohl, F., and T. Spohn, The interior structure of Mars: Implications from SNC meteorites, J. Geophys. Res., 102, 1613-1635, 1997.

Solomon, S. C., and J. W. Head, Evolution of the Tharsis province of Mars: The importance of heterogeneous lithospheric thickness and volcanic construction, J. Geophys. Res., 82, 9755-9774, 1981.

Solomon, S. C., and J. W. Head, Heterogeneities in the thickness of the elastic thickness of Mars: Constraints on heat flow and internal dynamics, J. Geophys. Res., 95, 11,073-11,083, 1990.

Solomon, S. C., C. L. Johnson, P. J. McGovern, O. Aharonson, W. B. Banerdt, J. W. Head, R. J. Phillips, and M. T. Zuber, An overview of lithospheric flexure on Mars: Implications of initial MOLA observations, Lunar and Planet. Sci. Conf., XXIX, abstract 1389, 1998.

Spudis, P. D., R. A. Riesse, and J. G. Gillis, Ancient multiring basins on the Moon revealed by Clementine laser altimetry, Science, 266. 1848-1851, 1994.

Squyres, S. W., and J. F. Kasting, Early Mars: How warm and how wet?, Science, 265, 744-749, 2001.

Standish, E. M., X. X. Newhall, J. G. Williams, and W. M. Folkner, Jpl Planetary and Lunar Ephemerides, DE403/LE403, JPL Rep., IOM 314.10-127, 1995. 
Stevenson, D. J., Mars' core and magnetism, Nature, 412, 214-219, 2001.

Stewart, E. M., and J. W. Head, Ancient Martian volcanoes in the Aeolis region: New evidence from MOLA data, J. Geophys. Res., this issue.

Sun, X., F. M. Davidson, L. Boutsikais, and J. B. Abshire, Receiver characteristics of laser altimeters with avalanche photodiode, IEEE Trans. Aerosp. Electron. Syst., 28, 268-274, 1992.

Tanaka, K. L., M. P. Golombek, and W. B. Banerdt, Reconciliation of the stress and structural histories of the Tharsis region, Mars, J. Geophys. Res., 96, 15,617-15,633, 1991.

Tanaka, K. L., D. K. Scott, and R. Greeley, Global stratigraphy, in Mars, edited by H. H. Kieffer, B. M. Jakosky, C. W. Snyder, and M. S. Matthews, pp. 345-382, Univ. of Ariz. Press, Tucson, 1992.

Tapley, B. D., and G. W. Rosborough, Geographically correlated orbit error and its effect on satellite altimeter missions, $J$. Geophys. Res., 90, 11,817-11,831, 1985.

Thomas, P. C., et al., North-south geological differences between the residual polar caps on Mars, Nature, 404, 161-164, 2000.

Thomson, B. J., and J. W. Head, Estimating the silica conten of Martian lava flows using MOLA, Lunar Planet. Sci. Conf. $X X X I$, abstract 1883, 2000.

Turcotte, D. L., R. J. Willemann, W. F. Haxby, and J. Norberry, Role of membrane stresses in support of planetary topography, J. Geophys. Res., 86, 3951-3959, 1981.

Tyler, G. L., et al., Radio science investigations with Mars Observer, J. Geophys. Res., 97, 7759-7779, 1992.

Tyler, G. L., G. Balmino, D. P. Hinson, W. L. Sjogren, D. E. Smith, R. A. Simpson, S. W. Asmar, P. Priest, and J. D. Twicken, Radio science observations with Mars Global Surveyor: Orbit insertion through one year in mapping orbit, J. Geophys. Res., this issue.

Vasavada, A. R., and K. E. Herkenhoff, Polar layered deposits and polar landing sites, Fifth Int. Conf. Mars, abstract 6086, 1999.

Ward, W. R., Climatic variations on Mars, J. Geophys. Res., 79, 3375-3386, 1974.

Watters, T. R., Compressional tectonism on Mars, J. Geophys. Res., 98, 17,049-17,060, 1993

Watts, A. B., J. H. Bodine, and M. S. Steckler, Observations of flexure and the state of stress in the oceanic lithosphere, J. Geophys. Res., 85, 5369-6376, 1980.

Wichman, R. W., and P. H. Schultz, Sequence and mechanisms of deformation around the Hellas and Isidis impact basins on Mars. J. Geophys. Res., 94, 17,333-17,357, 1989.

Wilhelms, D. E., and S. W. Squyres, The Martian hemispheric dichotomy may be due to a giant impact, Nature, 309, 138-140, 1984.

Williams, K. K., and M. T. Zuber, Measurement and analysis of lunar basin depths from Clementine altimetry, Icarus, 13I, 107122, 1998.

Williams, R. M., Examination of Martian outflow channels and valley network morphology using Mars Orbiter Laser Altimeter (MOLA), Ph.D. thesis, Washington Univ., 2000.

Williams, R. M., R. J. Phillips, and M. C. Malin, Flow rates and duration within Kasei Valles, Mars: Implications for the formation of a martian ocean, Geophys. Res. Lett., 27, 1073-1076, 2000.

Wilson, L., and J. W. Head, Review and analysis of volcanic eruption theory and relationsips of observed landforms, Rev. Geophys., 32, 221-264, 1994.

Wise, D. U., M. P. Golombek, and G. E. McGill, Tharsis province of Mars: Geologic sequence, geometry, and a deformation mechanism, Icarus, 35, 456-472, 1979a.

Wise, D. U., M. P. Golombek, and G. E. McGill, Tectonic evolution of Mars, J. Geophys. Res., 84, 7934-7939, 1979 b.

Withers, P., and G. A. Neumann, Enigmatic ridges on the plains of Mars, Nature, 410, 652, 2001.

Wu, P., and W. R. Peltier, Pleistocene glaciation and the Earth's rotation: A new analysis, Geophys. J. R. Astron. Soc., 76, 753$791,1984$.
Wu, S. S. C., Topographic maps of the polar, western, and eastern regions of Mars, scale 1:15,000,000, U.S. Geol. Surv. Map I$2160,1991$.

Wu, S. S. C., and F. J. Schaefer, Mars control network: American Society of Photogrammetry, Proc. 50th Annual Meet., pp. 456464, 1984.

Yuan, D. N., W. L. Sjogren, A. S. Konopliv, and A. B. Kucinskas, The gravity field of Mars: A 75th degree and order model, $J$. Geophys. Res., this issue.

Zeitler, W., and J. Oberst, The Mars Pathfinder landing site and the Viking control point network, J. Geophys. Res., 104, 8935-8941, 1999.

Zhong, S., and M. T. Zuber, Degree one mantle convection and the crustal dichotomy on Mars, Earth Planet. Sci. Lett., 189, 75-84, 2001.

Zuber, M. T., Wrinkle ridges, reverse faulting, and the depth penetration of lithosheric strain in Lunae Planum, Mars, Icarus, 114, 81-92, 1995.

Zuber, M. T., The crust and mantle of Mars, Nature, 412, 220-227, 2001.

Zuber, M. T., and D. E. Smith, Mars without Tharsis, J. Geophys. Res., 102, 28,673-28,685, 1997.

Zuber, M. T., D. E. Smith, S. C. Solomon, D. O. Muhleman, J. W. Head, J. B. Garvin, J. B. Abshire, and J. L. Bufton, The Mars Observer Laser Altimeter investigation, J. Geophys. Res., 97, 77817797, 1992.

Zuber, M. T., D. E. Smith, F. G. Lemoine, and G. A. Neumann, The shape and internal structure of the Moon from the Clementine mission, Science, 266, 1839-1843, 1994.

Zuber, M. T., D. E. Smith, A. F. Cheng, and T. D. Cole, The NEAR laser ranging investigation, J. Geophys. Res., 102, 23,76123,773, 1997.

Zuber, M. T., L. Lim, and H. J. Zwally, The role of viscous deformation onthe morphology of the Martian north polar cap, in First Int. Conf. on Mars Polar Science and Exploration, edited by S. Clifford, D. Fisher, and J. Rice, pp. 45-46, Lunar Planet. Inst., Houston, Tex., 1998a.

Zuber, M. T., D. E. Smith, R. J. Phillips, S. C. Solomon, W. B. Banerdt, G. A. Neumann, and O. Aharonson, Shape of the northern hemisphere of Mars from the Mars Orbiter Laser Altimeter (MOLA), Geophys. Res. Lett., 25, 4393-4396, 1998b.

Zuber, M. T., et al., Observations of the north polar region of Mars from the Mars Orbiter Laser Altimeter, Science, 282, 2053$2060,1998 \mathrm{c}$

Zuber, M. T., et al., Internal structure and early thermal evolution of Mars from Mars Global Surveyor topography and gravity, Science, 287, 1788-1793, 2000a.

Zuber, M. T., et al., The shape of asteroid 433 Eros from the NEARShoemaker Laser Rangefinder, Science, 289, 2097-2101, $2000 \mathrm{~b}$.

Zurek, R. W., J. R. Barnes, R. M. Haberle, J. B. Pollack, J. E. Tillman, and C. B. Leovy, Dynamics of the atmosphere of Mars, in Mars, edited by H. H. Kieffer, B. M. Jakosky, C. W. Snyder, and M. S. Matthews, pp. 835-933, Univ. of Ariz. Press, Tucson, 1992.

Zwally, H. J., and J. L. Saba, Driving stresses in Mars' polar ice caps and conditions for ice flow, Fifth Int. Conf. Mars, abstract $6151,1999$.

J. B. Abshire, R. S. Afzal, H. V. Frey, F. G. Lemoine, G. A. Neumann, D. D. Rowlands, D. E. Smith, X. Sun, Laboratory for Terrestrial Physics, Code 920, NASA/Goddard Space Flight Center, Greenbelt, MD 20771. (dsmith@tharsis.gsfc.nasa.gov; James. Abshire@gsfc.nasa.gov; Robert.Afzal@gsfc.nasa.gov; frey@ denali.gsfc.nasa.gov; flemoine@ares.gsfc.nasa.gov; neumann@ tharsis.gsfc.nasa.gov; drowland@helmert.gsfc.nasa.gov)

O. Aharonson, M. T. Zuber, Department of Earth, Atmospheric, and Planetary Sciences, Massachusetts Institute of Technology, Building 54, 77 Massachusetts Avenue, Cambridge, MA 021394307. (oded@mit.edu, zuber@mit.edu) 
W. B. Banerdt, T. C. Duxbury, M. P. Golombek, A. B. Ivanov, Jet Propulsion Laboratory, Pasadena, CA 91109. (bruce. banerdt@jpl.nasa.gov; thomas.c.duxbury@jpl.nasa.gov; Matthew. P.Golombek@jpl.nasa.gov; anton@gps.caltech.edu)

P. G. Ford, G. H. Pettengill, Center for Space Research, Massachusetts Institute of Technology, Building 37, 77 Massachusetts Avenue, Cambridge, MA 02139-4307. (pgf@space.mit.edu; ghp@ space.mit.edu)

J. B. Garvin, Office of Space Science, NASA Headquarters, Washington, DC 20546. (garvin@denali.gsfc.nasa.gov)

J. W. Head, Department of Geological Sciences, Box 1846, Brown University, Providence, RI 02912. (James.Head@brown. edu)

P. J. McGovern, Lunar and Planetary Institute, 3600 Bay Area Boulevard, Houston, TX 77058. (mcgovern@lpi.usra.edu)

D. O. Muhleman, Division of Geological and Planetary Sci- ences, California Institute of Technology, Pasadena, CA 91125. (dom@helene.gps.caltech.edu)

R. J. Phillips, Department of Earth and Planetary Sciences, Washington University, St. Louis, MO 63130. (phillips@wustite. wustl.edu)

C. L. Johnson, S. C. Solomon, Department of Terrestrial Magnetism, Carnegie Institution of Washington, 5241 Broad Branch Road, N.W., Washington, DC 20015. (cjohnson@clrs1.ciw. edu; scs@dtm.ciw.edu)

H. J. Zwally, Laboratory for Hydrospheric Processes, Code 970, NASA/Goddard Space Flight Center, Greenbelt, MD 20771. (jay. zwally@gsfc.nasa.gov)

(Received August 23, 2000; revised February 23, 2001; accepted March 12, 2001.) 